\title{
NO-PASSING ZONES: CRITERIA, \\ LEGISLATION AND LOCATION
}

\section{JUNE 1969 - NUMBER 19}

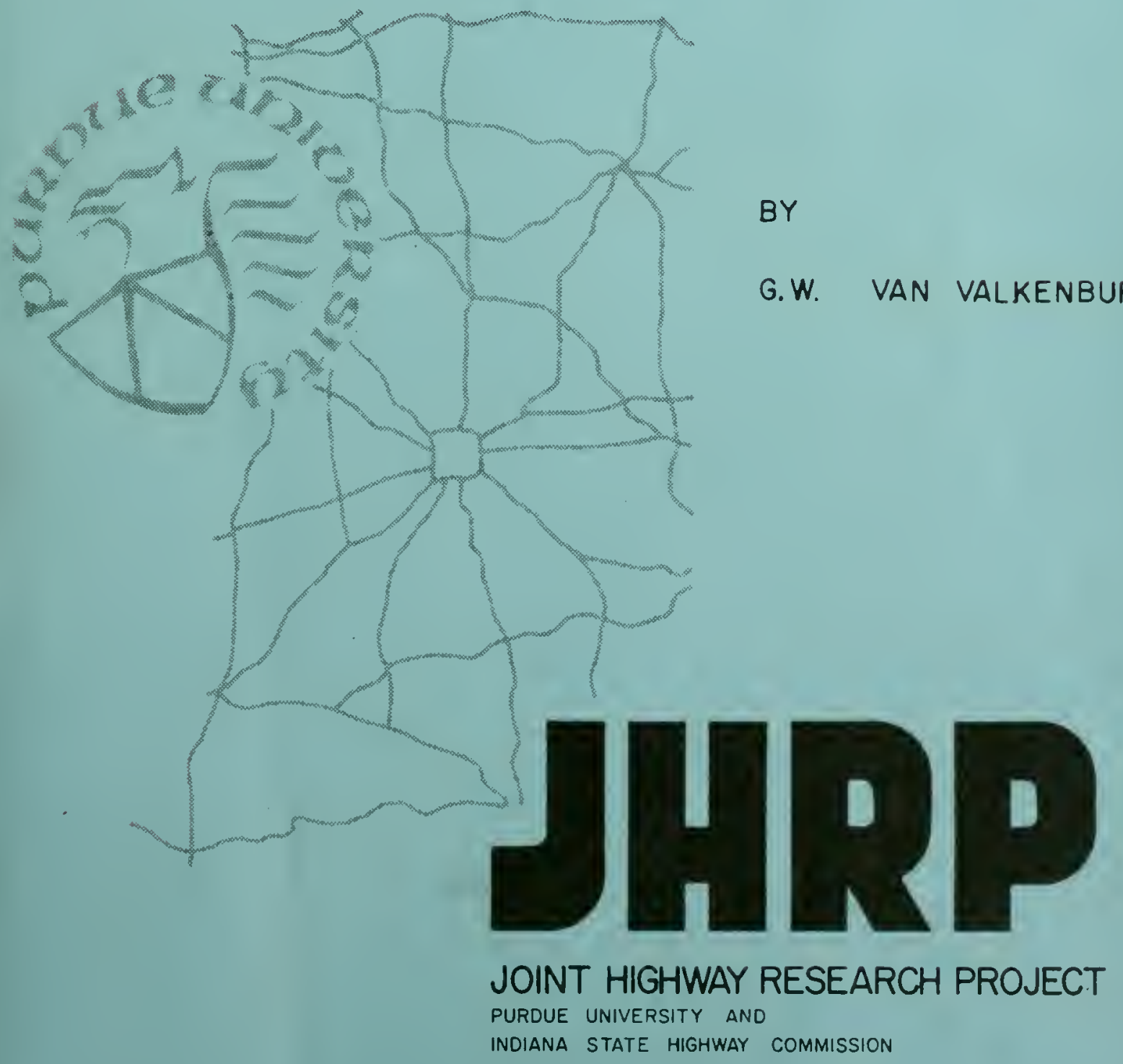




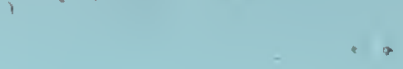




\section{Final Report}

\section{NO-PASSIIV ZCNTS: CRITHRIA, HEGISLATION AND INOCATION}

TO: J. F. McIaughin, Director

Joint Highway Research Pioject

From: H. I. Michael, Associate Director Joint Highway Research Project
June $1.7,1969$

Fine: $8-4-32$

Project: $\quad \mathrm{c}-36-17 \mathrm{TF}$

The attached Final Report "No-nassing Zones: Criteria, Iregislation and Iocetion" hos been authored by Mr. Gerald w. Van Valkenburg, Graduate Assistant in Research on our stafi. Prolessor H. I. Mithal served as director of the research and edvison on preparation of the report. Mr. Van Valkenbure also liged the report es his thesie for the RSCE degree. This Flnal Report conplets the research approved uncier a Plan of Study approved by the J.H.R.P. Board on Kay 9, 1968.

The research reported berein resulted from discussion with the ISIC Division of Irefric Ingireering and is directed at problems in Indians relative to crituria for selecting no-passing zones, the laws of Indian on no-passing zones, End problems of loczting no-passing zones in the field. The reseerch and its findings and conclusions are directed at solving these problems.

Tive report is presented to the Board for acceptance as the Final Report of this reserrch project.

Respectfully submit:

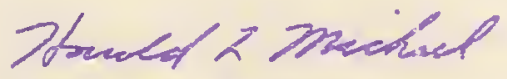

Harold Is. Michael

Associate Director

HIM:IOZ

ce: F. Is. Ashbaucher

W. I. Dolch

W. H. Goetz

H. I. Grecco

G. K. Hallock

M. E. Harr
R. H. Harrell

J. A. Havers

V. E. Harvey

G. A. Leonards

F. B. Mentienha.11

R. D. Miles
6. P. Scholer

B1. B. Scott

H. I. Spencer

H. R. J. Walsh

K. B. Woods

E. J. Ycder 


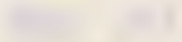

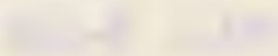

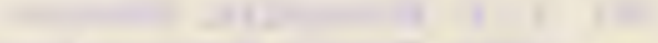

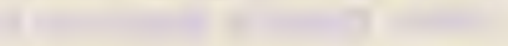

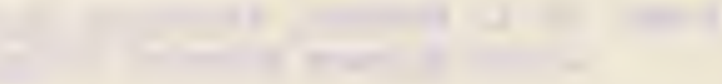
-

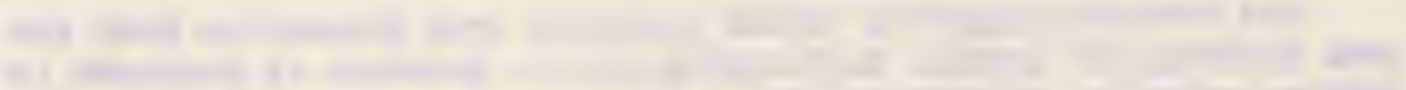
(1)

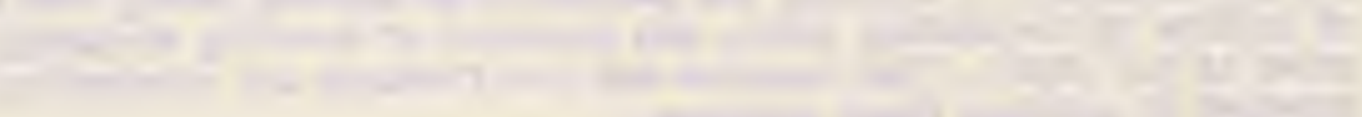
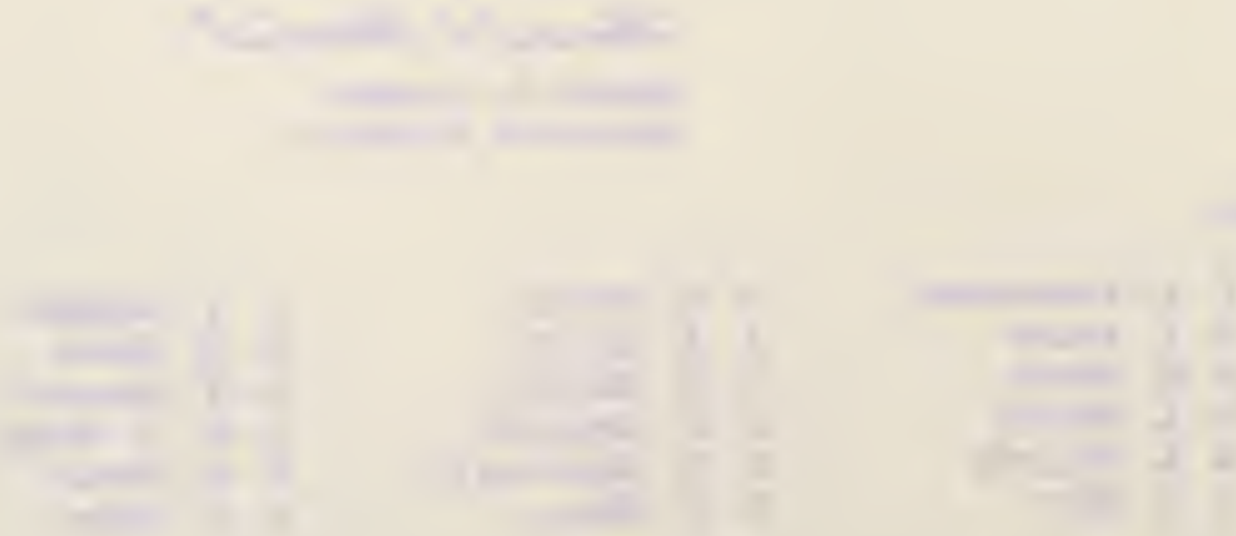
Final Report

NO-PASSITG ZGUES: CRIIERIA, IEGISIATION

AND HOCATION

by

Gerala W. Van Valkenburg

Graduate Assistant in Research

Joint Highwey Research Project

Project No: C-36-2TEF

File No: $8-4-32$

Purciue iniversity

Iafayetre, Indians

June 17,1969 
Digitized by the Internet Archive in 2011 with funding from

LYRASIS members and Sloan Foundation; Indiana Department of Transportation 
ACKNOWLEDGNENTS

The author wishes to express his sincere appreciation to Professor H. L. Michael for his guidance, advice and encouragement throughout this study. Appreciation is also extended to the other members of his committee, Professor W. L. Grecco and Professor V. I. Anderson for their special counsel and comments.

Special thanks are extended to his assistant, Harry Kantz, to George stafford for his ready cooperation and assistance when needed, to Richard E. James for his assistance, guidance and advice in the statistical analysis of the experiment and to Tammam Nakkash for his frequent consultations concerning computer problems.

The author is greatly indebted to his wife for her understanding and encouragement which made this effort possible. 
TABLE OF CONTENTS

Page

LIST OF TABLES......................... vi

LIST OF FIGURES......................... viii

ABSTRACT ..............................

CHAPTER I. INTRODUCTION ................... I

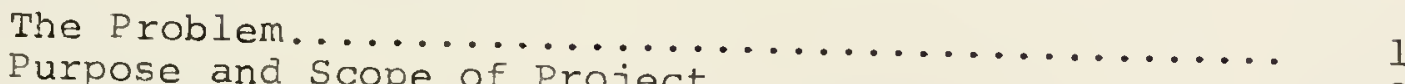

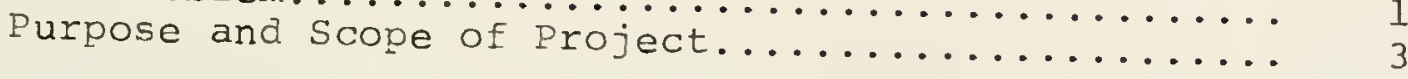

CHAPTER II. REVIEW OF LITERATURE AND LAWS.......... 4

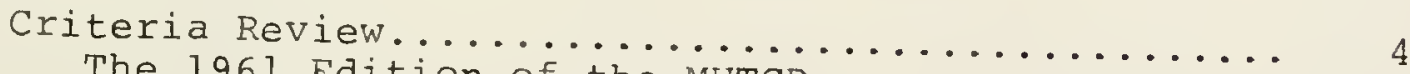

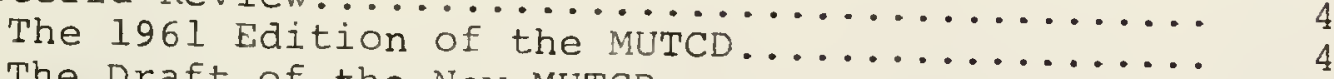

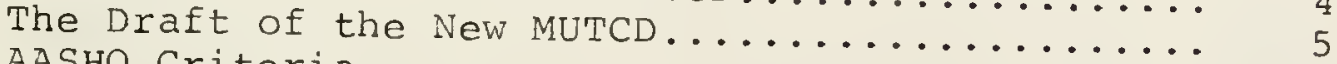

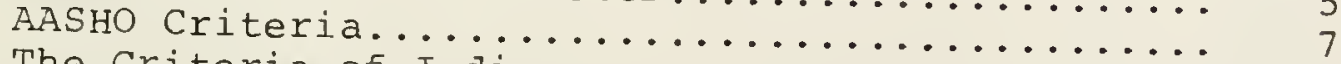

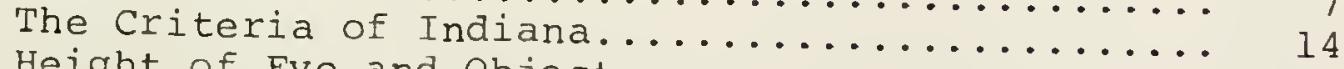

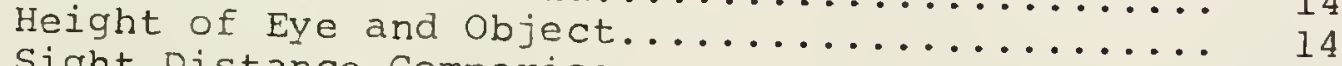

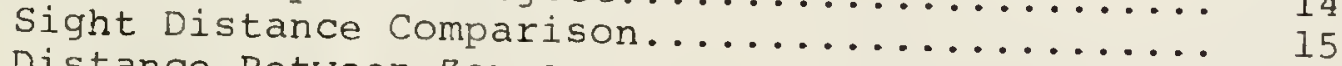

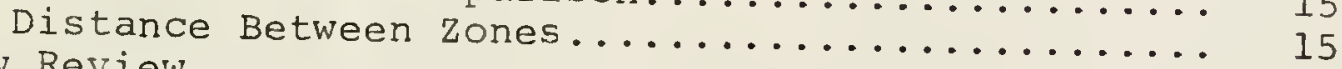

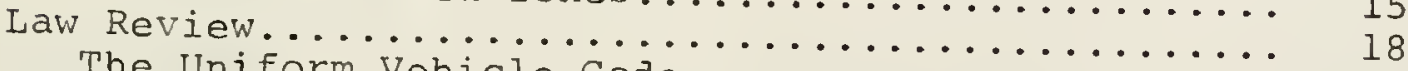

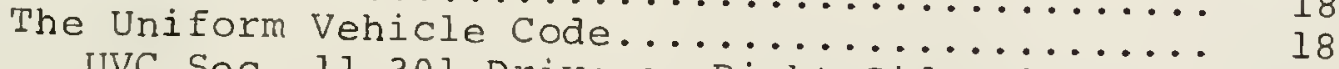

UVC Sec. 11-301 Drive on Right Side of

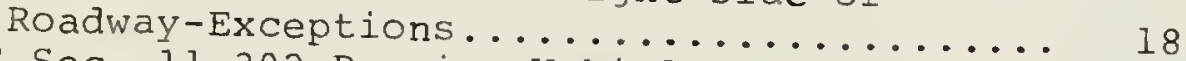

UVC Sec. 11-302-Passing Vehicles Proceeding in Opposite Directions........... 19

UVC Sec. 11-303-Overtaking a Vehicle on $\ldots . . .19$

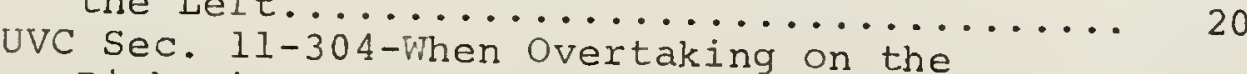

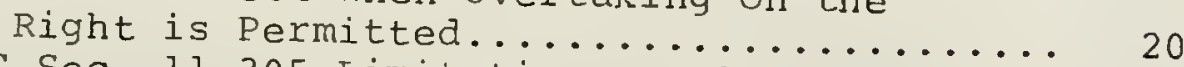

UVC Sec. 11-305-Limitations on Overtaking

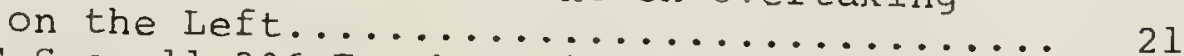

UVC Sec. 11-306-Further Limitations on

Driving to Left of Center of Roadway...... 21

UVC Sec. 11-307-No-Passing Zones............. 22 
Page

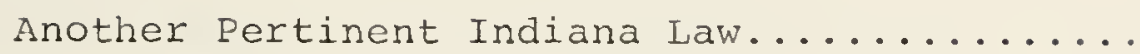

Indiana Law Number 372 - No-Passing Zones - Unlawful Acts - Penalty.......

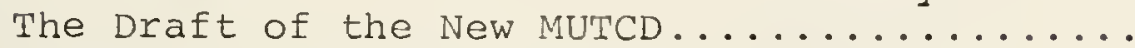

Comparison of the Laws of Indiana and

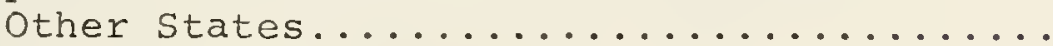

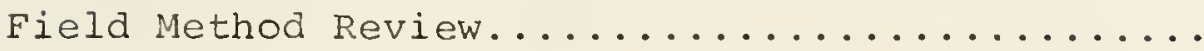

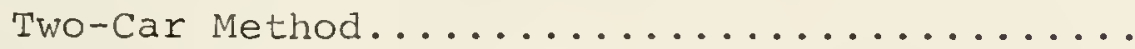

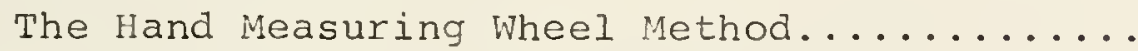

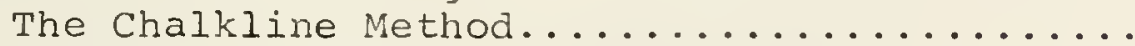

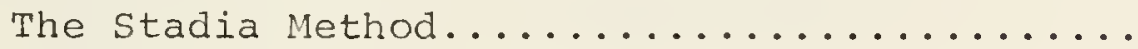

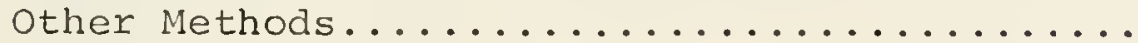

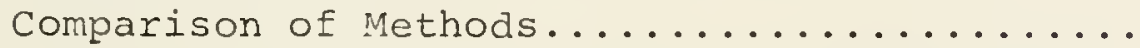

CHAPTER III. METHODOLOGY................

Length and Speed of Passing Maneuver..........

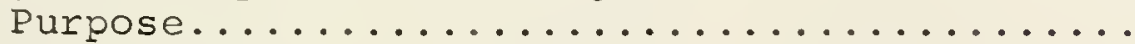

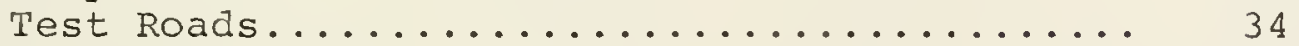

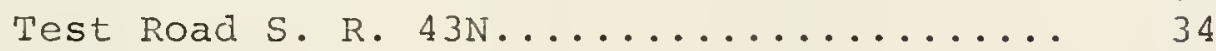

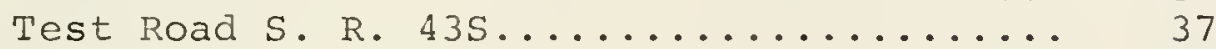

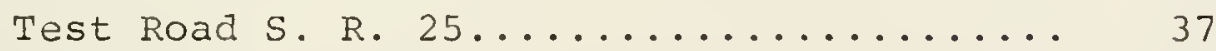

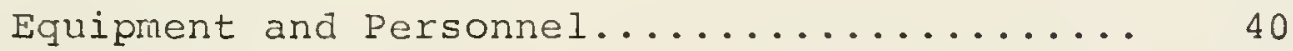

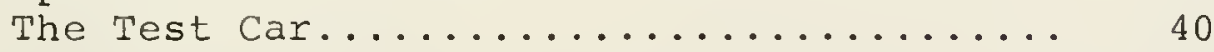

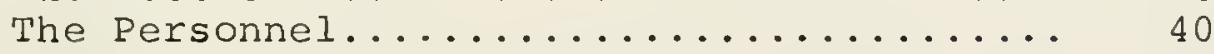

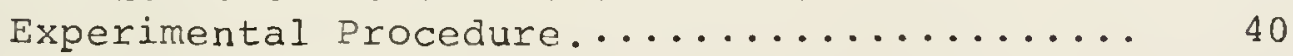

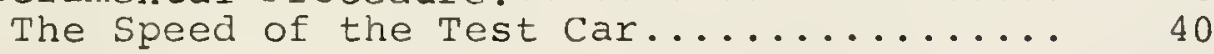

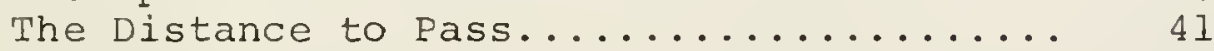

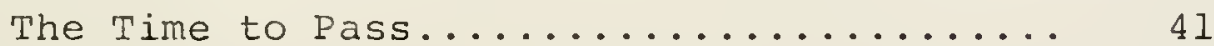

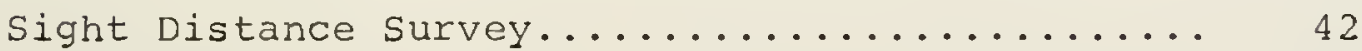

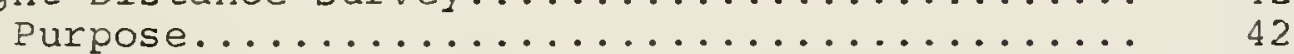

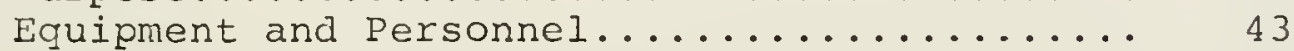

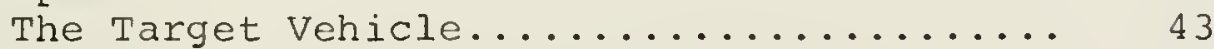

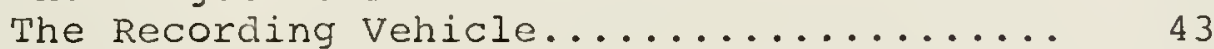

A Pickup Truck..................... 43

Two 1-1/2 Watt Rechargeable Walkie-

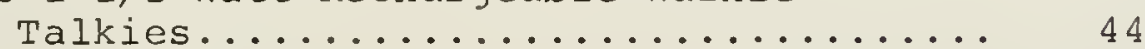

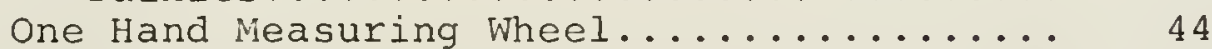

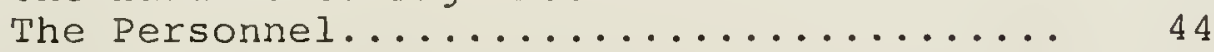

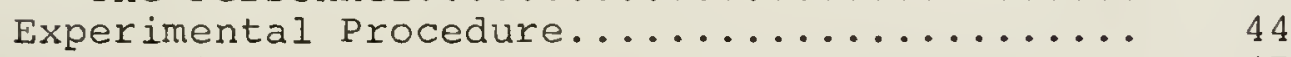

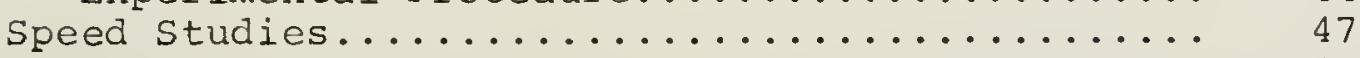

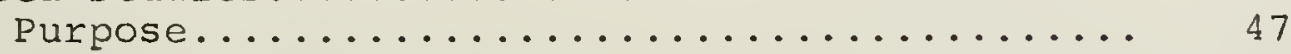

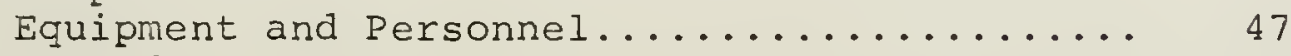

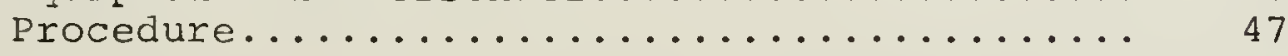


TABLE OF CONTENTS (continued)

Page

CHAPTER IV. EXPERIMENTAL RESULTS AND

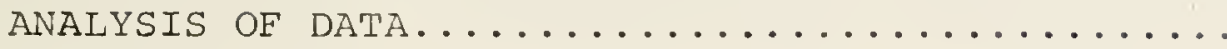

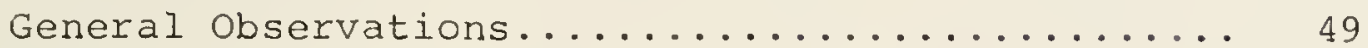

The Length and Speed of Passing Maneuvers....... 56

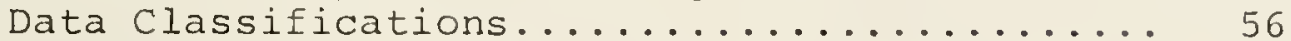

The Types of Passing Vehicles............ 56

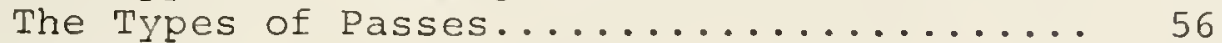

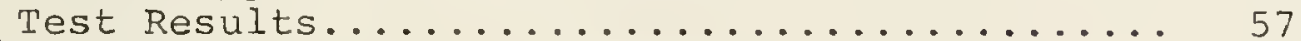

The Mean Length of Passing Maneuvers...... 57

The Mean Speed of Passing Vehicles........ 57

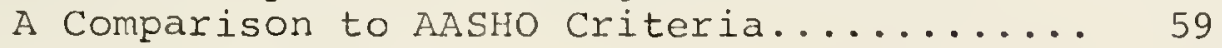

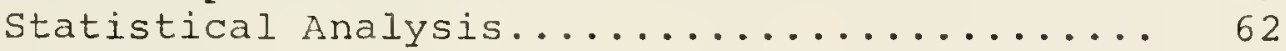

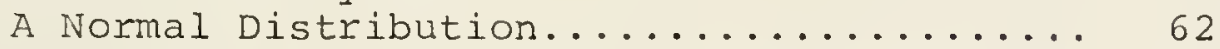

An Analysis of Data within Each Test Road.. 66

The Results of the Statistical Analyses.... 75

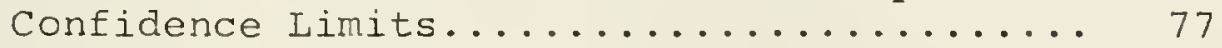

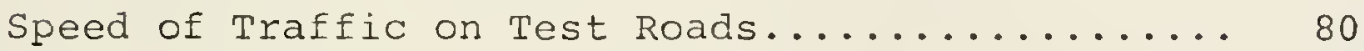

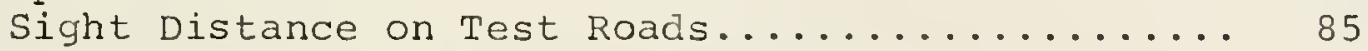

The Sight Distance - Passing Maneuver

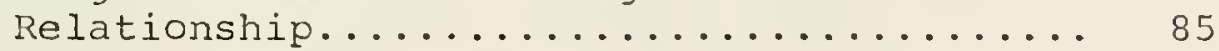

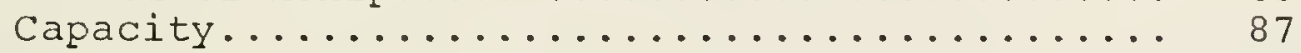

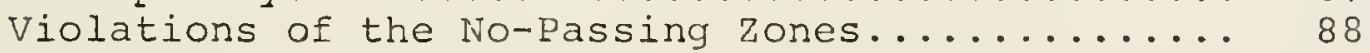

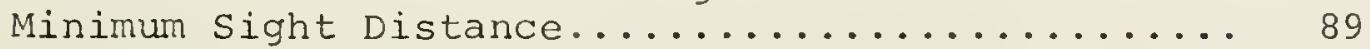

Comparison with the Criteria of MUTCD........... 93

Long zone vs. Short Zone Concept.............. 97

Minimum Distance Between No-Passing Zones........ 101

CHAPTER V. CONCLUSIONS AND RECOMMENDATIONS....... 104

Criteria for No-Passing Zones at Curves........ 104

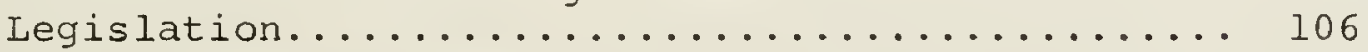

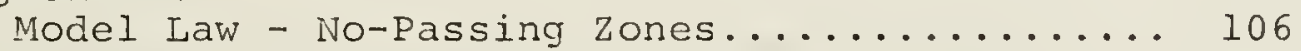

Indiana Laws - No-Passing Zones............. 107

Field Method to Locate Limits of No-Passing

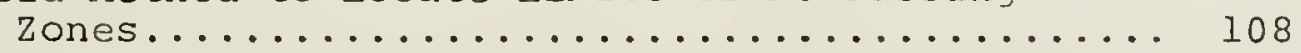

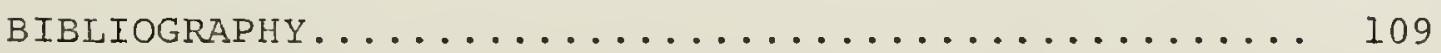

APPENDIX A. INDIANA TRAFFIC LAWS............. 111

APPENDIX B. DETAILS OF FIELD METHOD TO LOCATE

LIMITS OF INO-PASSING ZONES................ 115 


\section{LIST OF TABLES}

Table

Page

1. Elements of Safe Passing Sight Distance -

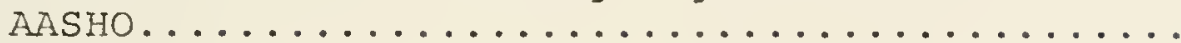

2. Minimum Passing Sight Distance for Design

of Two-Lane Highways - AASHO..............

3. Sight Distance Comparison................ 16

4. Comparison of Distance Between Zones......... 17

5. Mean Length and Speed of Passing Maneuvers..... 58

6. Statistical Test Results Comparing the Mean

Lengths of Passes in Northbound and

Southbound Directions for Each Test Road.......

7. Number of Observations and Mean Lengths of

Passing Maneuvers for Each Test Road.........

8. Analysis of Variance of Mean Length to Pass.... 70

9. Number of Observations and Mean Speeds of

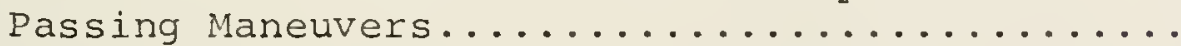

10. Analysis of Variance of Mean Speed to Pass....

11. Sight Distance, Length of Passing Maneuver and Speed of Passing Vehicle on Each Test

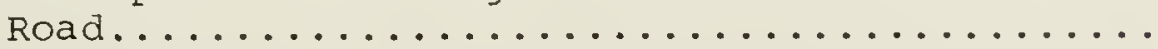

12. Confidence Limits of the Mean Distance to

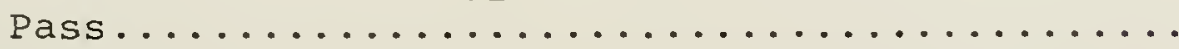

13. Confidence Limits of the Mean speed of the

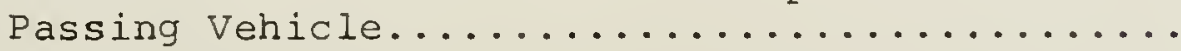

14. The Duration of Passing Maneuvers............ 90

15. Distance Traveled by oncoming Vehicle......... 91 


\section{IIST OF TABLES (continued)}

Table

Page

16. Total Distance Traveled by Passing Vehicle

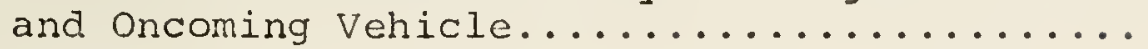

17. Recommended Minimum Sight Distance.......... 95

18. Minimum Distance Between No-Passing Zones.... 103 


\section{LIST OF FIGURES}

Figure

Page

I. Determination of No-Passing Zones...........

2. Elements of and Total Passing Sight

Distance - 2-Lane Highways...............

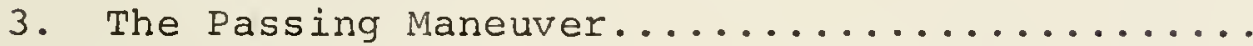

4. General Area Map....................... 35

5. Alignment of Test Road S. R. 43 N............ 36

6. Alignment of Test Road S. R. 43S........... 38

7. Alignment of Test Road S. R. 25............ 39

8. Sight Distance Survey Problem.............. 45

9. Location of Passing Maneuvers - S. R. $43 \mathrm{~N}$

Northbound........................

10. Location of Passing Maneuvers - S. R. $43 \mathrm{~N}$

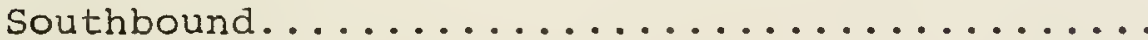

11. Location of Passing Maneuvers - S. R. 43 S

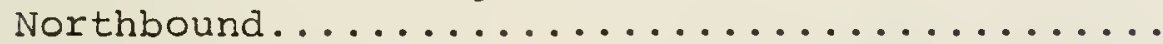

12. Location of Passing Maneuvers - S. R. 435

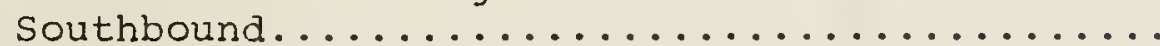

13. Location of Passing Maneuvers - S. R. 25 Northbound.

14. Location of Passing Maneuvers - S. R. 25 Southbound

15. Length of Passing Maneuvers............... 60

16. Speed of Passing Maneuvers............... 60

17. Frequency Distribution of Length of Passing

Maneuvers - $38 \mathrm{mph} . \ldots \ldots \ldots \ldots \ldots \ldots \ldots \ldots$ 


\section{LIST OF FIGURES (continued)}

Figure

Page

18. Frequency Distribution of Length of Passing

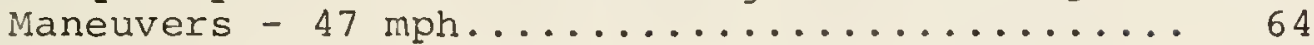

19. Frequency Distribution of Length of Passing

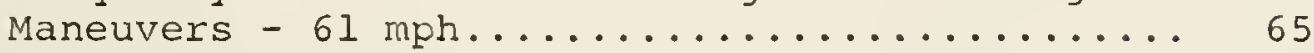

20. Accumulative Distribution of Traffic Speeds

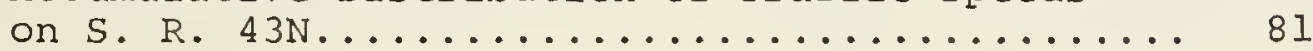

21. Accumulative Distribution of Traffic speeds

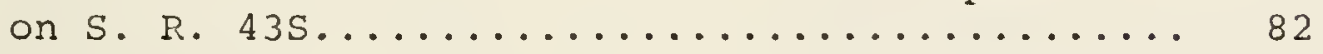

22. Accumulative Distribution of Traffic speeds

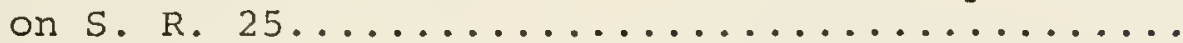

23. Sight Distance Available when Vehicles Reached the "Point-of-no-Return"........... 86

24. Minimum Sight Distance Required to Pass....... 94 
ABSTRACT

Van Valkenburg, Gerald W. M.S.C.E., Purdue University, August 1969. NO-PASSING ZONES: CRITERIA, LEGISLATION AND LOCATION. Major Professor: H. L. Michael.

The concept presently used by most states for establishing and marking no-passing zones on two-lane highways legally prohibits motorists from driving on the left side of a yellow line throughout the length of a no-passing zone. The shortcomings of this concept called the short zone concept, are well known. It is physically impossible for motorists to always complete a passing maneuver without crossing over the end of a yellow line because of the limited visibility of nopassing zone signs and pavement parkings. Consequently, drivers of passing vehicles often drive erratically by swerving in front of the passed vehicle to avoid crossing a yellow line. Furthermore, the crossing of a yellow line to complete a passing maneuver begun prior to the beginning of a nopassing zone is not an unsafe practice.

An alternative to the short zone concept is a concept that allows the yellow line to be crossed for the purpose of completing a passing maneuver. This concept, called the long zone concept, prohibits only the beginning of a passing maneuver in a marked no-passing zone. 
The purpose of this study was to determine which nopassing zone concept should be adopted to assure maximum safety and comfort for the motoring public; to determine appropriate criteria and legislation to implement the recommended concept; and to determine an economical, efficient method to establish the limits of no-passing zones in the field.

The research consisted of: (1) review of criteria, laws and methods presently used to establish no-passing zones; (2) an experiment designed to measure the length and speed of passing maneuvers on three test roads; (3) a survey of the test roads to determine sight distance; and (4) a study of the test roads to determine the distribution of traffic speeds.

The results of this research indicate that the long zone concept, which legally allows the completion of a passing maneuver within a no-passing zone, should be adopted. Criteria and a model law required to implement the concept and a suggested method for measuring sight distance and locating the limits of no-passing zones in the field were developed. 
CHAPTER I. INTRODUCTION

\section{The Problem}

Despite the present day emphasis on freeways, expressways, superhighways, etc., the bulk of the rural highway network throughout the United States is still the two-lane two-way highway. Ninety percent of the total rural mileage is of the two-lane type and much of this mileage was constructed before modern geometric design standards were established. Consequently the horizontal and vertical alignments create hazards that frequently are the indirect cause of many accidents.

One of the primary contributing factors to the cause of accidents is the limited sight distance that is available on some of these roads due to the poor alignments. Sight distance is especially important on two-lane two-way highways -- more than on four lane highways or freeways -- because the passing maneuver requires the use of the lane normally occupied by on-coming traffic. This constitutes a constant danger to the two-lane highway user.

To reduce this danger, traffic engineers have established and marked no-passing zones with yellow paint and signs for many years to warn drivers of impending sight restrictions. Laws have been passed in virtually every state, 
regulating the behavior of motorists within these zones to preserve the general welfare and safety of the motoring pubIic.

The speed of traffic has been increasing generally since the automobile was invented. During the past year, a study indicated that the average speed of traffic increased by nearly one mile per hour in the state of Indiana [1]* The automobile manufacturers are producing automobiles with bigger and better power plants under the hood. Furthermore, as more and more freeways are constructed, motorists become accustomed to driving at high speeds and expect to be able to drive fast when they leave the freeways and travel over two-lane highways to their desired destinations.

Obviously, warnings of inadequate sight distances for passing on such highways should be clear and motorists should always be certain what such warnings mean. The criteria for establishment of no-passing zones and the exact meaning of such markings, however, are not standard and some confusion does result.

Perhaps the biggest contribution to this confusion is the way the laws are written in regard to no-passing zones. In most states it is illegal to be left of an applicable yellow line at any time even though it is often impossible to see a yellow line or no-passing sign far enough away to always

* Numers in brackets refer to items in the Bibliography. 
complete a pass without being left of the yellow line. The law is clearly inconsistent with the physical capabilities of the driver and vehicle. The law as a consequence cannot always be obeyed. Such a situation can only contribute to disregard of laws in general and utter frustration for the unfortunate few who are apprehended.

\section{Purpose and Scope of Project}

The purpose of this research project is to improve the safety and efficiency of two-lane two-way highways through improved regulations and procedures for establishing nopassing zones. This involves three basic goals as follows:

1. Determine the optimum warrants or criteria for the establishment of no-passing zones at horizontal and vertical curves on two-lane two-way highways.

2. Determine the necessary legislation to provide a legal and fair basis for the enforcement of restrictions on the passing maneuver, established according to the above warrants.

3. Determine an economical, efficient and accurate method or procedure to mark the limits of no-passing zones on the pavements of two-lane two-way highways. 
CHAPTER II. REVIEW OF LITERATURE AND LAWS

\section{Criteria Review}

The 1961 Edition of the MUTCD

"The Manual on Uniform Traffic Control Devices,"

hereafter referred to as MUTCD, contains criteria or warrants for the establishment of no-passing zones on two-lane and three-lane two-way highways. The following is quoted from the manual [2]:

'Warrants for No-Passing Zones at Curves'

A no-passing zone at a horizontal or vertical curve is warranted where the sight distance as defined below is less than the minimum necessary for safe passing at the prevailing speed of traffic. Sight distance on a vertical curve is the distance at which an object 4 feet above the pavement surface can just be seen from another point 4 feet above the pavement. Similarly sight distance on a horizontal curve is the distance measured along the center line (or right-hand lane line of a threelane highway) between two points 4 feet above the pavement on a line tangent to the embankment or other obstruction that cuts off the view on the inside of the curve. A curve shall warrant a nopassing zone and shall be so marked where the sight distance is equal to or less than that listed below for the prevailing (off peak) 85-percentile speed:

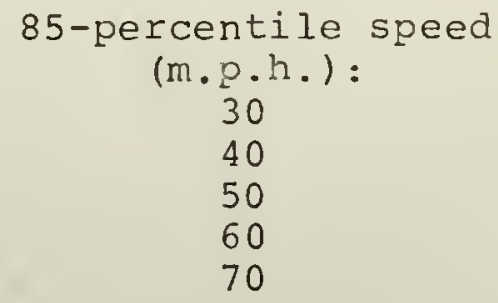

Minimum sight distance

$(\mathrm{m} . \mathrm{p} . \mathrm{h}):$.
30
40
50
60
70

(feet):
500
600
800
1,000
1,200


The beginning of a no-passing zone is that point at which the sight distance first becomes less than that specified in the above table. The end of the zone is that point at which the sight distance again becomes greater than the minimum specified.

The Draft of the New NUTCD

Changes in the MUTCD warrants have been proposed in a draft dated May 23, 1968 [3]. The following is quoted from that araft.

'Varrants for No-Passing Zones at Curves'

A no-passing zone at a horizontal or vertical curve is warranted where the sight distance as defined below is less than the minimum necessary for safe passing at the prevailing speed of traffic. Passing sight distance on a vertical curve is the distance at which an object 3.75 feet above the pavement surface can just be seen from another point 3.75 feet above the pavement. (See Figure 1). Similarly passing sight distance on a horizontal curve is the distance measured along the center line (or right-hand lane line of a three-lane highway) between two points 3.75 feet above the pavement on a line tangent to the embankment, or other obstruction that cuts off the view on the inside of the curve. (See Figure 1). Where center lines are installed, a curve warrants a no-passing zone and should be so marked where the sight distance is equal to or less than than listed below for the prevailing (off peak) 85-percentile speed:

85-percentile speed

$$
(\mathrm{m} \cdot \mathrm{p} \cdot \mathrm{h} .):
$$

30

40

50

60

70
Minimum Passing Sight Distance (feet):

$$
\begin{array}{r}
500 \\
790 \\
1,065 \\
1,375 \\
1,710
\end{array}
$$

The beginning of a no-passing zone (point "a" in Figure 1 ) is that point at which the sight distance first becomes less than that specified in the above table. The end of the zone (point "b") is that point at which the sight distance 


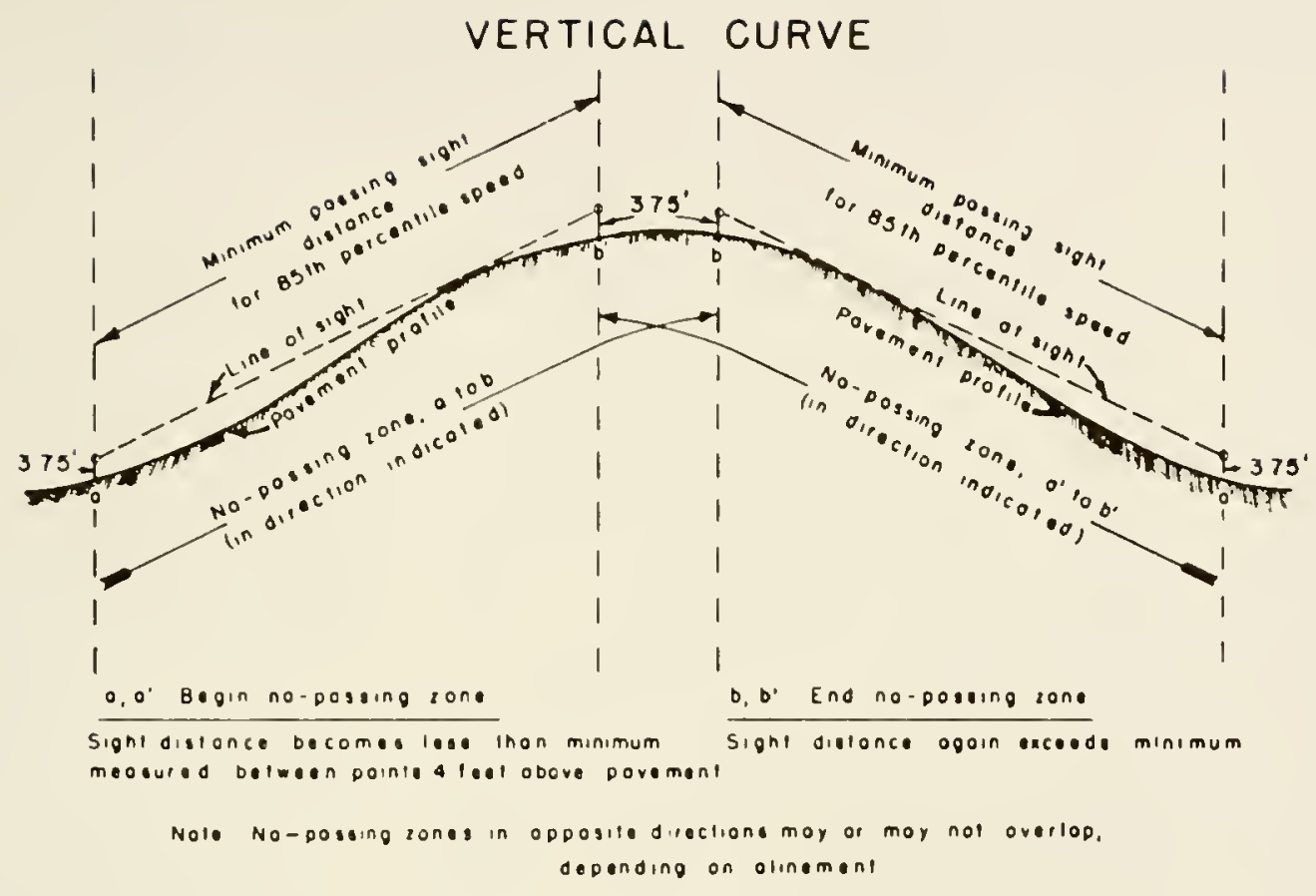

HORIZONTAL CURVE

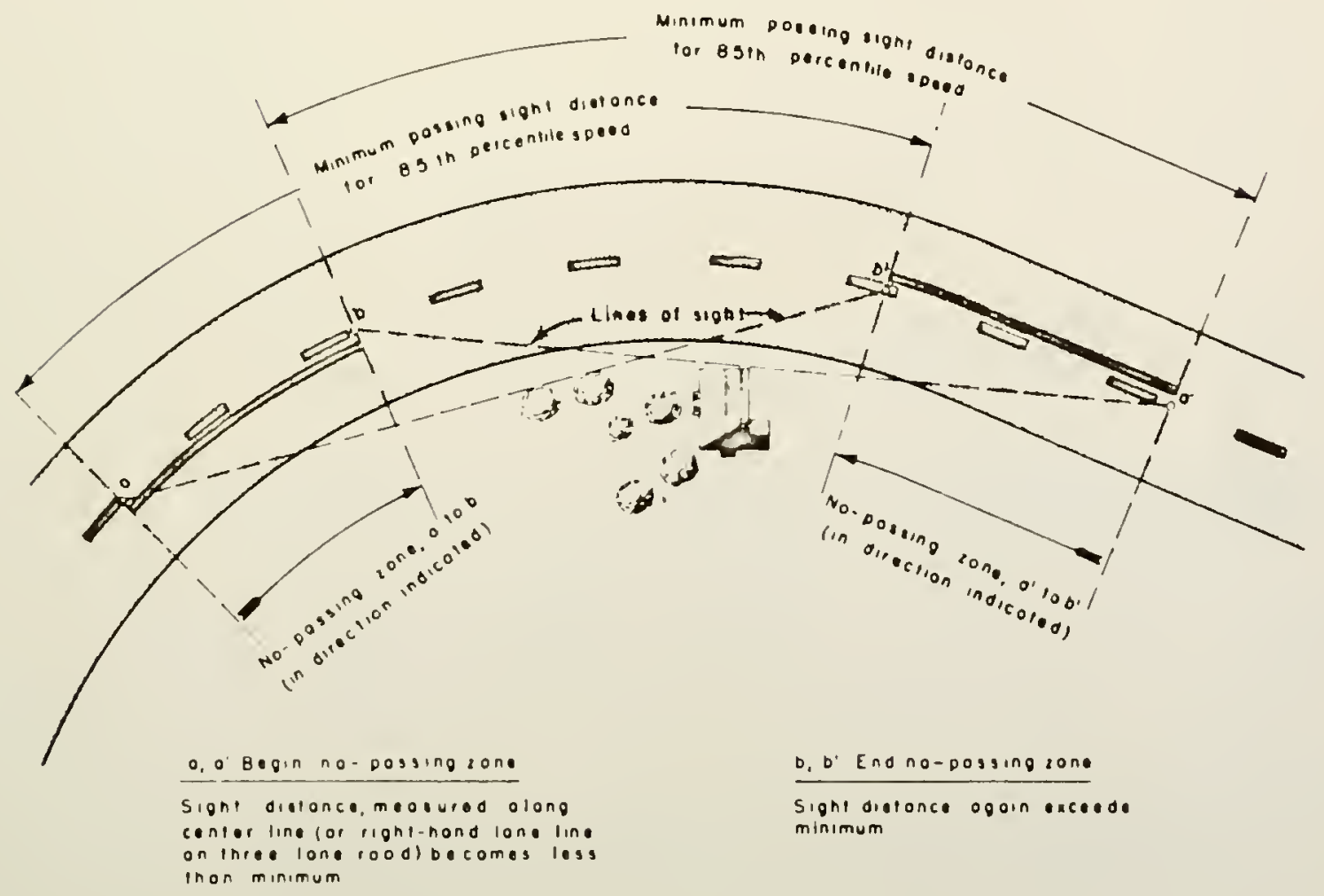

Nol. No-dossing zones in opposile direclions moy of moynol ovellop. SOURCE: Manual on Uniform Traffic Control Devices.

FIGURE I. DETERMINATION OF NO-PASSING ZONES. 
again becomes greater than the minimum specified.

\section{AASHO ${ }^{*}$ Criteria}

AASHO criteria for design as recommended in the manual "A Policy on Geometric Design of Rural Highways," [4] provides a clear insight into the assumptions and basis for the minimum passing sight distance required for the design of two-lane two-way rural highways. The criteria are to be used as a guide in the design of new facilities and are not supposed to be used as a criteria for establishing nopassing zones on roads that do not have adequate sight distance.

The criteria were developed on the basis of extensive field observations of passing maneuvers during the years 1938 to 1941 [5]. A sumary of pertinent findings and assumptions are listed below.

1. When reguired, a driver can return to the right lane if he sees opposing traffic when the maneuver is only partially accomplished.

2. Passing sight distance for use in design should be determined on the basis of the length needed to safely complete a normal passing maneuver.

3. Sight distance is determined for a single vehicle passing a single vehicle.

4. The overtaken vehicle travels at uniform speed.

5. The passing vehicle has reduced speed and trails the overtaken vehicle as it enters a passing section.

American Association of State Highway Officials. 
6. When the passing section is reached, the driver requires a short period of time to perceive the clear passing section and to react to start his maneuver.

7. Passing is accomplished under what may be termed a delayed start and a hurried return in the face of opposing traffic.

8. The passing vehicle accelerates during the maneuver and its speed during the occupancy of the left lane is $10 \mathrm{~m} . \mathrm{p} . \mathrm{h}$. higher than that of the overtaken vehicle.

9. When the passing vehicle returns to its lane there is a suitable clearance length between it and an oncoming vehicle in the other lane.

10. For simplicity, extraordinary maneuvers are ignored and passing distances developed using speeds and times observed which fit the practices of a high percentage of drivers.

11. The minimum passing sight distance for two-lane highways is determined as the sum of four distances (see diagram at the top of Figure 2);

$d_{1}$ - Distance traversed during perception and reaction time and during the initial acceleration to the point of enroachment on the left lane.

$a_{2}$ - Distance traveled while the passing vehicle occupies the left lane.

$a_{3}$ - Distance between the passing vehicle at the end of its maneuver and the opposing vehicle.

$\mathrm{d}_{4}$ - Distance traversed by an opposing vehicle for two-thirds of the time the passing vehicle occupies the left lane, or two-thirds of $\mathrm{d}_{2}$ above.

12. Data from the earlier study were grouped into three passing speed groups, 30 to 40,40 to 50 , and 50 to 60 miles per hour. A fourth group has been added, 60 to 70 miles per hour, based on extrapolated data...

13. Time and distance values were determined in relation to the average speed of the passing vehicle. 
FIRST PHASE
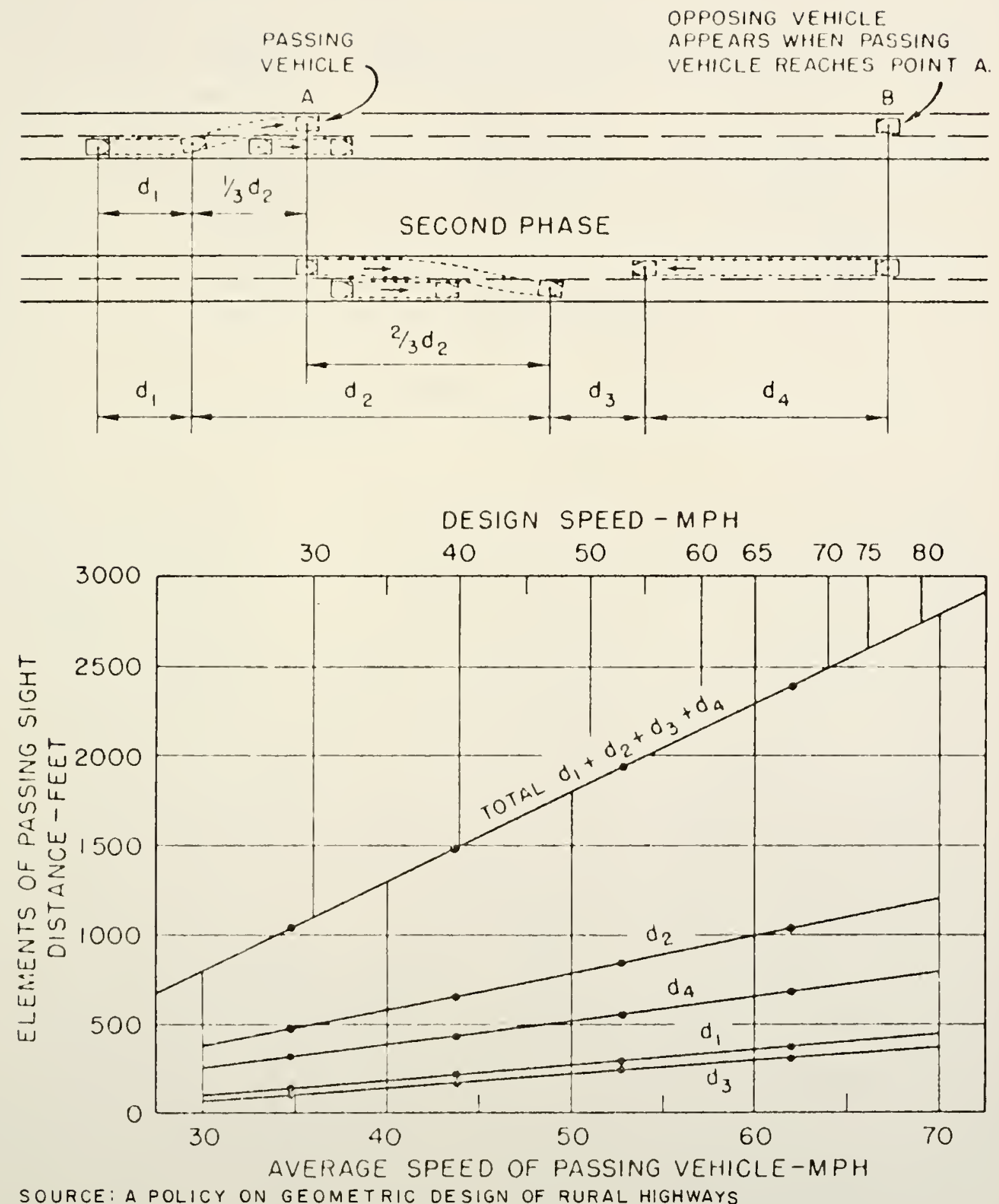

SOURCE: $A$ POLICY ON GEOMETRIC DESIGN OF RURAL HIGHWAYS

FIGURE 2. ELEMENTS OF AND TOTAL PASSING SIGHT DISTANCE-2-LANE HIGHWAYS 
14. Passing vehicles were found in the study to occupy the left lane from 9.3 to 10.4 seconds.

15. Clearance lengths between the opposing and passing vehicles at the end of the maneuvers found in the passing study varied from 110 to 300 feet.

16. During the first phase of the passing maneuver the passing vehicle has not yet pulled abreast of the vehicle being passed and, even though the passing vehicle occupies the left lane, its driver can return to the right lane if he sees an opposing vehicle. It is unnecessary to include this trailing time interval in computing the distance traversed by an opposing vehicle.

17. The opposing vehicle is assumed to be traveling at the same speed as the passing vehicle, and $\mathrm{d}_{4}=2 \mathrm{~d}_{2} / 3$

The elements of the safe passing sight distance are shown in Table 1 and the recommended values for design are shown in Table 2. The total sight distance recommended for design, however, may not be reasonable for establishing nopassing zones on older roads that do not meet the present day design standards. To unduly restrict the passing maneuver would reduce the capacity of the highway. There does seems to be some logic, however, in using a portion of the sight distance criteria developed for design as criteria for establishing no-passing zones. As quoted previously during the first phase of the passing maneuver -- namely $d_{1}$ and $1 / 3 d_{2}$ - the driver can return to the right lane if he sees an opposing vehicle. The remaining distance $--2 / 3 \mathrm{~d}_{2}$, $\mathrm{d}_{3}$ and $\mathrm{d}_{4}$-- could be considered the absolute minimum sight distance suitable as a basis for no-passing zone criteria. There are certain dangers inherent in this, however, that should be pointed out. The speed of the oncoming 


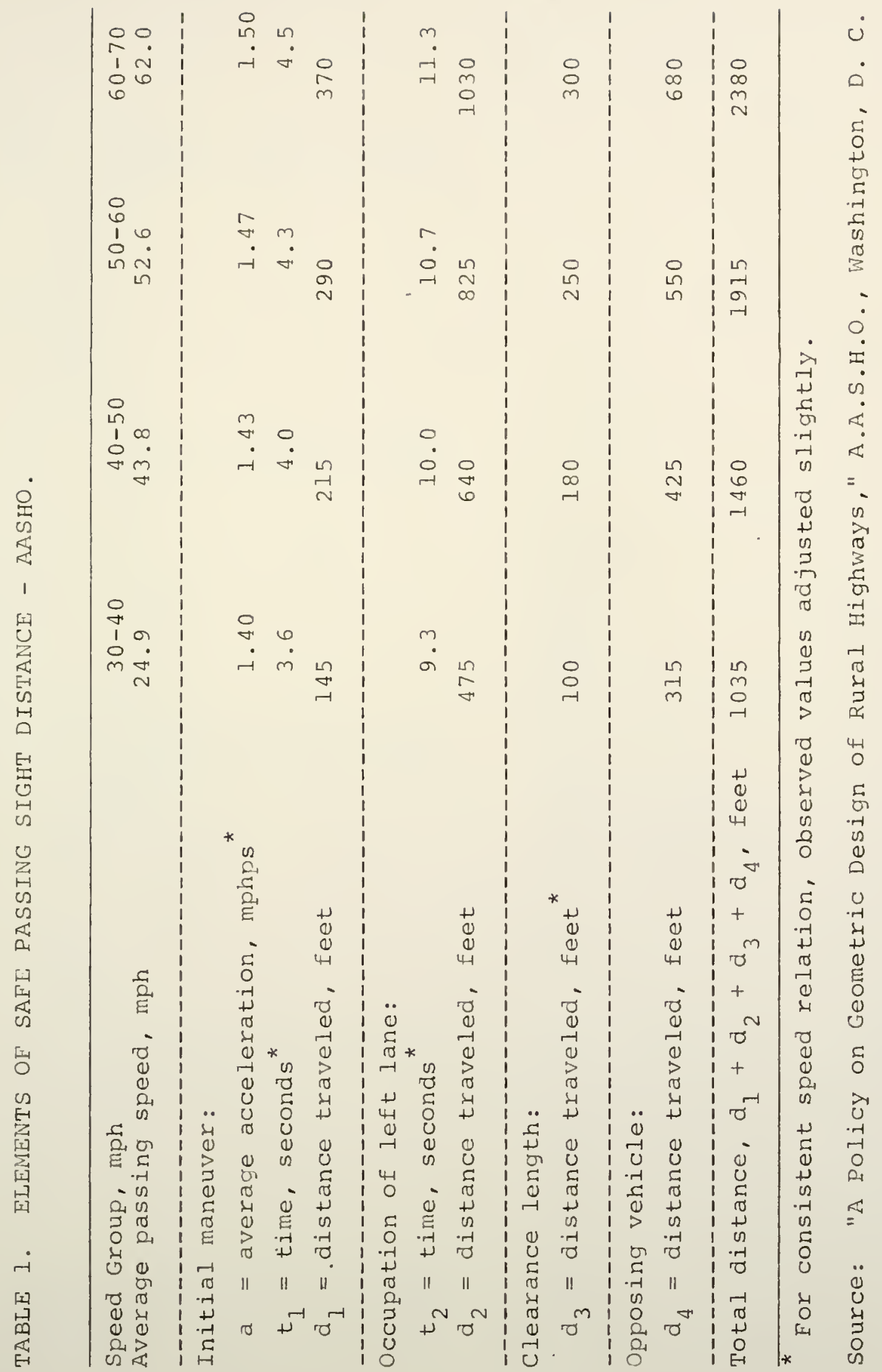




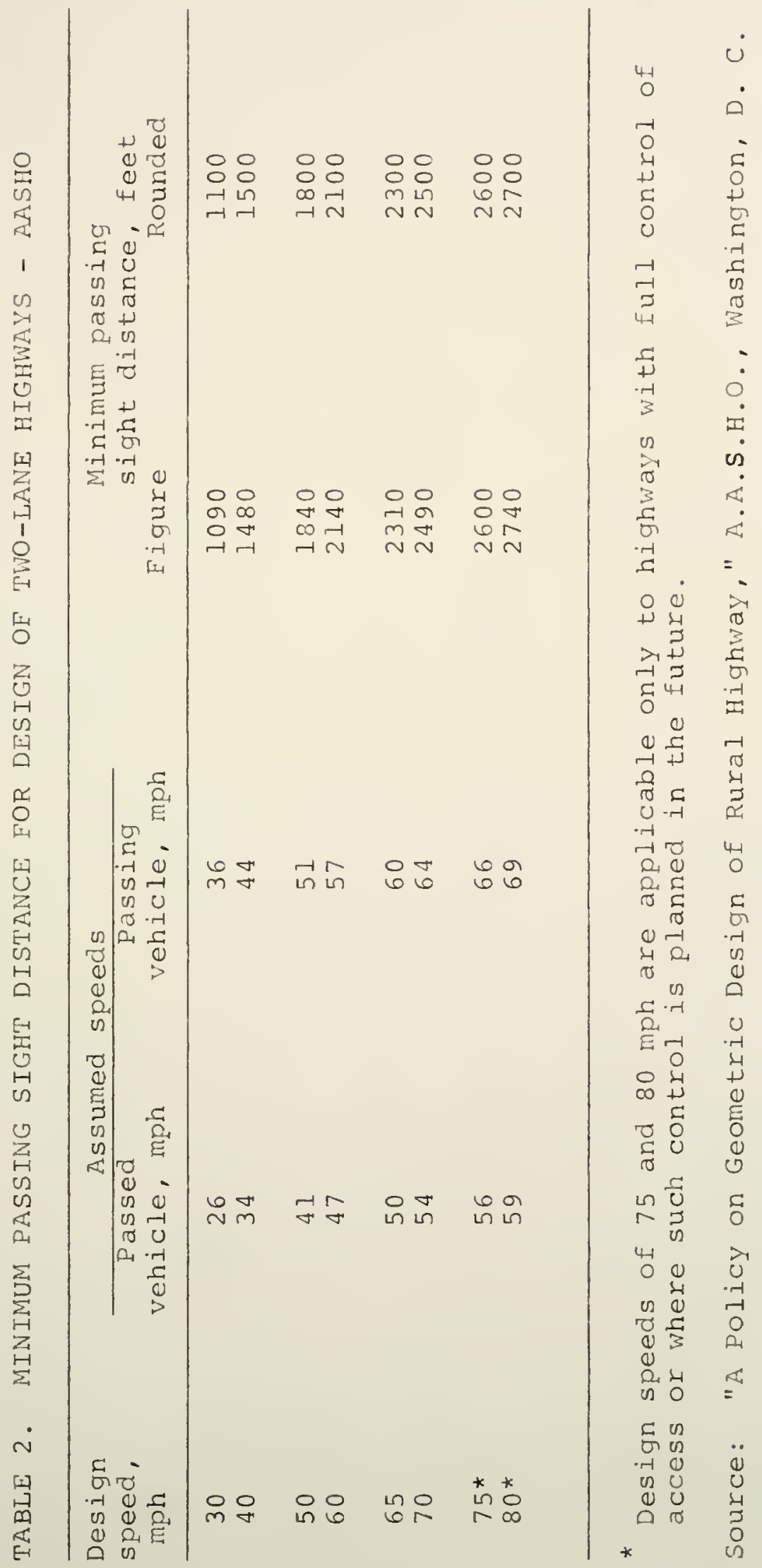


vehicle is considered to be the same as the speed of the passing vehicle, which may or may not be so. The data from which these distances were developed, were taken in the 1939 - 1941 period while vehicle characteristics have changed appreciably since then. The lengths and duration of passing maneuvers are based on the speed of the passing vehicle instead of the passed vehicle. The fourth speed group has been added by extrapolating data. Ind the portion of the distance $d_{2}$ where the driver can still abort the passing maneuver was arbitrarily chosen to be $1 / 3 \mathrm{~d}_{2}$. All of these aspects should be investigated to ascertain the present day criteria applicable for determining the limits of no-passing zones.

The minimum passing sight distance for design should also be investigated. In Table 2, the assumed speed of the passed vehicle is considerably less than the design speed of the highway. For instance, it is assumed the speed of the passed vehicle is $50 \mathrm{~m} . \mathrm{p} . \mathrm{h}$. On a highway with a design speed of $65 \mathrm{~m} . \mathrm{p} . \mathrm{h}$. This seems like a dangerous assumption considering the fact that the average speed of traffic on a new two-lane two-way highway would be about $60 \mathrm{~m} . \mathrm{p} . \mathrm{h}$. or more with less than $15 \%$ of the vehicles traveling slower than $50 \mathrm{~m} . \mathrm{p} . \mathrm{h} .[1]$. The speed of the oncoming vehicle is assumed to be the same as the speed of the passing vehicle, which in this example would be $60 \mathrm{~m} \cdot \mathrm{p} . \mathrm{h}$. That also is a dangerous assumption for the same reasons as stated above. 
The Criteria of Indiana

Present Indiana criteria, as stated in the Indiana State Manual on Uniform Traffic Control Devices, are in verbatim conformity with the Federal Manual. However, this is in direct conflict with another Legislative Act in Indiana. Section \#372 of Burns Statutes section 36-2934 of the Original Act 1937, Chap. 272, Sec. 4, page 1262 states in part that:

... Where the vision of a person traveling a highway in the state highway system is obstructed or any portion thereof by reason of a curve, hill or other obstruction for a distance of seven hundred and fifty feet or less ahead of such person the state highway commission is authorized and empowered to mark with yellow or orange paint...

Height of Eye and Object

Driver eye height and height of object are proposed to be reduced from 4 feet to 3.75 feet according to the draft of the new MUTCD (see Figure 1).

In a 1967 study of the height of autos conducted by the Michigan Department of State Highways [6] it was found that $94.47 \%$ of the total registered vehicles in the United States had a loaded eye height of 45 inches or more but only $9.05 \%$ had an eye height of 48 inches or more. This is proof enough that the eye height should be lowered below the 4 foot level.

The height of target is more arbitrary because a certain percentage of the vehicle needs to be seen to be visible as an object. The top part of the modern automobile 
does not offer a good visual target because of the windshield and narrow roof profile. Most American cars range between 51 and 55 inches in height. It therefore seems logical to lower both the eye height and target height to the same 3.75 foot elevation.

\section{Sight Distance Comparison}

A comparison of sight distance as stated in: (1) the 1961 "Manual on Uniform Traffic Control Devices"; (2) the proposed new MUTCD; and (3) "A Policy on Geometric Design of Rural Highways" is shown in Table 3 .

The basis for the sight distances as shown for MUTCD is unknown to the author. The proposed increase in the sight distance for the new manual varies from $0 \%$ at $30 \mathrm{~m} \cdot \mathrm{p} . \mathrm{h}$. to $42.5 \%$ at $70 \mathrm{~m} \cdot \mathrm{p} . \mathrm{h}$. Everything else remaining the same, it seems to the author that a significant increase such as this would be unnecessary unless there has been an analysis of accidents which has shown the need for change. It is doubtful that the present criteria contribute to a significant number of accidents.

\section{Distance Between zones}

The minimum äistance between no-passing zones is also proposed in the draft to be changed as shown in Table 4. If the distance between zones is less than that 1 isted, then one continuous zone would be established. 


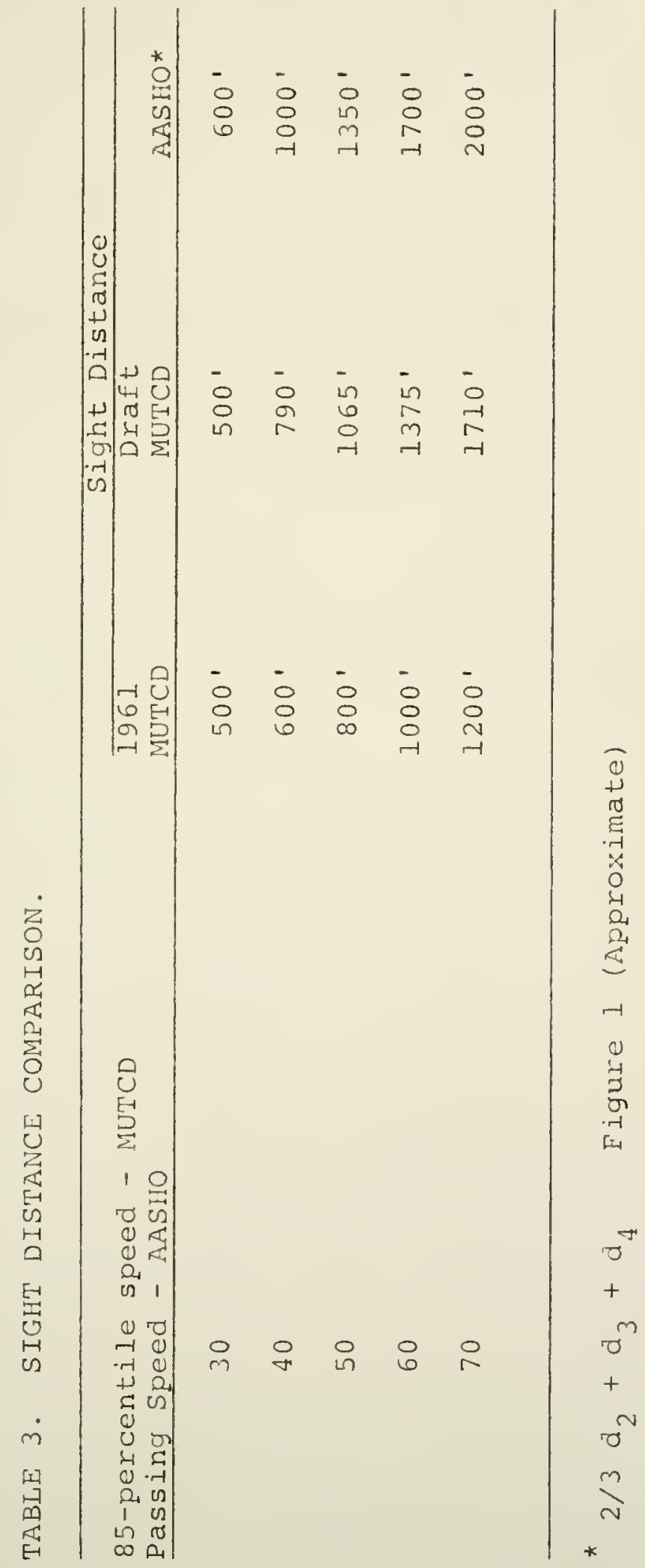


TABLE 4. COMPARISON OF DISTANCE BETWEEN ZONES.

\begin{tabular}{ccc}
\hline Prevailing speed & \multicolumn{2}{c}{ Minimum Distance } \\
\hline $30 \mathrm{mph}$ & MUTCD & $\begin{array}{c}\text { Draft } \\
\text { MUTCD }\end{array}$ \\
\hline $4 \mathrm{mph}$ & $400^{\prime}$ & $480^{\prime}$ \\
$50 \mathrm{mph}$ & $400^{\prime}$ & $640^{\prime}$ \\
$60 \mathrm{mph}$ & $400^{\prime}$ & $820^{\prime}$ \\
& & $1030^{\prime}$ \\
\hline
\end{tabular}


These recommended minimum distances are based on prevailing speed of traffic instead of 85-percentile speed. This seems to be inconsistent and confusing. The basis for the proposed minimum distances is unknown to the writer. However, to prohibit the passing of slow moving vehicles where ample sight distance is available for a distance of 1000 feet seems to be a severe restriction.

\section{Law Review}

The Uniform Vehicle code

"The Uniform Vehicle Code," referred to as UVC hereafter [7] contains several statutes pertaining to the passing maneuver and no-passing zones. These statutes are included here for reference. The Indiana law that pertains to the subject and any variations of the Indiana law is noted immediately after each section. The Indiana law number is taken from the 1965 and 1967 "Indiana Motor Vehicle Laws." $[8,9]$

\section{UVC Sec. 11-301-Drive on Right Side of Roadway-Exceptions}

(a) Upon all roadways of sufficient width a vehicle shall be driven upon the right half of the roadway, except as follows:

1. When overtaking and passing another vehicle proceeding in the same direction under the rules governing such movement;

2. When an obstruction exists making it necessary to drive to the left of the center of the highway; provided, any person so doing shall yield the right of way to all vehicles traveling in the proper direction upon the unobstructed portion of the highway within such distance as to constitute an immediate hazard; (revised, 1962 ). 
3. Upon a roadway divided into three marked lanes for traffic under the rules applicable thereon; or

4. Upon a roadway designated and signposted for one-way traffic.

(b) Upon all roadways any vehicle proceeding at less than the normal speed of traffic at the time and place and under the conditions then existing shall be driven in the right-hand lane then available for traffic, or as close as practicable to the right-hand curb or edge of the roadway, except when overtaking and passing another vehicle proceeding in the same direction or when preparing for a left turn at an intersection or into a private road or driveway.

(c) Upon any roadway having four or more lanes for moving traffic and providing for two-way movement of traffic, no vehicle shall be driven to the left of the center line of the roadway, except when authorized by official traffic-control devices designating certain lanes to the left side of the center of the roadway for use by traffic not otherwise permitted to use such lanes, or except as permitted under subsection (a) (2) hereof.

Indiana law 233 is in verbatim conformity with paragraphs (a) and (b) with the exception of paragraph (a) 2 Which is replaced by:

When the right half of a roadway is closed to traffic (while under construction or repair);

Indiana does not have a law comparable with paragraph (c).

UVC Sec. 11-302-Passing Vehicles Proceeding in Opposite Directions.

Drivers of vehicles proceeding in opposite directions shall pass each other to the right, and upon roadways having width for not more than one line of traffic in each direction each driver shall give to the other at least one-half of the main-traveled portion of the roadway as nearly as possible.

Indiana law 234 is in verbatim conformity. 
UVC Sec. 11-303-Overtaking a Vehicle on the Left.

(a) The ariver of a vehicle overtaking another vehicle proceeding in the same direction shall pass to the left thereof at a safe distance and shall not again drive to the right side of the roadway until safely clear of the overtaken vehicle.

(b) Except when overtaking and passing on the right is permitted, the driver of an overtaken vehicle shall give way to the right in favor of the overtaking vehicle on audible signal and shall not increase the speed of his vehicle until completely passed by the overtaking vehicle.

Indiana law 235 is in verbatim conformity.

UVC Sec. 11-304-When Overtaking on the Right is Permitted.

(a) The driver of a vehicle may overtake and pass - upon the right of another vehicle only under the following conditions:

1. When the vehicle overtaken is making or about to make a left turn;

2. Upon a street or highway with unobstructed pavement not occupied by parked vehicles of sufficient width for two or more lines of moving vehicles in each direction;

3. Upon a one-way street, or upon any roadway on which traffic is restricted to one direction of movement, where the roadway is free from obstructions and of sufficient width for two or more lines of moving vehicles.

(b) The driver of a vehicle may overtake and pass another vehicle upon the right only under conditions permitting such movement in safety. In no event shall such movement be made by driving off the pavement or main-traveled portion of the roadway.

Indiana law 236 reads as follows:

236. When Overtaking on the Right is Permitted.

(a) The driver of a vehicle may overtake and pass upon the right of another vehicle which is making or is about to make a left turn. 
(b) The driver of a vehicle may overtake and, allowing a sufficient clearance, pass another vehicle proceeding in the same direction either upon the left or upon the right on a roadway with unobstructed pavement of sufficient width for four or more lines of moving traffic when such movement can be made with safety. No person shall drive off the pavement or upon the shoulders of the roadway in overtaking or passing on the right. $(47-2013)$

This Indiana law does not cover the condition stated in section (a) paragraph 3, which allows a driver to pass on the right on a one-way roadway that is unobstructed and wide enough for two lines of traffic. Othervise, the intent conforms to the "Uniform Vehicle code."

UVC Sec. 11-305-Limitations on Overtaking on the Left.

No vehicle shall be driven to the left side of the center of the roadway in overtaking and passing another vehicle proceeding in the same direction unless authorized by the provisions of this article and unless such left side is clearly visible and is free of oncoming traffic for a sufficient distance ahead to permit such overtaking and passing to be completely made without interfering with the operation of any vehicle approaching from the cpposite direction or any vehicle overtaken. In every event the overtaking vehicle must return to an authorized lane of travel as soon as practicable and in the event the passing movement involves the use of a lane authorized for vehicles approaching from the opposite direction, before coming within 200 feet of any approaching vehicle. (Revised, 1962).

Indiana law 237 is in verbatim conformity except it stipulates 100 feet instead of 200 feet.

UVC Sec. 11-306-Further Limitations on Driving to Left of Center of Roadway.

(a) No vehicle shall at any time be driven to the left side of the roadway under the following conditions: 
1. When approaching the crest of a grade or upon a curve in the highway where the driver's view is obstructred within such distance as to create hazard in the event another vehicle might approach from the opposite direction;

2. When approaching within 100 feet of or traversing any intersection or railroad grade crossing;

3. When the view is obstructed upon approaching within 100 feet of any bridge, viaduct or tunnel.

(b) The foregoing limitations shall not apply upon a one-way roadway.

Indiana law 238 is in verbatim conformity.

UVC Sec. 11-307-No-Passing Zones.

(a) The (State highway commission) is hereby authorized to determine those portions of any highway where overtaking and passing or driving to the left of the roadway would be especially hazardous and may by appropriate signs or markings on the roadway indicate the beginning and end of such zones and when such signs or markings are in place and clearly visible to an ordinarily observant person every driver of a vehicle shall obey the directions thereof.

(b) Where signs or markings are in place to define a no-passing zone as set forth in paragraph (a) no driver shall at any time drive on the left side of the roadway within such no-passing zone or on the left side of any pavement stripping designed to mark such no-passing zone throughout its length.

Indiana law 239 is in verbatim conformity with paragraph

(a) except the words "by an engineering and traffic investigation" are inserted after the word "determine." The Indiana law does not contain section (b). 
Another Pertinent Indiana Law

Indiana Law Number 372 - No-Passing Zones - Unlawful Acts Penalty.

Where the vision of a person traveling a highway in the state highway system is obstructed on any portion thereof by reason of a curve, hill or other obstruction for a distance of seven hundred and fifty feet or less ahead of such person the state Highway Commission is authorized and empowered to mark with yellow or orange colored paint a stripe at the center line of said portion of said highway or next to the center line thereof and to place at each end of said portion of said highway on the shoulders of said portion of said highway a sign with letters at least two inches in height, reading in substance: No Passing Zone. On the rear of said sign shall be printed in substance as follows: End of No Passing Zone. Whenever any such portion of any such highway is so marked it shall be unlawful for any person driving or operating a vehicle of any kind on said highway to pass or attempt to pass within said zone any other vehicle traveling on said highway and going in the same direction, and upon conviction of such person shall be fined any sum not less than five dollars nor more than one hundred dollars. $(36-2934)$.

The Draft of the New MUTCD

The draft of the proposed changes in the MUTCD dated

May 23, 1968 includes the following paragraph:

Where center lines are installed, no-passing zones shall be established at vertical and horizontal curves and elsewhere on two- and three-lane highways where an engineering study indicates passing must be prohibited because of inadequate sight distances or other special conditions.

Where signs or markings are in place to define a no-passing zone, no driver shall at any time drive on the left side of the roadway within such nopassing zone or on the left side of any pavement marking designed to mark such no-passing zone throughout its length.

The second paragraph is exactly the same as listed in the "Uniform Vehicle Code" Section 11-307 paragraph (b). 
Comparison of the Laws of Indiana and other states

The Indiana law is in general agreement with most provisions of the "Uniform Vehicle Code" concerning no-passing zones. There is one exclusion in Indiana law that is of highest importance as far as policy is concerned. In both the UVC and MUTCD, the recommended law would prohibit a driver from driving on the left side of a yellow line at any time, even to complete a passing maneuver. (Sec. II307, para. (b)). Indiana law number 372 states that to pass or attempt to pass another vehicle within a no-passing zone is illegal. It is a matter of interpretation of whether or not it is illegal to finish a passing maneuver within a no-passing zone in Indiana. Different interpretations may be applied throughout the state and it is quite certain that many citizens of Indiana do not know if it is legal or not to cross a yellow line.

The law relative to beginning and finishing a passing maneuver is most important in developing criteria for the establishment of no-passing zones. A discussion of this is included in Chapter IV where the criteria of the MUTCD are compared with the criteria developed in this study. Eight states were (in 1966) in verbatim conformity with both paragraphs (a) and (b) of UVC Sec. 11-307 mentioned above.[10]. Five more states were in substantial agreement with paragraph (b). Seven other states had a law which was similar to the 1934 code provision which prohibited overtaking and passing or driving to the left side 
of the roadway where signs directing traffic to keep to the right were in place or where a distinctive center line so directed traffic.

In summary, 20 states prohibited driving on the left of the yellow line at any time and 23 others including Indiana had laws that could be interpreted either way. One state -New Jersey -- expressly provided that "yellow lines may be crossed from the left-hand lane for the purpose of completing a pass that was begun prior to the beginning of a yellow line in the drivers direction of travel." However, another law of New Jersey, stated that "...the driver of a vehicle shall not cross an appropriately marked 'No Passing' line in a 'No Passing' zone duly established..."

Five states and the District of Columbia did not have provisions which are directly comparable to those in UVC SEC. 11-307. In four of those states it was allowed to cross the yellow line to finish a passing maneuver $[10,11]$.

\section{Field Method Review}

There are numerous methods of determining the limits of no-passing zones in the field. In response to a questionnaire sent to all state highway departments by two students at the University of Kentucky [11] there were at least eleven different methods listed. The same basic principle is used in most of the methods; namely, the use of two targets and a method of measuring and keeping a constant distance between these two targets. Following is a description of some of the 
most commonly used methods.

\section{Two-Car Method}

The two-car method is probably the most commonly used method. Two cars are each equipped with an odometer which reads to at least one hundredth of a mile and a two-way radio. The target vehicle has a target light located the proper elevation (3.75') off the pavement. The target vehicle advances until it is the proper distance (the minimum sight distance) away from the recording vehicle and then the odometers are both set to zero. At the count of three both vehicles accelerate slowly until reaching a predetermined speed. This speed is held constant and the odometer readings are checked periodically over the radio to maintain the proper distance between vehicles. When the target light disappears the position of the trailing vehicle is recorded and when the target light on the target vehicle reappears, the position of the trailing vehicle is again recorded. The area between these two positions constitutes a no-passing zone.

There are variations to the method of recording data. A second man in the trailing vehicle can record the positions manually, as done by the Minnesota Department of Highways [12]. Or, instead of recording the position on paper, he can mark the position by dropping a marker along side the road. Another variation used by the Arizona State Highway Department [13] is to rig up a special machine which they 
call a stamping odometer. The machine is a converted traffic recorder which prints the odometer reading on a tape when activated. Another variation to the method of recording is that used by the state Bureau of Traffic Safety in New Jersey [14]. A tape recorder is used by the driver to verbally record the position of the recording vehicle when the light on the target vehicle disappears and reappears .

Certain safety equipment may be required, such as flashing amber lights, signs and flags to warn traffic of slowly moving vehicles.

The Hand Measuring Wheel Method

This method [15] is basically the same as the two-car method except the work is done on foot, walkie-talkies are used for communication, and hand measuring wheels are used instead of odometers. The targets are mounted on rods which are attached to the hand measuring wheels.

The Chalkline Method

This method [15] requires the use of a chalk line that is stretched between two men to keep the desired distance apart. This method may be adequate on vertical curves but on horizontal curves this is a very cumbersome and difficult method to use. 
The Stadia Method

The stadia method involves the use of a transit and stadia rod to measure distances. This method is impractical because of the many time-consuming transit set-ups [12].

\section{Other Methods}

Other methods listed by the state highway departments [11] include: (1) one car and a series of cones; (2) judgment; and (3) car, weight and target. The exact description of these methods is unknown to the author.

\section{Comparison of Methods}

The author has very limited experience with the various methods of establishing limits of no-passing zones in the field. However, it seems only logical that a method that requires men to walk, stand, bend over, etc., in the middle of a busy highway is going to cause extreme danger to both the men and the motoring public. Therefore, all but the first method can be ruled out on this one condition.

The two-car method has its problems, however. If the cars are constantly moving, the chance of error due to perception and reaction time could be large. Also; as the distance between the vehicles increases due to longer sight distance criteria, the more difficult it is to determine exactly when the target disappears or reappears. 
The greatest danger of inaccuracy occurs when there is a dip in the road between the vehicles [16]. A dip in the road that hides oncoming vehicles is of primary importance because motorists may think they have sufficient sight distance to pass when actually there may be an oncoming vehicle close by that is hidden from view. Marking these areas is by far the most critical aspect of the nopassing zone investigation and survey.

The author is convinced that there is no easy solution to the problem. Time, money, patience and hard work will be required to do an accurate sight distance survey. The reward will be a safer road that may save Iives and reduce injuries. 
CHAPTER III. METHODOLOGY

\section{Length and Speed of Passing Maneuver}

Purpose

Two factors are of primary importance in the determination of the sight distance needed to pass another vehicle; the distance traversed by the passing vehicle and the distance traversed by an oncoming vehicle while the passing vehicle is in the "wrong" Iane. This second distance is a function of the time needed to complete the passing maneuver which is dependent on the speed and distance traversed by the passing vehicle.

The passing maneuver is illustrated in Figure 3. The first part of the passing maneuver ( $S_{0}$ ) was disregarded when calculating the minimum sight distance required for establishing no-passing zones. During this phase of the passing maneuver it is still possible to apply the brakes and pull back into a queue if an obstruction or oncoming vehicle comes into view. The exact location of this point may vary for each individual and between individuals. This may be caused by characteristics of the passing vehicle, the speed of the passed vehicle and/or the speed of an approaching vehicle. However, it is generally assumed that this so called "point-of-noreturn" occurs when the passing vehicle is abreast or nearly 


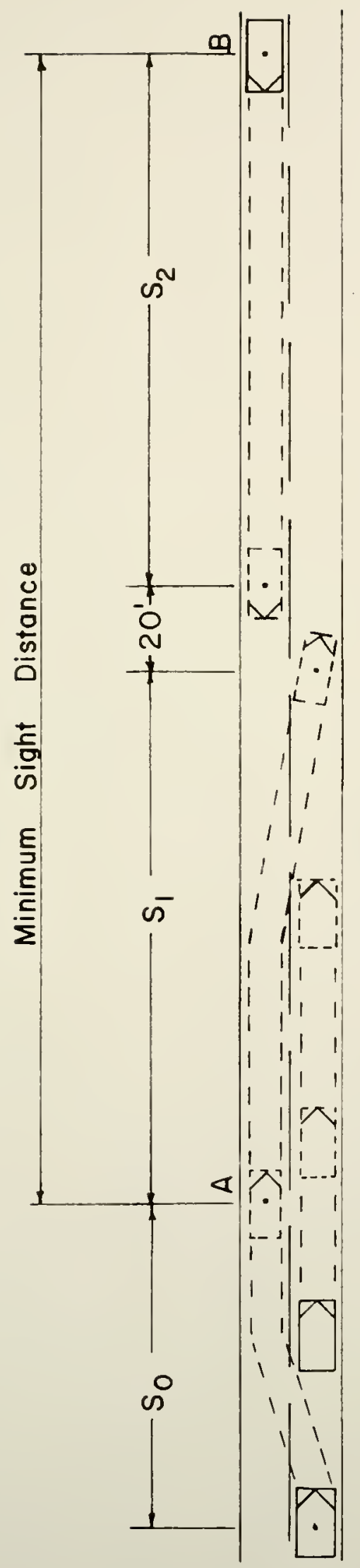

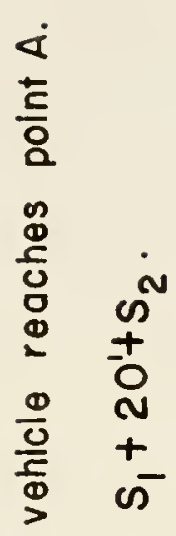

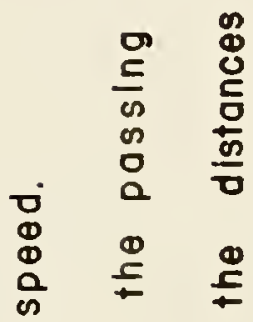

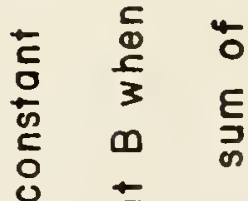

- 등

$\alpha$
$w$
$j$
$w$
$z$
$\Sigma$
$\Sigma$

¿ o

\begin{tabular}{lll}
0 & $\Phi$ & $\Phi$ \\
\hline & 0 & 0 \\
\hline & 0 & 0 \\
\hline & 0 & $\frac{5}{0}$ \\
\hline & & $\frac{0}{0}$
\end{tabular}

$\begin{array}{lll}\frac{D}{0} & \frac{\omega}{0} & \frac{0}{C} \\ \frac{D}{D} & \frac{\hbar}{D} & \frac{5}{\sigma}\end{array}$

$\frac{3}{2}$

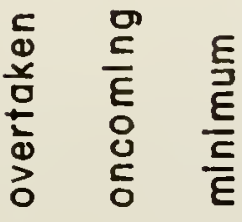

$a$

W

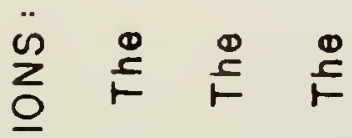

$\sum_{j}^{\circ}-\infty i$

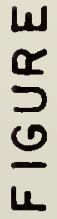


abreast of the vehicle being passed. Based initially on personal judgment and subsequently confirmed through observation, the point chosen for this project occurs where the front bumper of the passing vehicle is abreast of the middle of the vehicle being passed. This point is shown as point $A$ in Figure 3. It is assumed that if a vehicle is at or beyond this point, the driver will determine generally that it is safer and easier to continue and complete the passing maneuver than to apply the brakes and pull back into position behind the vehicle being passed. The minimum required sight distance to be determined by this research project is considered to be the sum of the following distances, as shown in Figure 3.

- The distance traveled by a passing vehicle between the "point-of-no-return" and the point where it is completely clear of the "wrong" lane used by opposing traffic.

$S_{2} \quad-$ The distance traversed by an oncoming vehicle while the passing car occupies the "wrong" lane as described above. 20 feet - An absolute minimum clearance distance between vehicles that would allow the two vehicles to avoid a head-on collision if the other assumptions were all met.

There are a few evasive actions that can be exercised to reduce the total distance needed for the passing maneuver. For instance the speed of the vehicle being passed 
or the speed of the oncoming vehicle could be reduced during the passing maneuver. The passing vehicle could accelerate faster than normal or return to the proper lane with less clearance than normal. Or the oncoming car may run onto the shoulder in an emergency -- providing a shoulder exists. Any or all of these actions could be involved in a passing maneuver but it is obvious that a design of minimum sight distance cannot be based on these possibilities.

Following are the basic assumptions considered reasonable and necessary for the determination of the minimum sight distance:

1. The vehicle being passed travels at a constant speed.

2. The oncoming vehicle appears at point $B$ when the passing car reaches point $A$, the "point-of-noreturn." (See Figure 3).

3. The minimum sight distance is the sum of the distance $S_{1}$ traveled by a passing vehicle, a 20 foot clearance and the distance $S_{2}$ traveled by an oncoming vehicle.

To determine the distances mentioned above it was necessary to perform extensive field investigations of the passing maneuver. The distance and time taken for passing maneuvers was observed by driving a test car at various speeds over selected sections of rural highways. 
Test Roads

It was assumed that there may be a difference in the length and speed of passing maneuvers on different types of roads. Some of the features of a road which might introduce a bias would include horizontal and vertical alignment, width and condition of pavement, the number and length of passing zones and the volume and speed of traffic on the road.

Obviously, it was not feasible to test the effect of all possible variables. However, the one overall important variable -- sight distance -- which is known to have an effect on the decision to pass, could be tested if test roads of different geometric design were chosen. For this reason, three test roads each five to six miles long with varying amounts of visual restrictions were chosen to be test roads. All are located at least partially within Tippecanoe County (see Figure 4). Each test road has two test sections, one in each direction, giving a total of six test sections.

Test Road S. R. 43N, 5.53 miles long, is a portion of State Route 43 located about eight miles north of West Lafayette. The southern terminus is at county Road 600 and the northern terminus is at the driveway into the standard Oil Distribution Depot south of Brookston. The horizontal alignment shown in Figure 5 , is generally straight. On the southern end there are numerous vertical curves that restrict 


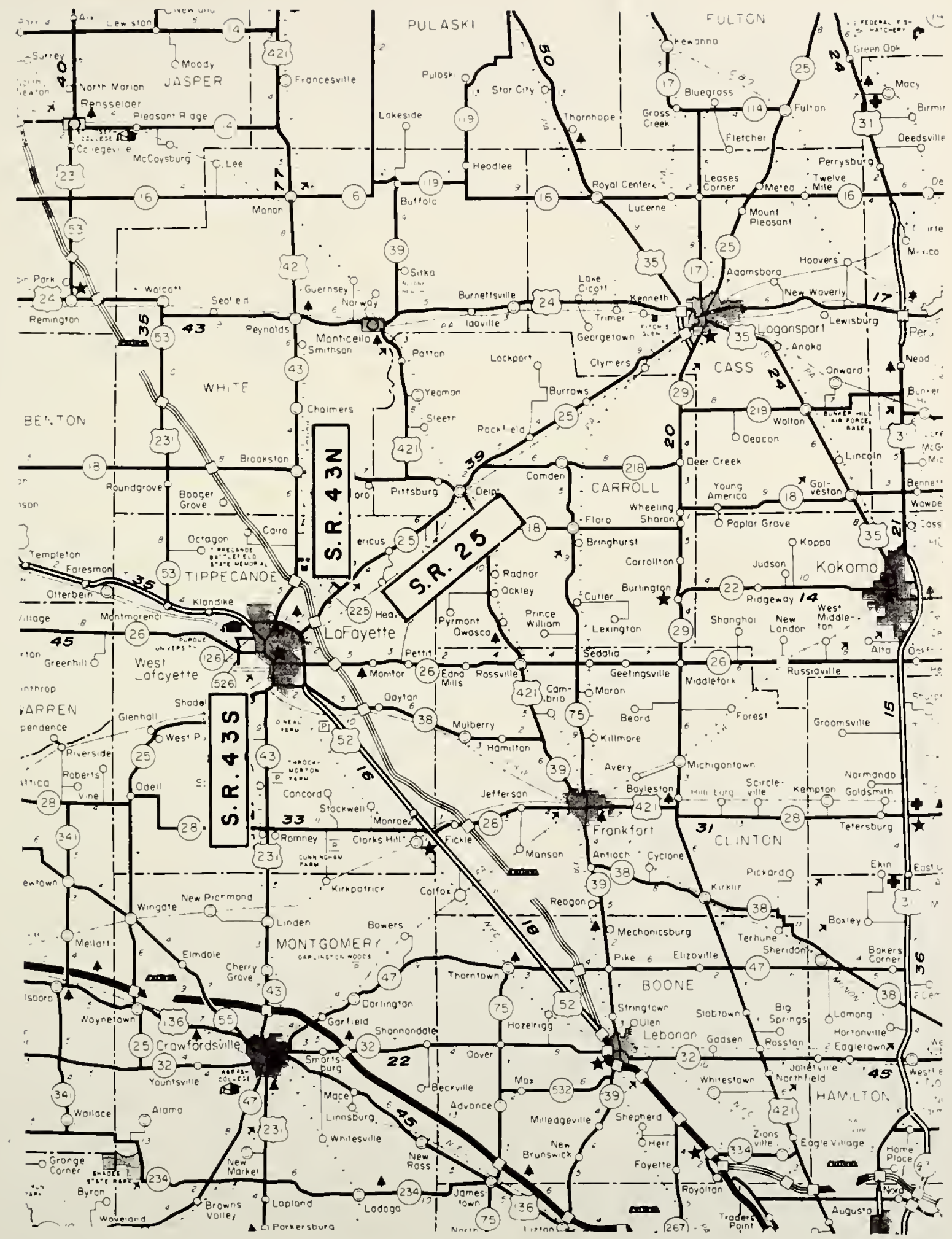

SOURCE: Official Indiana State Highway Map

FIGURE 4. GENERAL AREA MAP. 


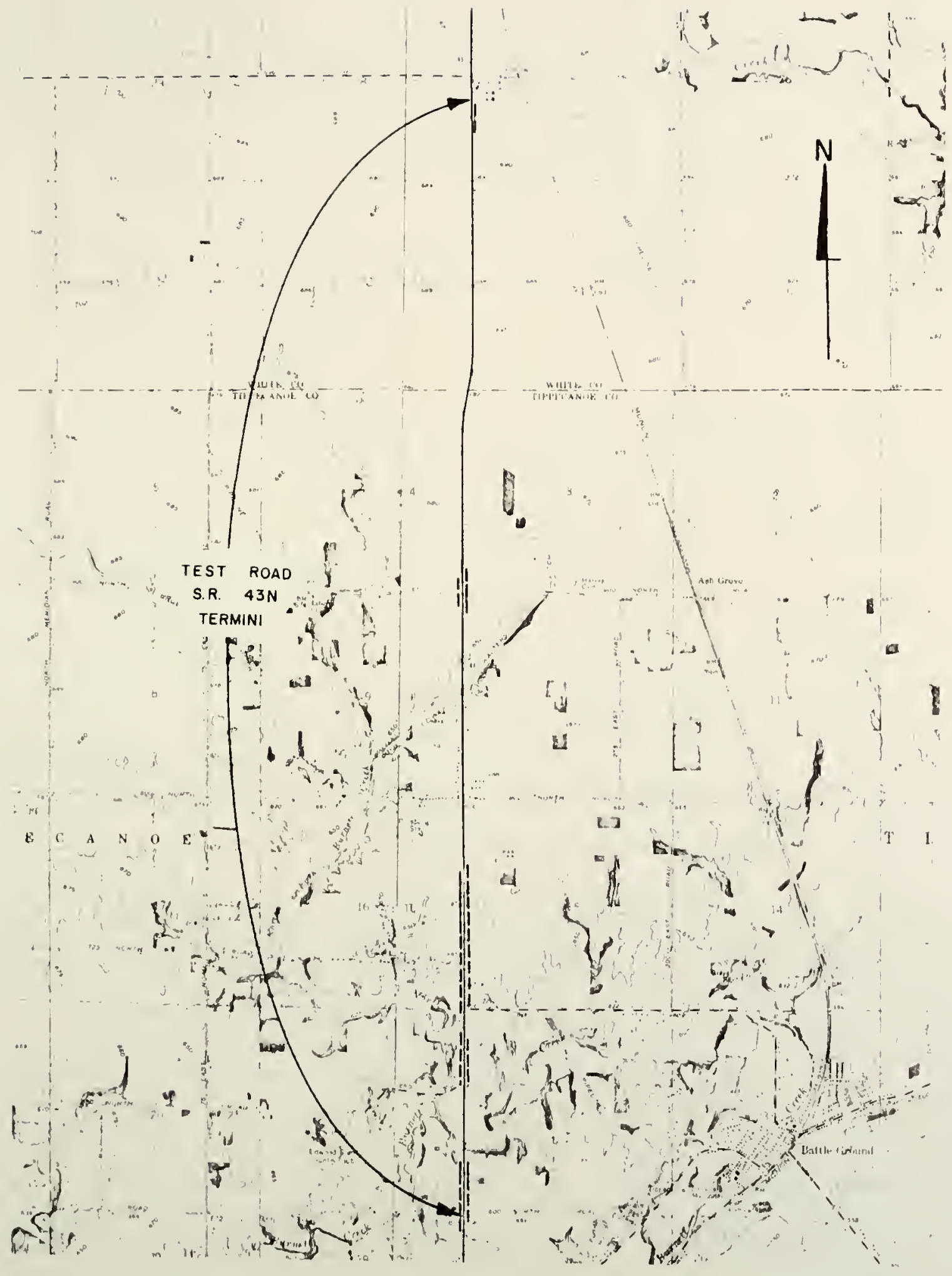

FIGURE 5. ALIGNMENT OF TEST ROAD S.R. $43 \mathrm{~N}$. 
the sight distance.

In the northbound and southbound directions, respectively, there are five and four no-passing zones totaling 1.53 miles and 1.40 miles in length. There is an average for both directions of $26 \%$ of the road where the passing maneuver is prohibited; $28 \%$ of the road has a sight distance of less than 1500 feet.

Test Road S. R. $43 \mathrm{~S}$ is a 6.20 mile portion of state Route 43 located about seven miles south of Lafayette. The northern terminus is at the intersection of County Road 800 . The horizontal alignment is shown in Figure 6 .

There are five no-passing zones in each direction totaling $2.72 \mathrm{miles}$ in the northbound direction and 2.82 miles in the southbound direction. The passing maneuver is therefore prohibited on about $45 \%$ of the road. About $40 \%$ of the road has a sight distance of less than 1500 feet.

Test Road S. R. 25 is a portion of State Route $25,5.4$ miles long, located northeast of Iafayette. The southern terminus is on the edge of the village of Americus and the northern terminus is at a driveway to a farmhouse (see Figure 7).

The road has many hills and horizontal curves which restrict sight distance; $63 \%$ of the road has a sight distance of less than 1500 feet. There are eight no-passing zones totaling 1.81 miles in the northbound direction and nine nopassing zones totaling 1.53 miles in the southbound direction. 


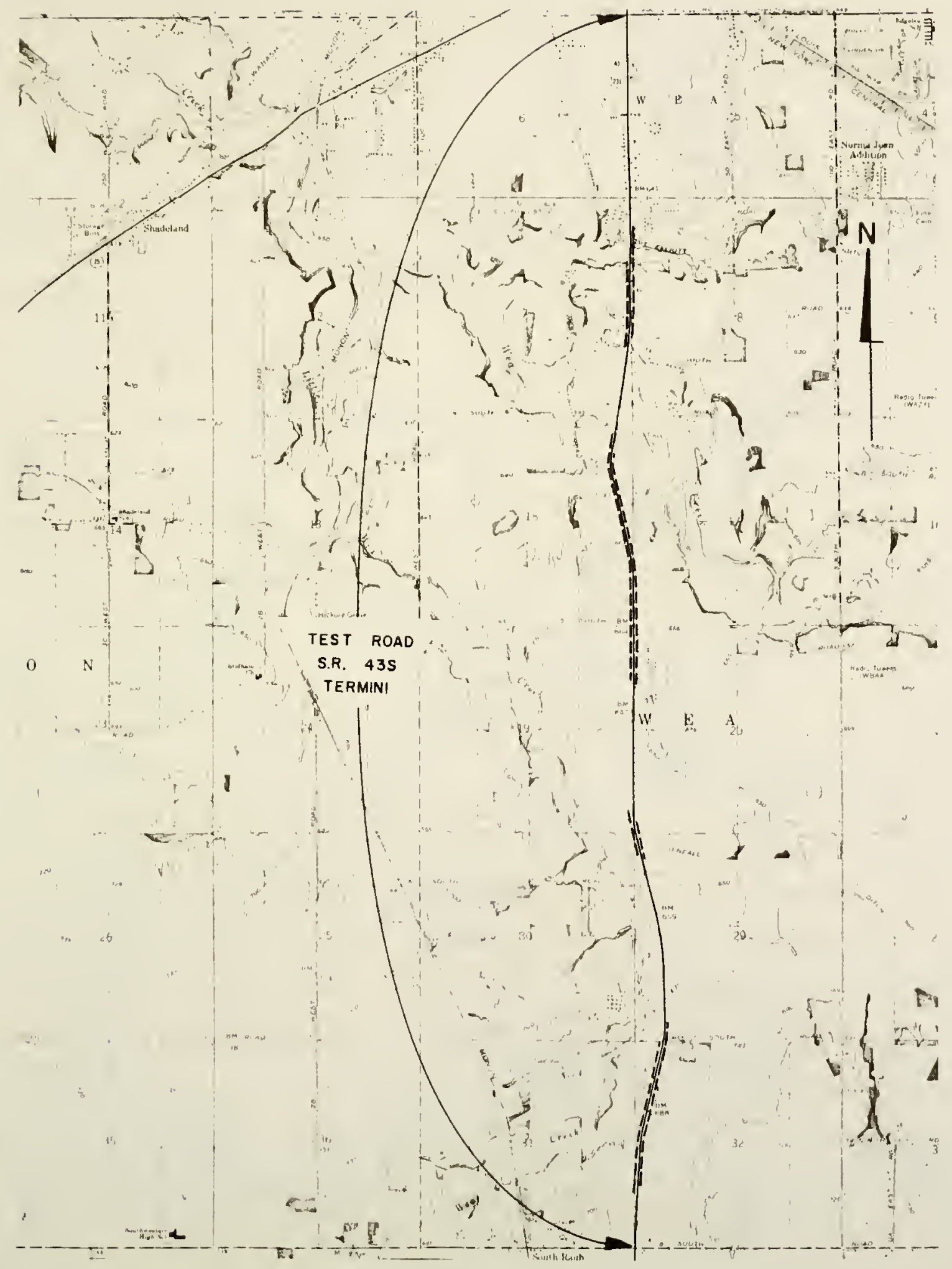

FIGURE 6. ALIGNMENT OF TEST ROAD S.R. $43 \mathrm{~S}$. 


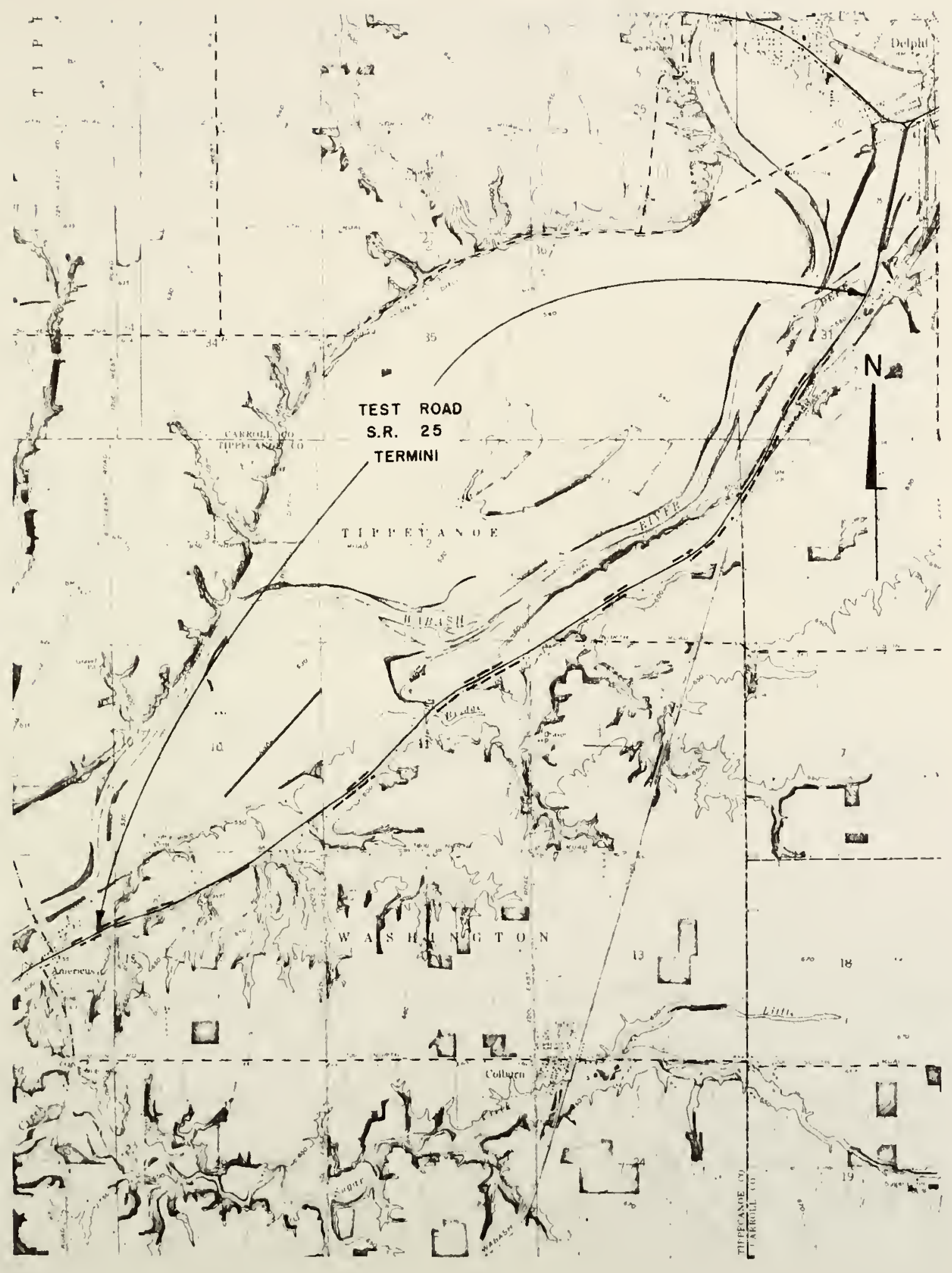

FIGURE 7. ALIGNMENT OF TEST ROAD S.R.25. 
Equipment and Personnel

The Test Car used throughout the experiment was a blue 19624 door Chevrolet sedan owned by Purdue University. It was considered advisable to use an old car to avoid suspicion that the car was involved in an experiment.

A Stewart Warner survey speedometer with an odometer that reads to one-hundredth of a mile (52.8 feet) was mounted under the dashboard where it could be seen easily by both the driver and a passenger sitting in the front seat. The odometer was connected to the transmission like a regular speedometer. A stop watch was used to measure the time used during the passing maneuver.

The Personnel required consisted of a driver and a recorder. The same driver and recorder were used throughout the experiment.

\section{Experimental Procedure}

Numerous test runs were made by the test vehicle over the test roads to measure the length of the passing maneuver and the time to complete a pass. The odometer was reset to zero at the beginning of each test run at the exact same beginning point for each test section. By doing this the location of each passing maneuver within the test section could be plotted.

The speed of the Test Car was maintained constant throughout each test run. Three speeds were used to collect 
data - 40, 50 and 65 miles per hour. However, the actual speed of the test car corresponding to these speedometer readings was 38,47 and $61 \mathrm{~m} . \mathrm{p} . \mathrm{h} .$, respectively. These speeds span the range of average traffic speeds that are found usually on two-lane two-way roads during the off peak hours.

The Distance to Pass was determined by taking a reading of the odometer when a vehicle was at the "point-of-noreturn" and taking another reading when the back wheels of the test car passed over the point where the left rear wheel of the passing vehicle crossed the centerline. The difference between these two readings gave a close approximation of the distance taken to pass.

The Time to Pass was determined by starting the stop watch when the passing vehicle reached the "point-of-noreturn" and stopping it when the passing vehicle crossed the centerline as described above. The decision of when the passing vehicle was at the beginning and ending point of the passing maneuver was made always by the driver of the test car. The driver also operated the stop watch to minimize error due to perception and reaction time. The duty of the recorder was to read the odometer upon the instruction of the driver and to record the readings. Because the one-hundredth dial of the odometer was moving constantly, the recorder had to observe the odometer constantly. 
The beginning and ending of the no-passing zones were recorded only once for each test section. The type of vehicle and type of pass were noted in the remarks column if other than a pass with a voluntary or un-hurried return by a common American car. For instance, a pass by a foreign car, pickup, single unit truck or semi-trailer truck was noted in the remarks column. It was noted also if the finish of a pass maneuver was hurried or forced by the presence of an oncoming vehicle or yellow line. Obviously, this was a judgment factor but in most cases the abrupt unnatural movement of the passing vehicle could be discerned easily.

Test runs were made only when the pavement was dry between the off peak hours of $9: 30 \mathrm{a} \cdot \mathrm{m}$. and $3: 30 \mathrm{p} . \mathrm{m}$. Monday through Saturday during the months of January, February and March, 1969.

\section{Sight Distance Survey}

Purpose

The purpose of this phase of the project was to determine how far the driver of a vehicle could see at any point within the test section. From this information it could be determined how far the driver of a passing vehicle could see when he reached the "point-of-no-return." Also, the limits of no-passing zones on the test roads could be determined for various criteria. 
Equipment and Personnel

The Target Vehicle used in the survey was a white 1968 Chevrolet Sportsvan truck owned by Purdue University. An electronic measuring wheel, which measured distance to onethousandth of a mile, was attached to the rear bumper. A revolving amber emergency light was temporarily fastened to the side of the van to serve as a target. The light was positioned $3.75^{\prime}$ above the pavement. Another revolving amber emergency light was fastened on top of the van to serve as a safety light.

The Recording Vehicle used was the same 1962 Chevrolet sedan described earlier. The stewart warner odometer reading to one-hundredth of a mile was used to determine the position of the vehicle within the test section. The only additional equipment was a bar mounted on the roof which had four flashing amber lights, two facing forwards and two facing backwards.

\section{A Pickup Truck was furnished by the traffic division} in the Crawfordsville District office of the Indiana state Highway Commission. It was equipped with a revolving amber light mounted on the roof. Two traffic survey signs were furnished also for placement at the beginning and ending of the test section under survey. 
Two 1-1/2 Watt Rechargeable Walkie-Talkies were used to communicate between target and recording vehicles. The power was sufficient for distances of one-half mile or more.

One Hand Measuring Wheel was needed to measure distance occasionally when the target vehicle needed to go in the reverse direction. This is illustrated in Figure 8 . The fifth wheel behind the target vehicle was mounted so that it could pivot. If the target vehicle were to back up, the wheel would turn and be crushed. Therefore, a lightweight measuring wheel that could be operated by a target man on foot was used when the target needed to be moved in the reverse direction.

The Personnel used for this phase of the project totaled five. Two men were in the target vehicle -- a driver and a man to operate the portable measuring wheel and walkie-talkie. Only one man was needed in the recording vehicle. Two flag men -- one with each vehicle -- were used to direct traffic around the survey vehicles.

\section{Experimental Procedure}

The field survey consisted basically of recording the positions of each vehicle when the target light on the target vehicle was just out of sight of the driver in the recording vehicle. Initially, the odometers on both vehicles were set at zero at the beginning point of each test section. The target vehicle proceeded slowly up the road until the 


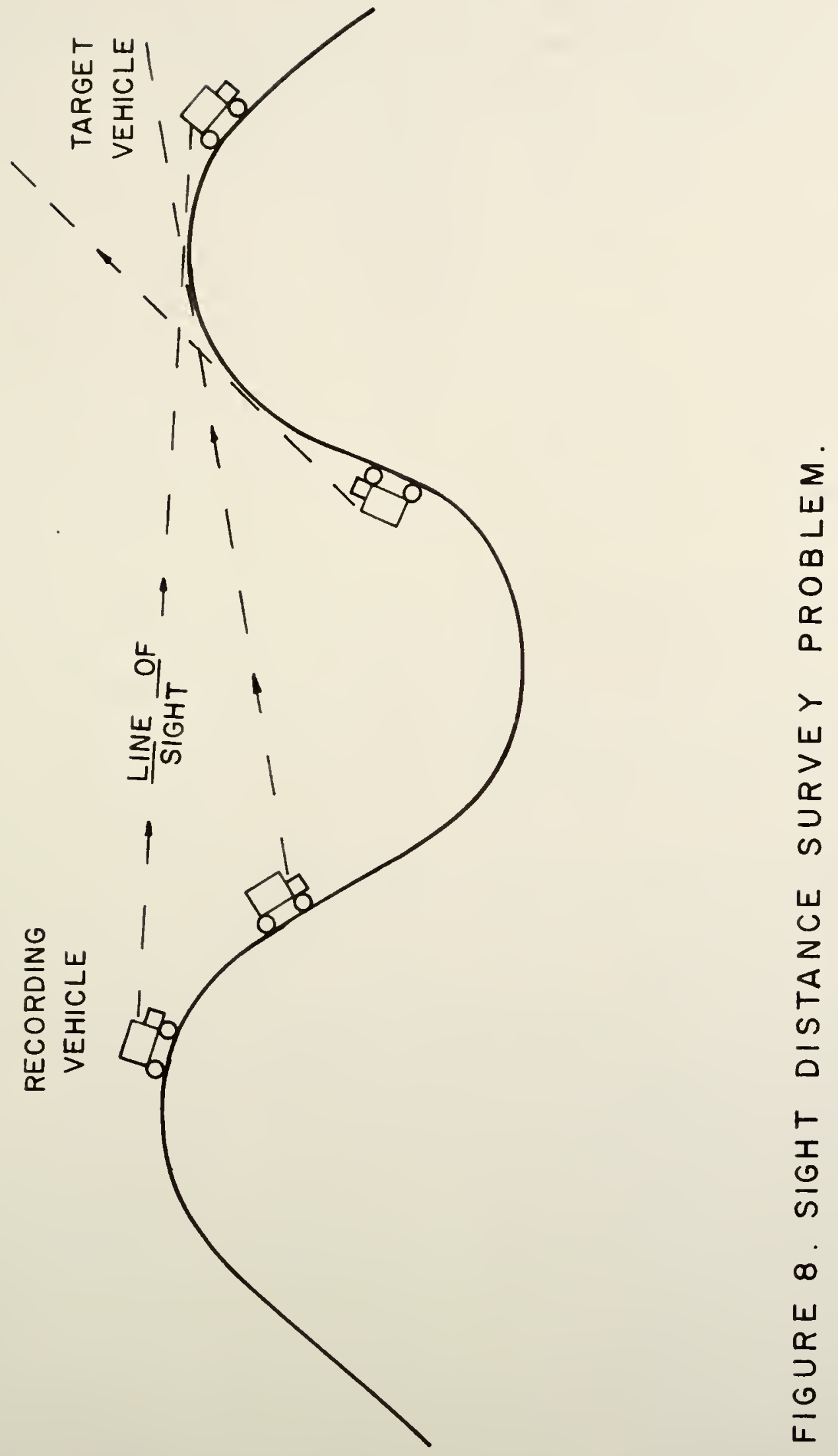


target light disappeared from view. At that moment the driver in the recording vehicle gave the command over the walkie-talkie to stop and give a reading. The position of the target vehicle was entered opposite the position of the recording vehicle on the recording form. The difference between the two readings provided the sight distance. Then the recording vehicle moved up to a desired position, usually .05-.10 mile and gave the command for the target vehicle to advance. This procedure was repeated over and over.

The flagmen directed traffic to help people pass safely and to try to keep the interval between the recording vehicle and target vehicle clear of traffic. The pickup truck was positioned in back of the recording vehicle to warn traffic of the obstruction.

Both the target vehicle and the recording vehicle were driven close to the centerline of the road so that the target light and driver in the recording car werle nearly in the midale of the road. It was necessary for the driver in the recording vehicle to slouch down in his seat slightly to bring his eye sight to the required 3.75 feet elevation above the pavement. The survey was done in one direction only and the sight distance was computed for the opposite direction. 


\section{Speed Studies}

Purpose

It is known that the speed of the vehicle being passed has an effect on the length and speed of the passing maneuver. However, which speed should be used as a basis for developing a criteria for minimum sight distance requirements is questionable. Obviously, the slower a vehicle travels, the more often it will be passed. On the other hand, the faster a vehicle travels, the less often it is passed but when it is passed, a longer sight distance is required. Therefore, it was deemed necessary to make speed studies of the test roads to determine the speed distribution and provide an insight into the problem.

\section{Equipment and Personnel}

An Electro-Matic Model S-5 radar meter was used to measure the speed of traffic. The radar antenna was concealed in a large cardboard barrel. The cables to the battery and the meter were brought out through a hole in the bottom of the barrel. A concrete.block was placed in the bottom of the barrel to stabilize it. Only one man was needed to do this study.

\section{Procedure}

The radar antenna was placed in the barrel near the edge of the road with the antenna aimed at the approaching traffic in the nearest lane. The meter and observer were 
hidden from view to avoid suspicion or attention. The speed of traffic in both directions could be recorded from the same location.

The survey was taken at a central location within each test road. The location in each case was on a tangent, level portion of the road where there was no restriction to the passing maneuver. This type of location was picked because this is where passing maneuvers occur most often. Readings were taken during the off peak hours on week days when there was good visibility. 


\section{CHAPTER IV. EXPERIMENTAL RESULTS AND} ANALYSIS OF DATA

\section{General Observations}

Over three thousand miles were driven to collect data on the length and speed of the passing maneuver. Information on 915 passing maneuvers was recorded over a period of three months. Throughout the experiment there were no accidents but there were enough close calls at slow speeds to convince the writer of the danger created by slow moving vehicles. Drivers, especially truck drivers, often became impatient when forced to follow a slow moving vehicle and they tended to take chances more frequently than when following a fast moving vehicle.

The location of each passing maneuver was plotted in the band corresponding to the speed of the passed vehicle shown in Figures 9-14. The point where each passing vehicle reached the "point-of-no-return" was plotted and then a line was drawn to the point where the vehicle returned to the right hand lane. The location of no-passing zones corresponding to the yellow lines painted on the pavement were indicated.

The sight distance as determined in the sight distance survey was plotted for each test section. The amount of 


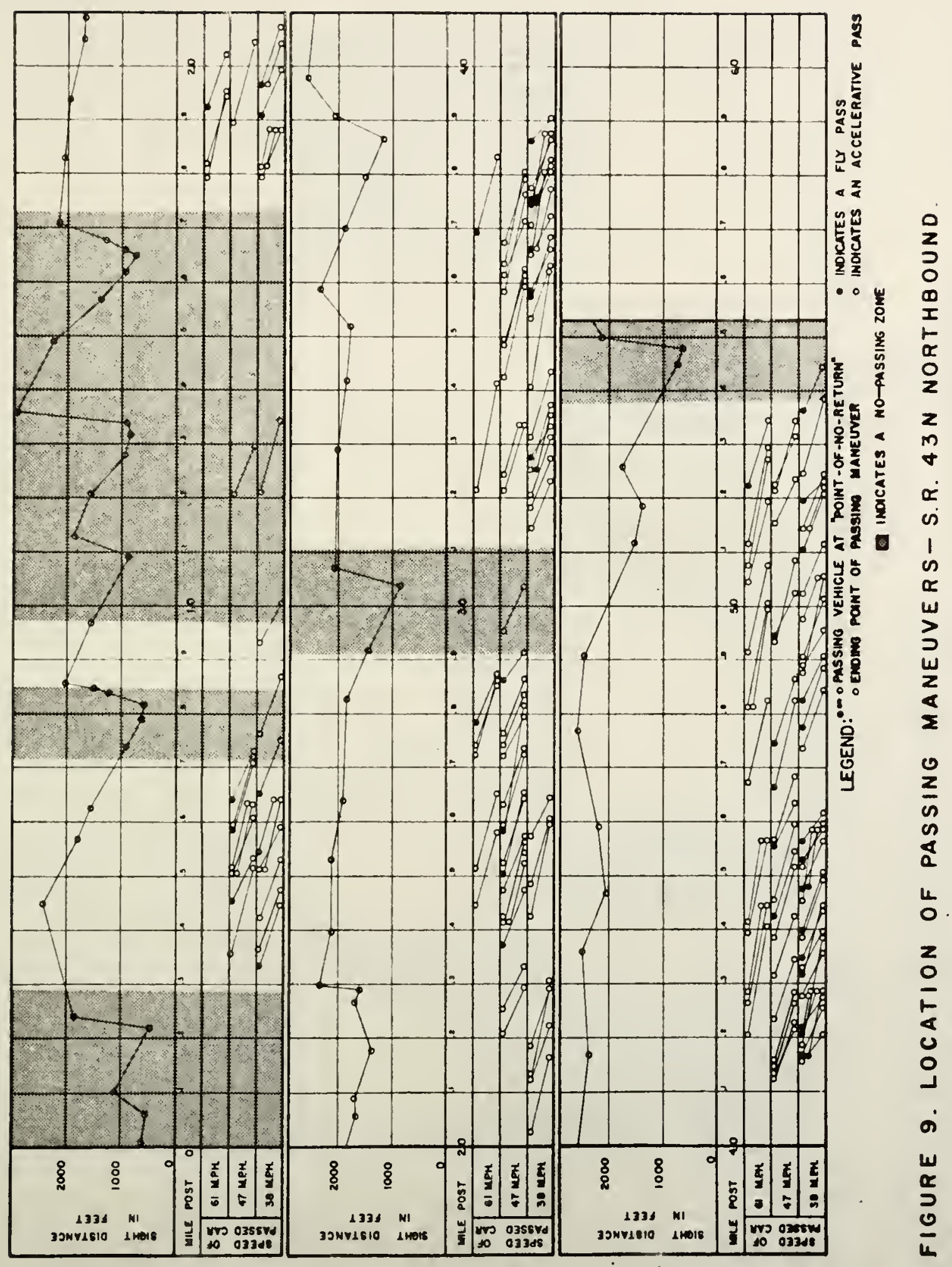




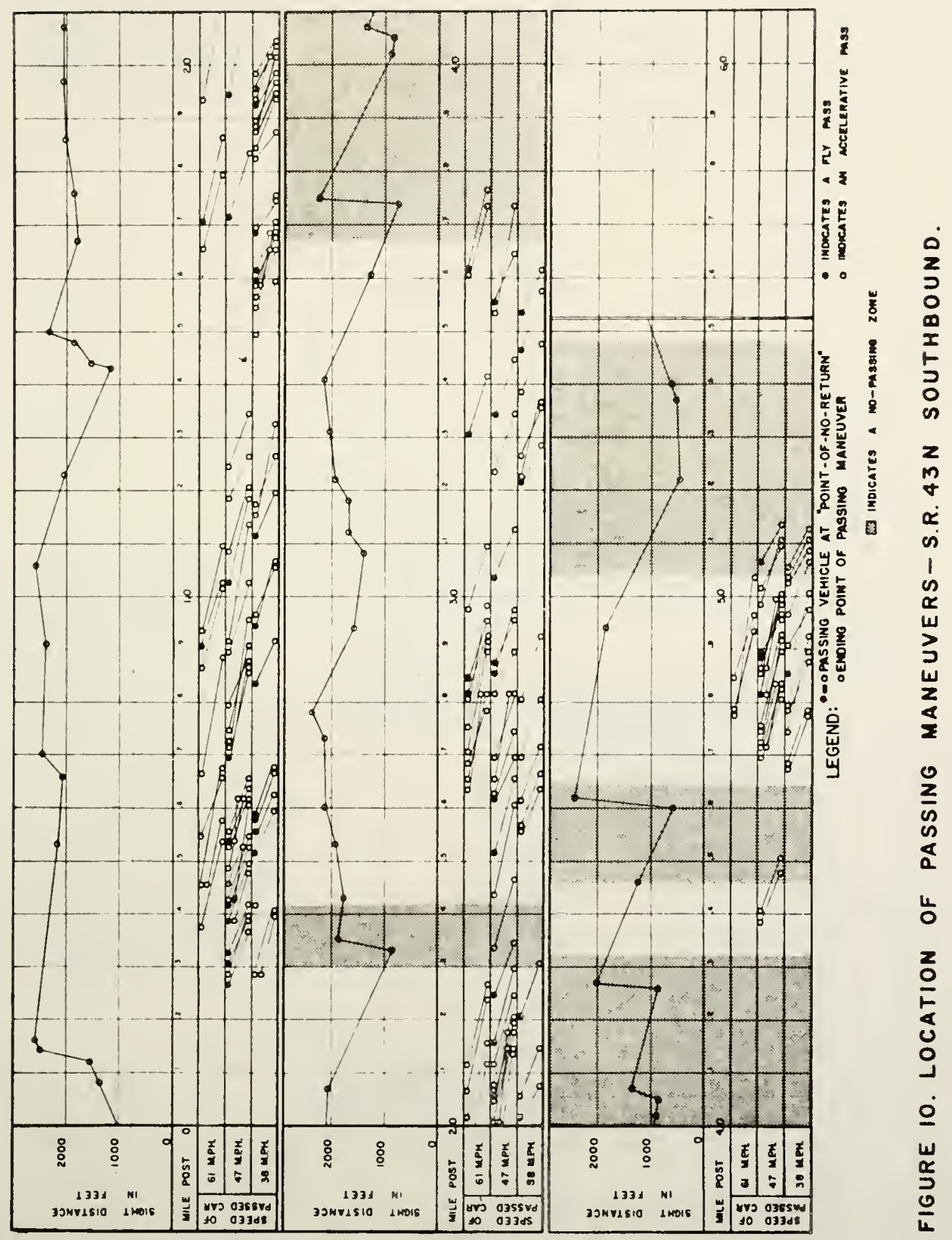




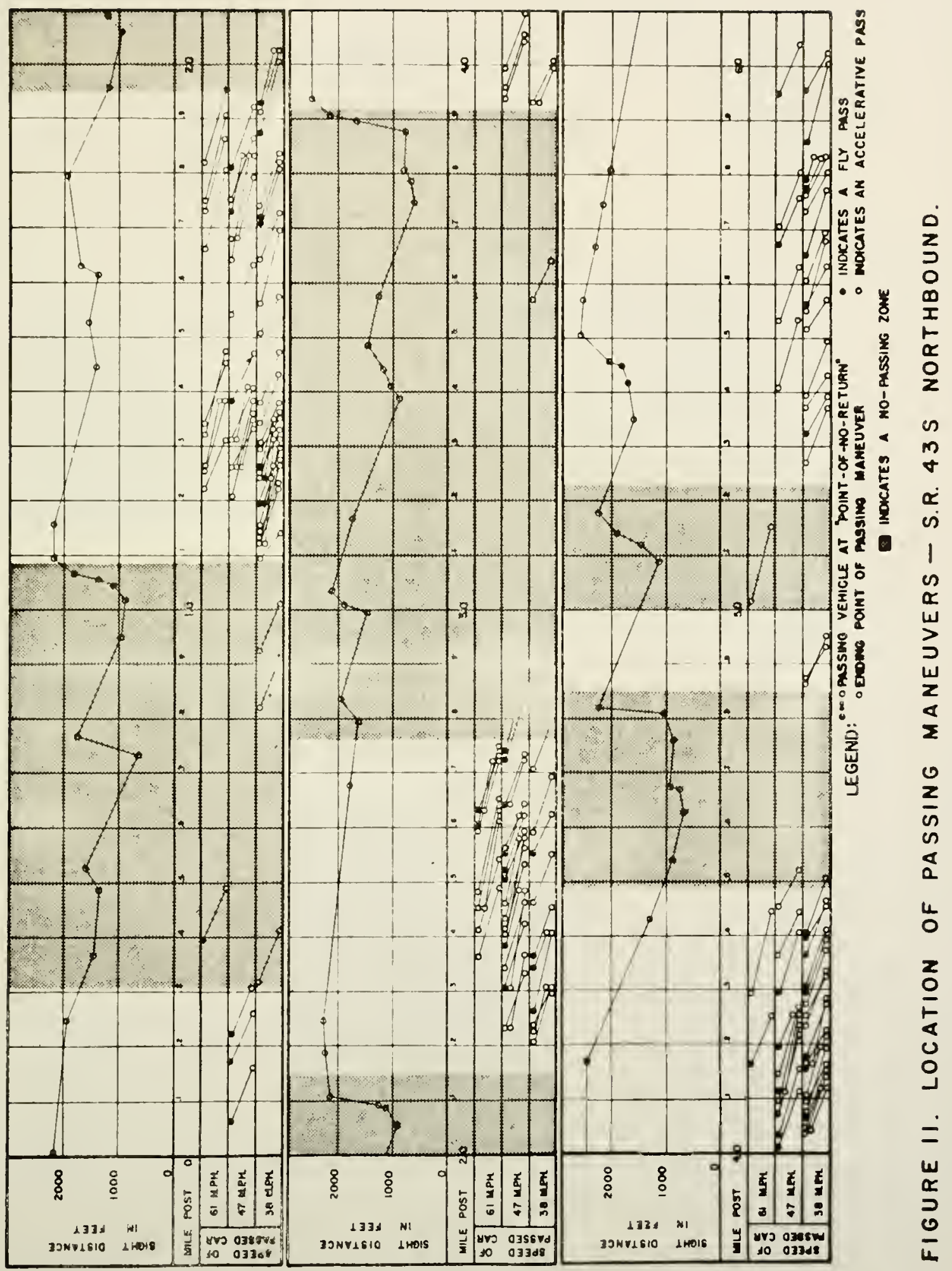




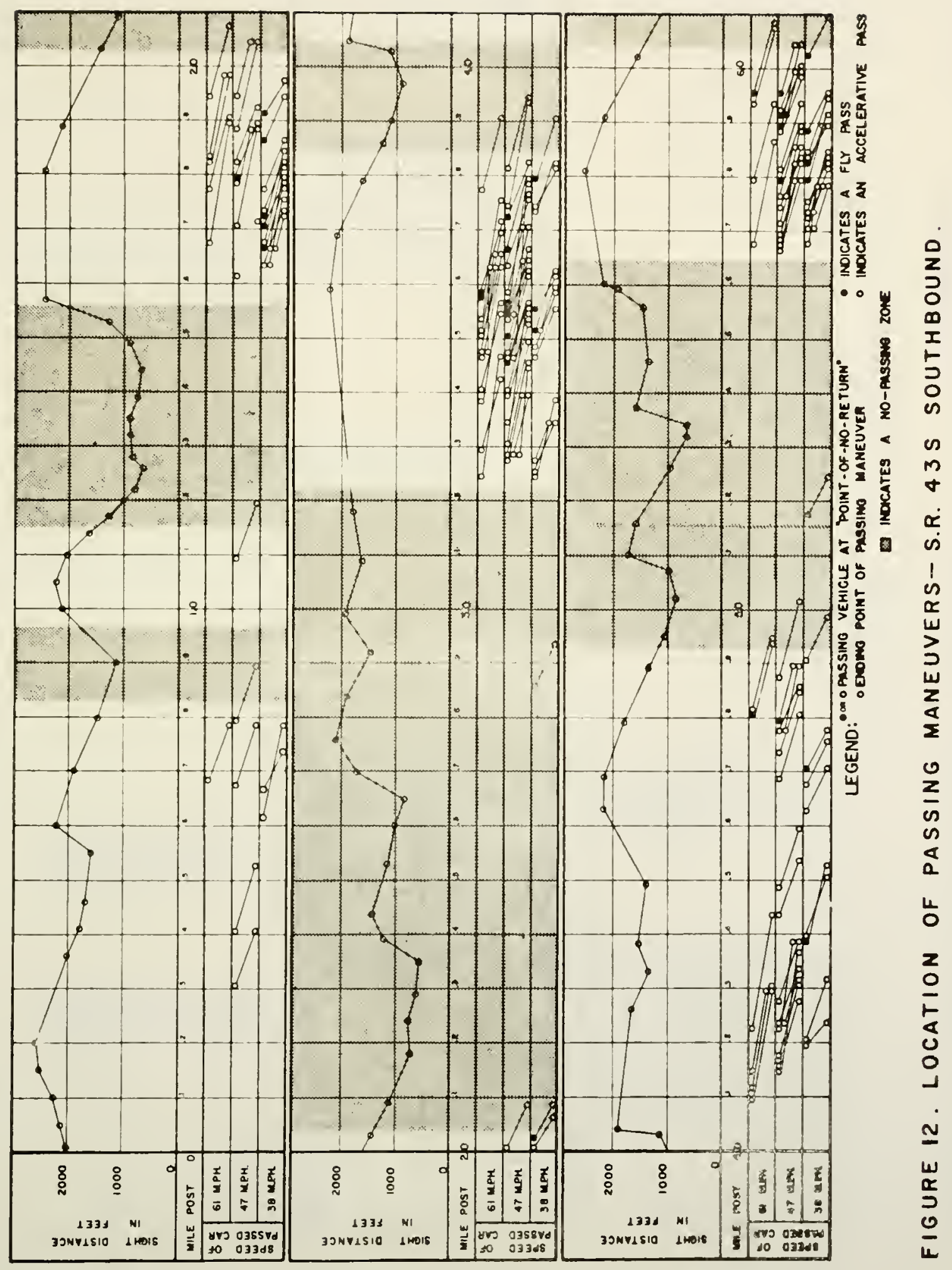




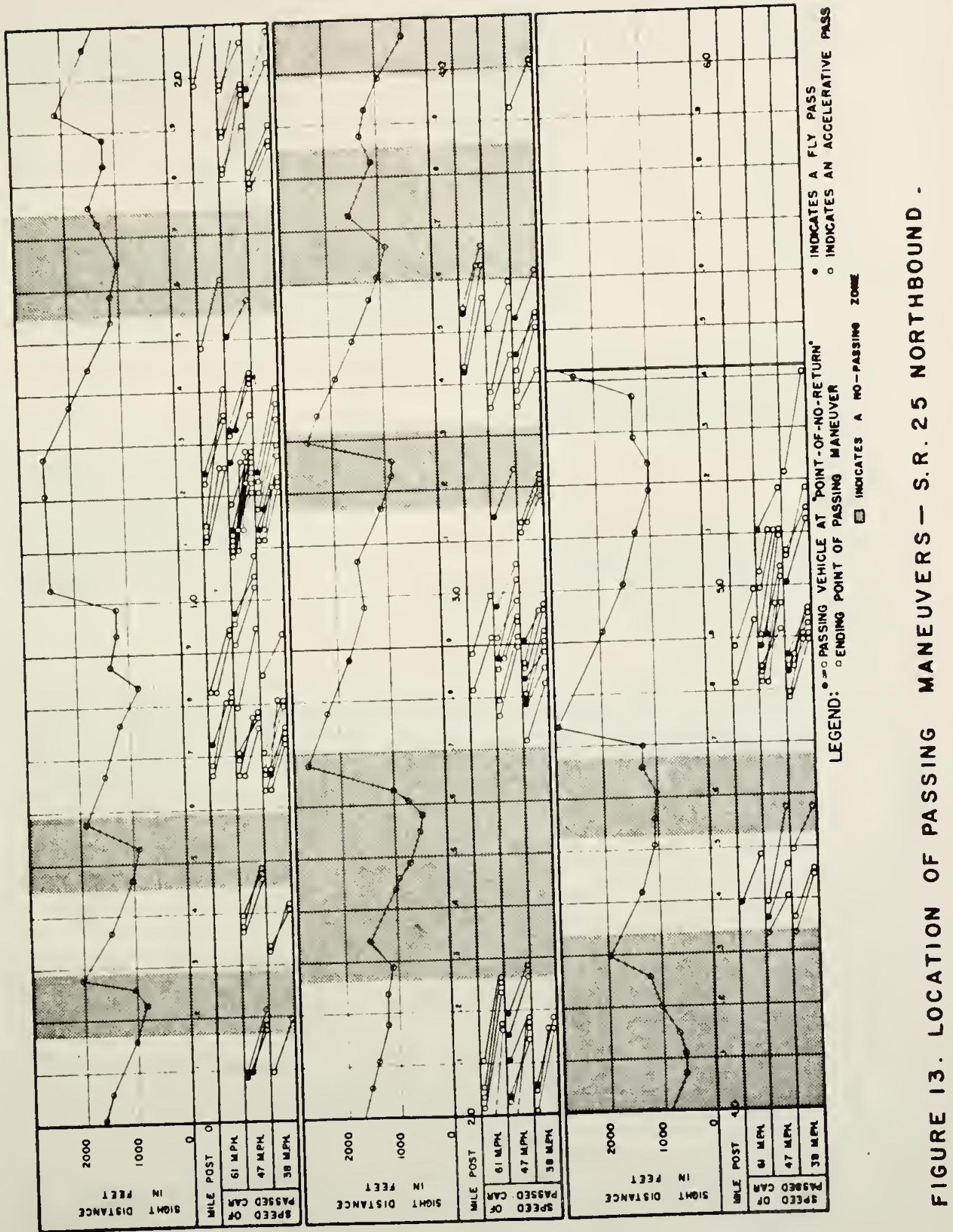




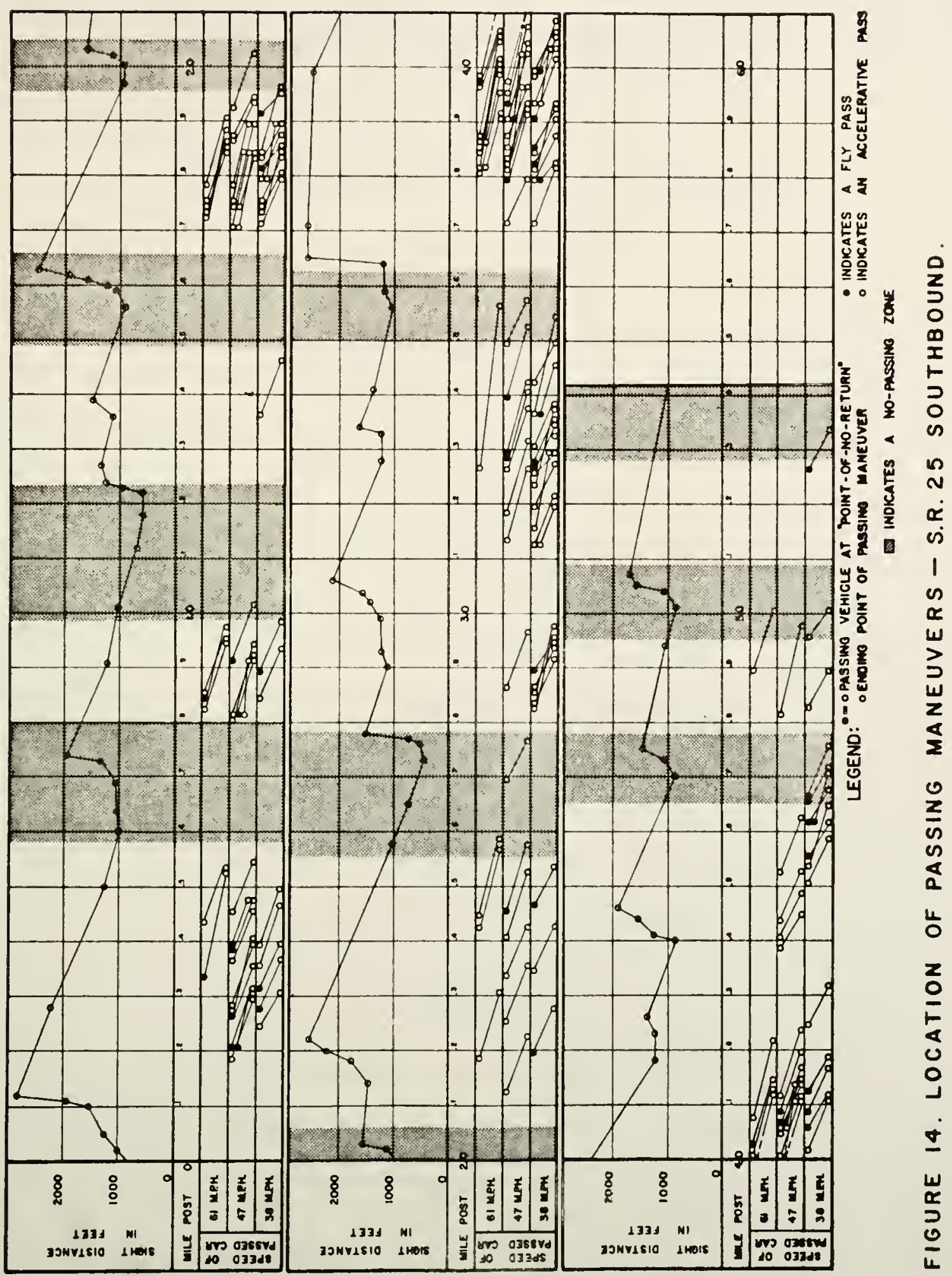


sight distance available when each passing vehicle reached the "point-of-no-return" was taken from the plots shown in Figures 9 through 14 .

\section{The Length and Speed of Passing Maneuvers}

Data Classification

The Types of Dassing Vehicles were separated into four groups; automobiles, pickups, single unit trucks and semitrailer trucks. The purpose of this was to determine for what type of vehicles the no-passing zones should be designed. The number of passing maneuvers completed by pickups, trucks and semi-trailer trucks totaled 67,24 and 27 , respectively, for all types of passing maneuvers and all roads. A statistical analysis comparing the length and speed of passing maneuvers by these various vehicles was not undertaken because there were not enough observations to come to definite conclusions. However, merely by inspection of the mean lengths and speeds of the passing maneuvers (see Table 5) it was evident that no-passing zone criteria could not be evolved for all types of vehicles without increasing the lengths of no-passing zones beyond that which would be reasonable or tolerable. Therefore, the statistical analysis was confined to passing maneuvers of automobiles only.

The Types of Passes were separated into four basic categories. An "accelerative pass" was a pass by a motorist who for one reason or another slowed down to the speed of 
the test car and followed behind the test car before initiating the passing maneuver. A "fly pass" was a pass by a motorist who did not slow down to the speed of the test car and passed the car "on the fly."

"Voluntary return" is a term used to describe the completion of a pass by a motorist when there was nothing forcing him to return to the right hand lane. A "forced return" indicates the opposite, usually being forced by the presence of an approaching vehicle or the beginning of a nopassing zone.

Test Results

The Mean Length of Passing Maneuvers is shown in Table 5 for the four types of passes; accelerative-voluntary return, flying-voluntary return, accelerative-forced return and flying-forced return. Of these four types of passes, the mean length of the accelerative pass with a voluntary return by automobiles was consistently longer when passing the test car at speeds of 38,47 , and $61 \mathrm{~m} . \mathrm{p} . \mathrm{h}$. than for the other types of passes. This is illustrated in Figure 15. Therefore, as far as length of passing maneuvers is concerned, the minimum sight distance requirements should be based on the accelerative-voluntary return type of pass to meet proper safety requirements.

The Mean speed of Passing Vehicles could not be determined for all passing maneuvers observed. During the 


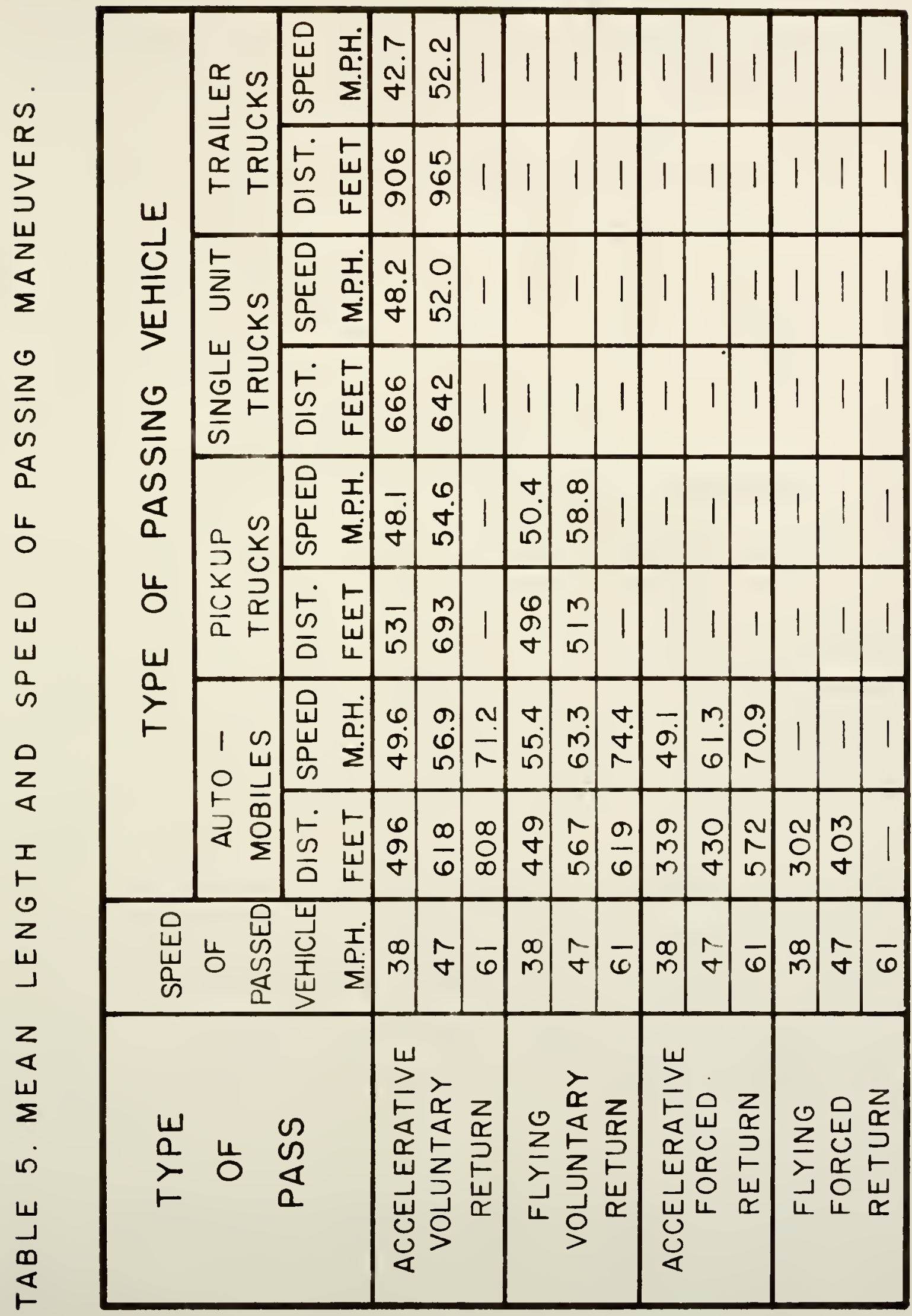


collection of data occasional errors in operating the stop watch occurred because of preoccupation of the driver with driving and some passing maneuvers occurred too quickly -one after another -- to obtain the speeds of all vehicles. Also, no readings were taken of the time used to pass the test vehicle on the first test road -- S.R.43N-- at speeds of 38 and $47 \mathrm{~m} \cdot \mathrm{p} \cdot \mathrm{h}$. However, there were sufficient observations on the other test roads to make a statistical analysis, discussed later in this chapter.

The mean speeds of the various types of passing vehicles for the four types of passing maneuvers are shown in Table 5. A plot of the mean speeds of the passing cars vs. the speeds of the passed cars for three types of passing maneuvers is shown in Figure 16. From this it was apparent that the speed of passing vehicles in an accelerative type of pass with a voluntary return was lower than for other types of passes.

In conclusion, both the speed and length of an accelerative-voluntary return type of pass were most critical. Also, this type of pass predominated in occurrence over all others. Therefore, the minimum sight distance requirements should be based on the accelerative-voluntary return type of pass.

A Comparison to AASHO Criteria is shown in Figures 15 and 16. The dashed lines represent the AASHO criteria taken from "ㄱ. Policy on Geometric Design of Rural Highways." 


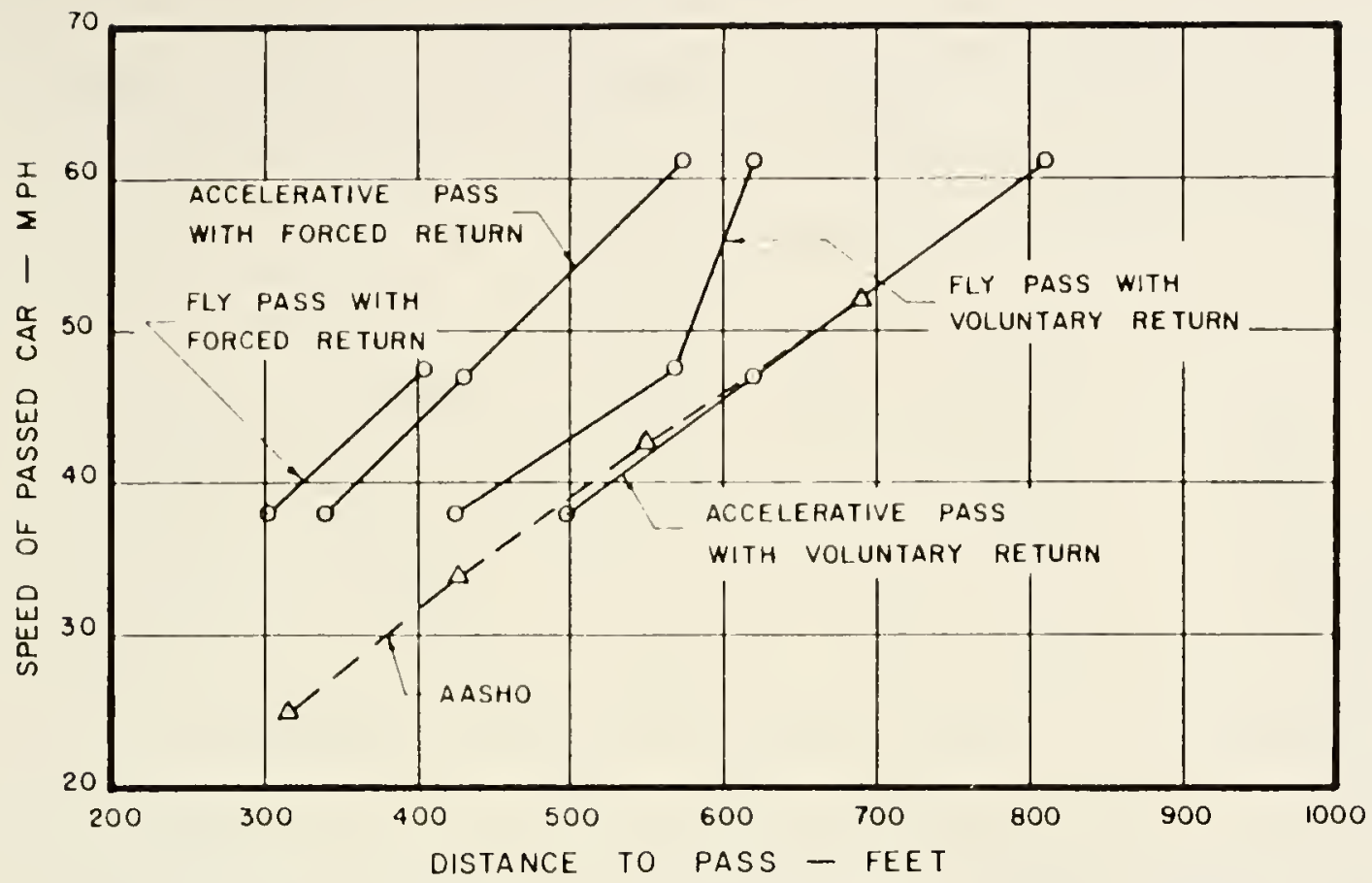

FIGURE 15. LENGTH OF PASSING MANEUVERS.

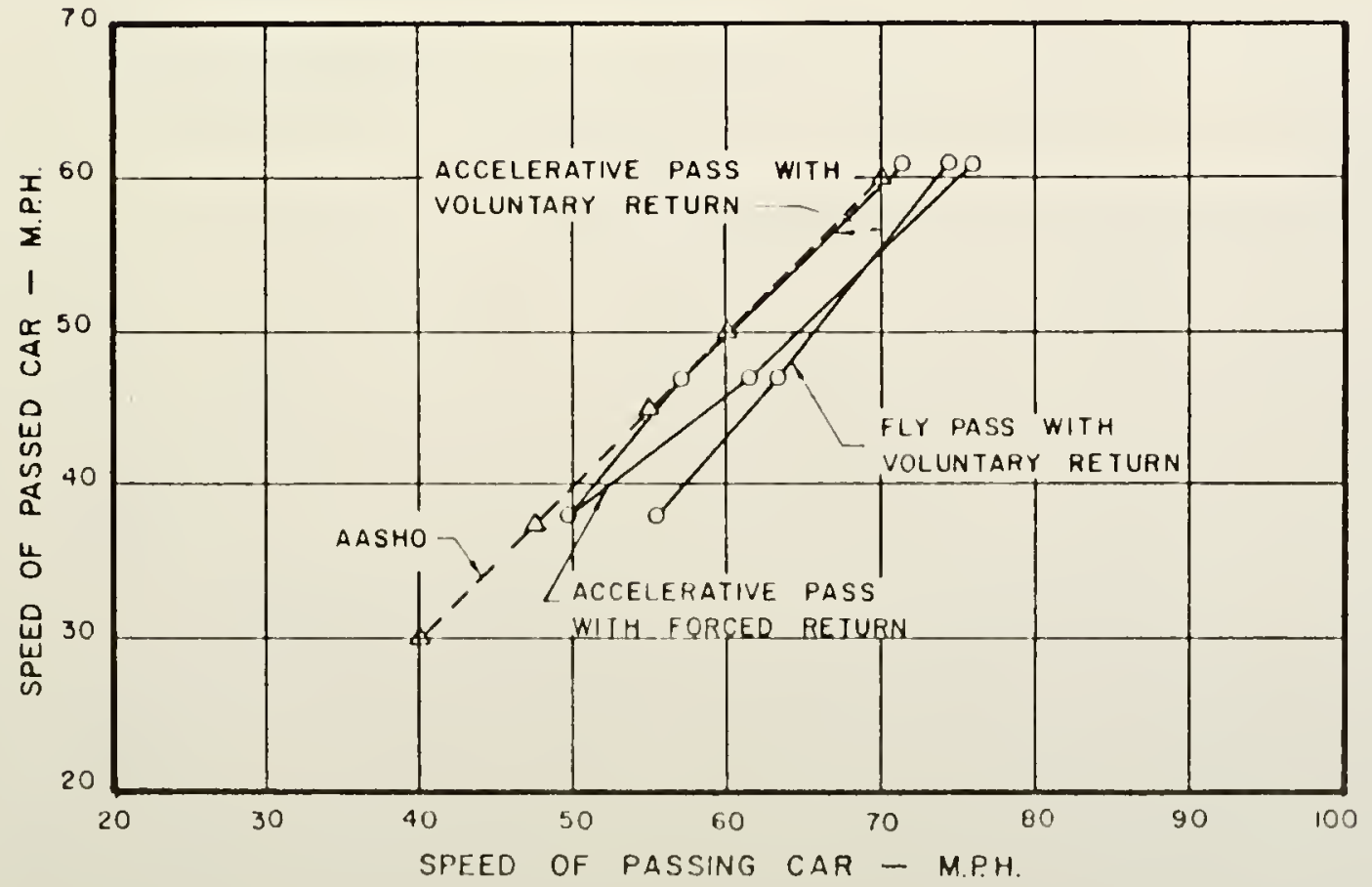

FIGURE I6. SPEED OF PASSING MANEUVERS. 
These criteria are based on experimental data developed in 1938-1941 and 1957. The plot of AASHO criteria agrees quite well with the data obtained in this research project. In Figure 2 the elements of a complete passing maneuver used to develop minimum sight distance requirements for highway design purposes, according to AASHO, are shown. The sight distance required for each element of the passing maneuver is plotted in Figure 2 and is tabulated in Table 1. The distance labeled $2 / 3 \mathrm{~d}_{2}$ in Figure 2 approximates the distance $\left(S_{1}\right)$ measured in this research project. According to AASHO [4], "Speeds of overtaken vehicles were approximately 10 miles per hour less than speeds of passing vehicles," This was substantiated in this project and is illustrated in Figure 16. The dashed line in Figure 16 is a plot of the speed of the overtaken or passed car vs. the speed of the passing car assuming that the speed of the passing car is 10 miles per hour faster than the passed car. As can be seen the plot of the mean speed of accelerativevoluntary return type of pass nearly coincides with the AASHO plot.

To compare passing distances, the values of $2 / 3 a_{2}$ taken from Table 1 were plotted by subtracting 10 miles per hour from the average passing speed to obtain the average speed of the passed car. This plot, shown by a dashed line in Figure 15 falls very close to the plot of the mean length of the accelerative-voluntary type of pass obtained in this 
research project. Even the point plotted at 52 miles per hour, which is an extrapolated value, falls directly on the line.

This leads to the conclusion that the assumptions regarding the location of the "point-of-no-return" for this study are valid. Furthermore, it can be concluded that the criteria developed by AASHO for the length of passing maneuvers as shown in Table 1 are adequate. However, the relationship between highway design speed and speed of passed car as given by AASHO in Table 2 is worthy of further investigation as discussed earlier in Chapter II of this study.

\section{Statistical Analysis}

The purpose of the statistical analyses primarily was to determine if there was a significant difference in mean length to pass on various test roads and at various speeds. Through these analyses it was possible to determine what effects these variables had on the mean lengths and speeds and to place confidence limits on the test results.

A Normal Distribution was assumed in all of the statistical analyses. Frequency distribution plots were made of the accelerative-voluntary return type of pass for each speed of the test car. These plots are shown in Figures 17 , 18 and 19 for passed vehicle speeds of 38,47 and 61 miles per hour, respectively.

It was apparent from these plots that the distribution was skewed, as one would expect, because of the limitation 


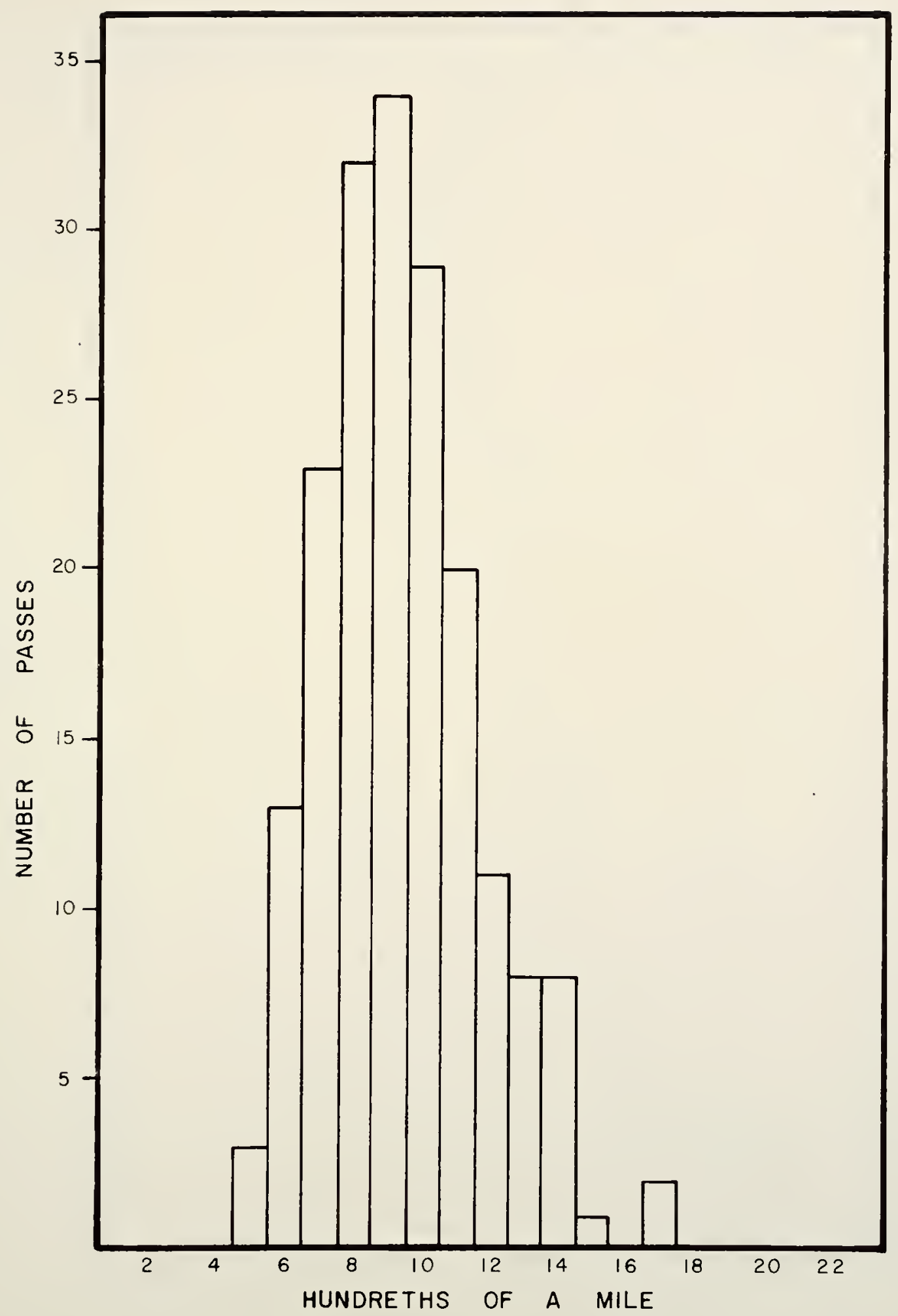

FIGURE 17. FREQUENCY DISTRIBUTION OF LENGTH OF PASSING MANEUVERS-38 MPH. 


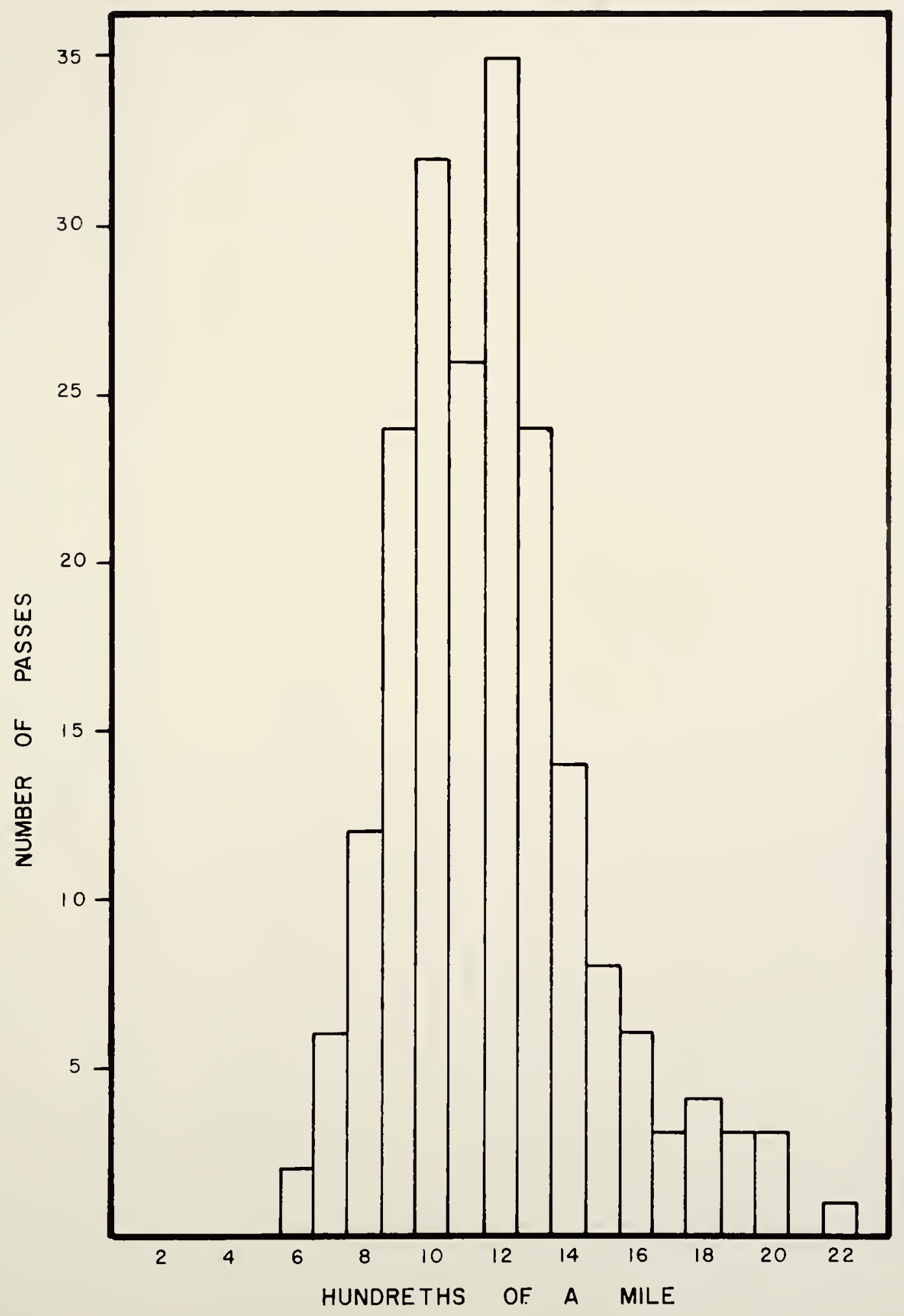

FIGURE 18. FREQUENCY DISTRIBUTION OF. LENGTH OF PASSING MANEUVERS $-47 \mathrm{MPH}$. 


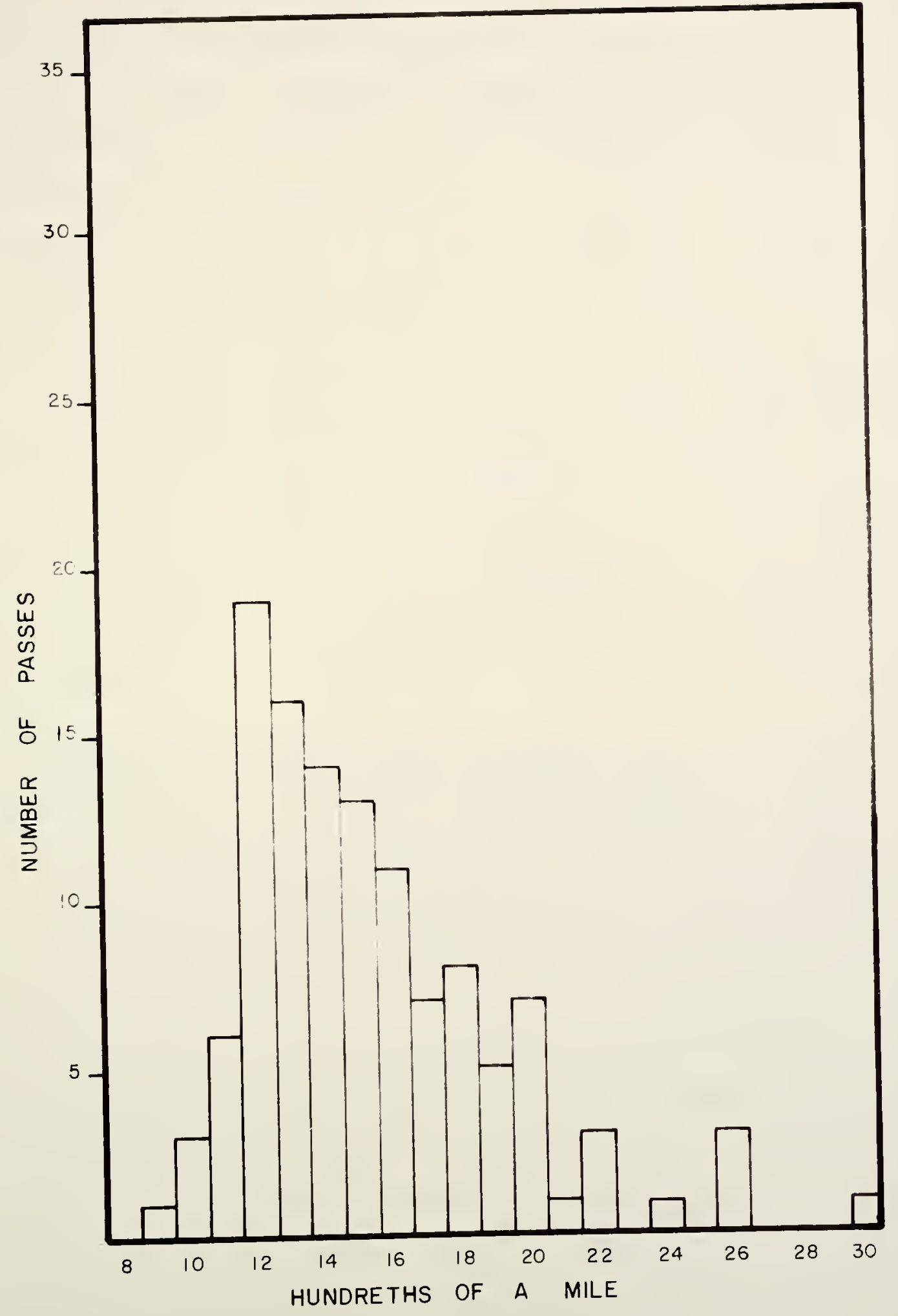

FIGURE 19. FREQUENCY DISTRIBUTION OF LENGTH OF PASSING MANEUVERS- $6 I M P H$. 
sample on minimum length of pass while there was no limit on maximum length. Using the median to compute the theoretical cumulative frequency, a test for normality using the Kolmogrov-Smirnov goodness of fit test was run for data at each speed of the test car. The results show that there was no significant difference from a normal distribution at the alpha level of .15,.15, and .10 for lengths of passing maneuver at speeds of 38,47 and $61 \mathrm{~m} . \mathrm{p} . \mathrm{h} .$, respectively. The frequency plot of the $61 \mathrm{~m} \cdot \mathrm{p} . \mathrm{h}$. passes shows some skew to the right which was confirmed by the lower alpha level of the K-S test. Results at all speed levels were sufficiently close to the theoretical, however, to justify the assumption of normality.

An Analysis of Data Within Each Test Road was undertaken to determine if there were significant differences in the length of passing maneuvers between test sections on the same road, i.e., northbound and southbound directions on each test road. The hypothesis that the mean lengths of passing maneuvers in both directions were equal was tested against the alternative hypothesis that they were not equal, assuming equal population variances.

The tests were calculated only on accelerativevoluntary return and flying-voluntary return types of passes. The results of the statistical tests are shown in Table 6 . The hypothesis that the mean lengths of passing maneuvers in 


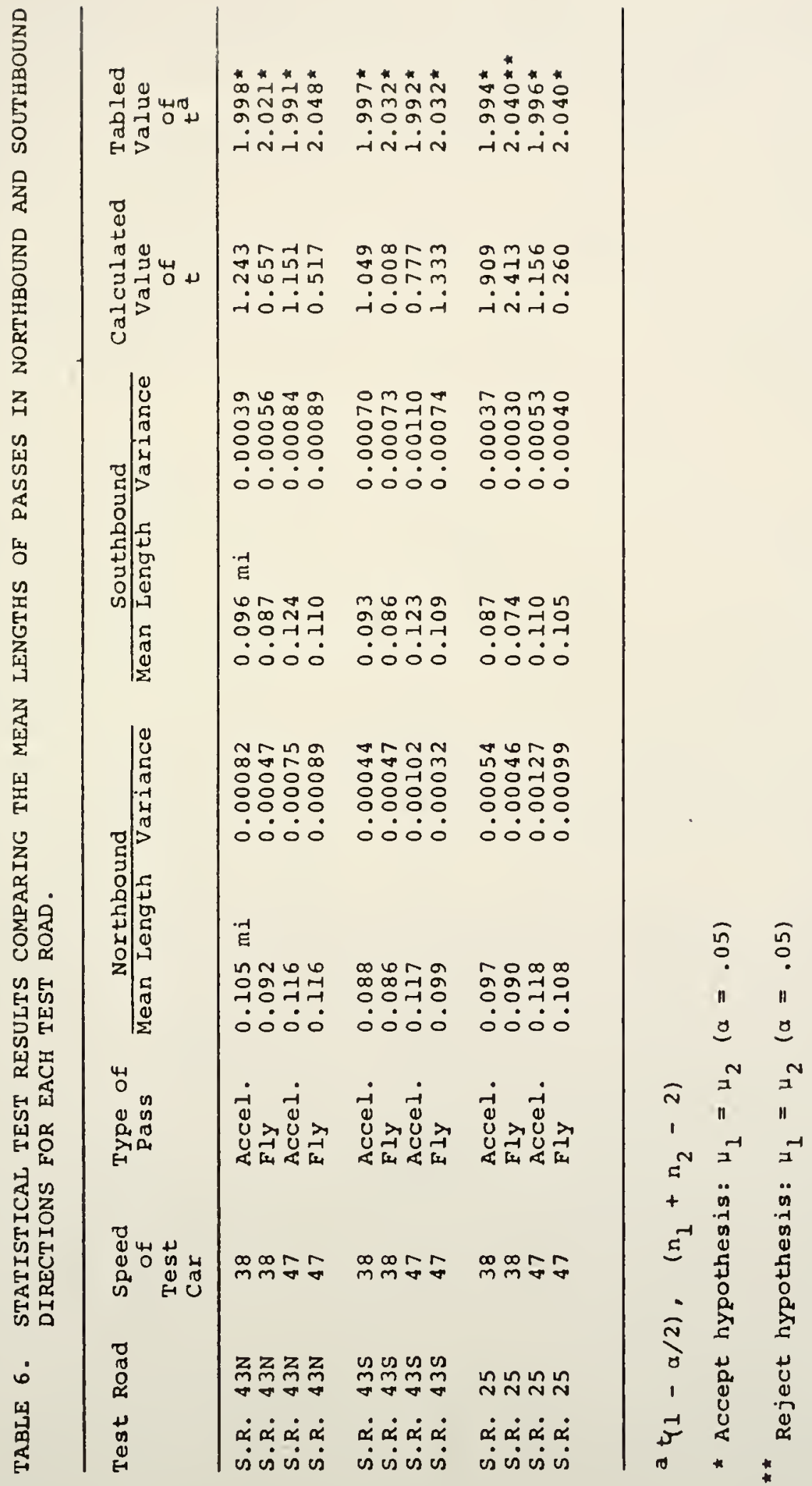


both directions were equal for each road could not be rejected at $\alpha=.05$ in every case except one. The one rejection was a comparison of lengths on S.R. 25 of fly passes at a test car speed of 38 miles per hour. At the alpha level of .01 the difference would not have been significant. It is believed that the reason for the one rejection at the alpha level of .05 is that the sample size of fly passes was small.

It was concluded that overali it could be stated with a confidence level of $95 \%$ that there was no significant difference in the lengths of accelerative-voluntary return type of passing maneuvers in one direction over the other for a given test road. Therefore, test data taken in the northbound and southbound directions were combined to allow comparisons by test roads.

Analysis of Variance was performed on both the length and speed of the accelerative-voluntary return type of pass. Through this mathematical procedure it was possible to determine the effects on the length and speed of the passing maneuver caused by the individual test roads and the speed of the passed or overtaken vehicle. The number of observations and the mean distances used in the analysis are shown in Table 7 .

The results of the two-way analysis of variance on length of passing maneuver is shown in Table 8 . This shows that the interaction between test road and the speed of the 


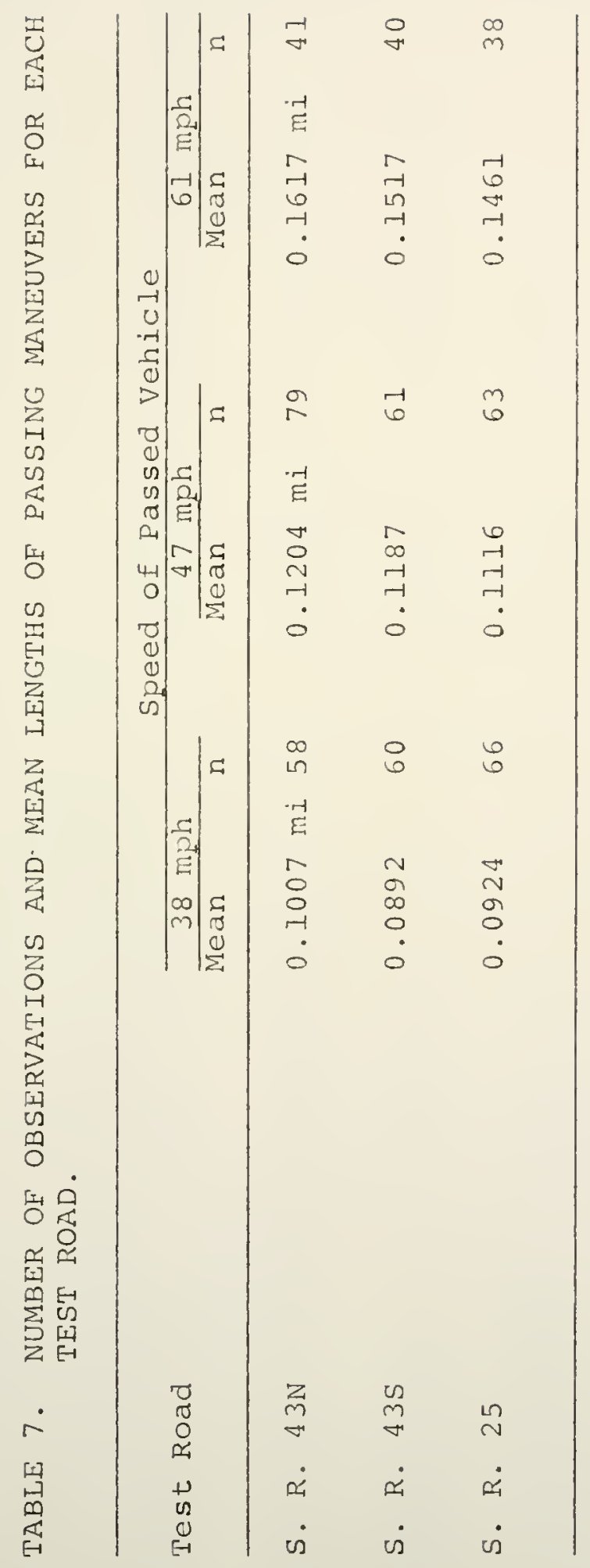




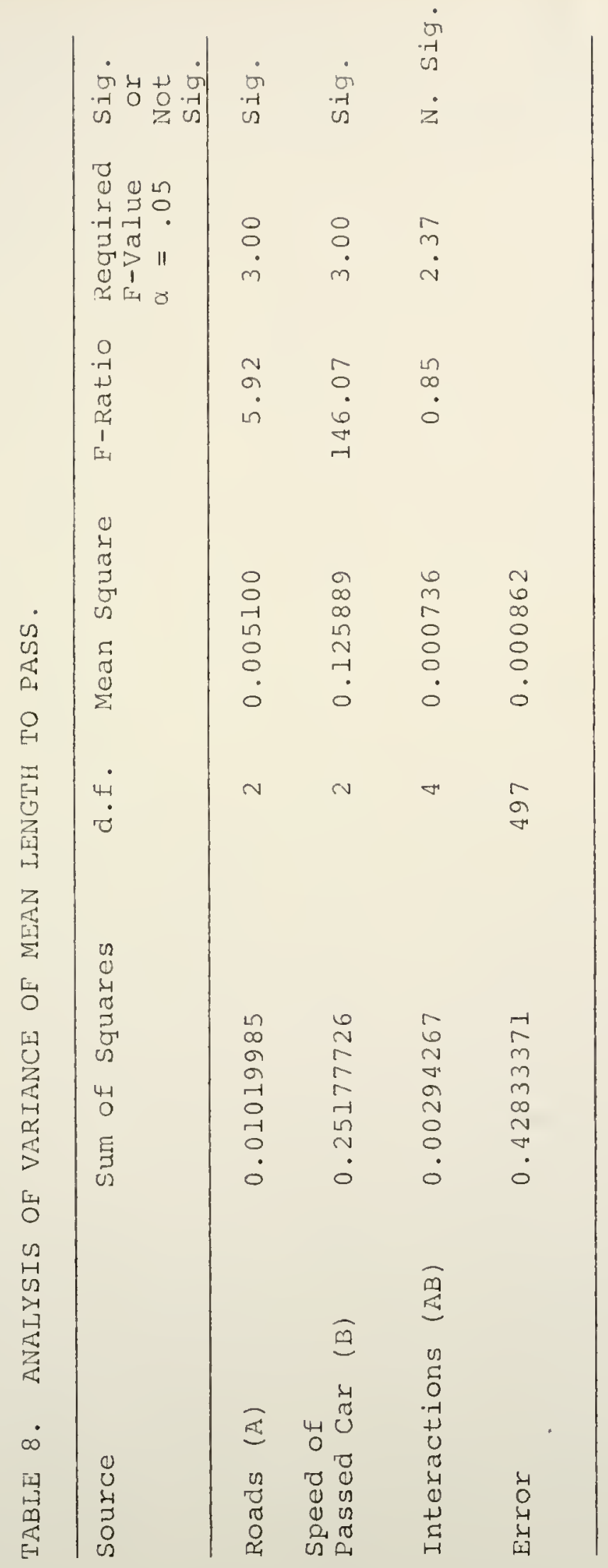


passed vehicle was insignificant. However, both the effects of test road and speed of passed vehicle were significant at the alpha level of .05.

The computer program used for this analysis, called ANOVA at Purdue University, contains output which can be used to make multiple comparisons (Scheffé Method) between the various levels of each main effect [17]. The purpose of these comparisons was to determine which roads and which speeds were causing the difference in means. The interpretations are as follows:

1. The difference in the mean length to pass among roads shown by the significant $F$-test in the AiNOVA is caused by the mean length to pass on S. R. $43 \mathrm{~N}$ being significantly larger, at the alpha level of .10, than that of S. R. 43 S and S. R. 25.

2. The difference in mean length to pass a car traveling at speeds of 38,47 and $61 \mathrm{~m} \cdot \mathrm{p} . \mathrm{h}$. is caused by all three levels being significantly different from each other, at the alpha level of .05 .

In conclusion it can be stated that the individual test roads had an effect on the length of passing maneuver but not an overwhelming effect. As can be seen in Table 9, there was a maximum difference of means between roads of only .015 mile which is only 80 feet. However, the length of the 


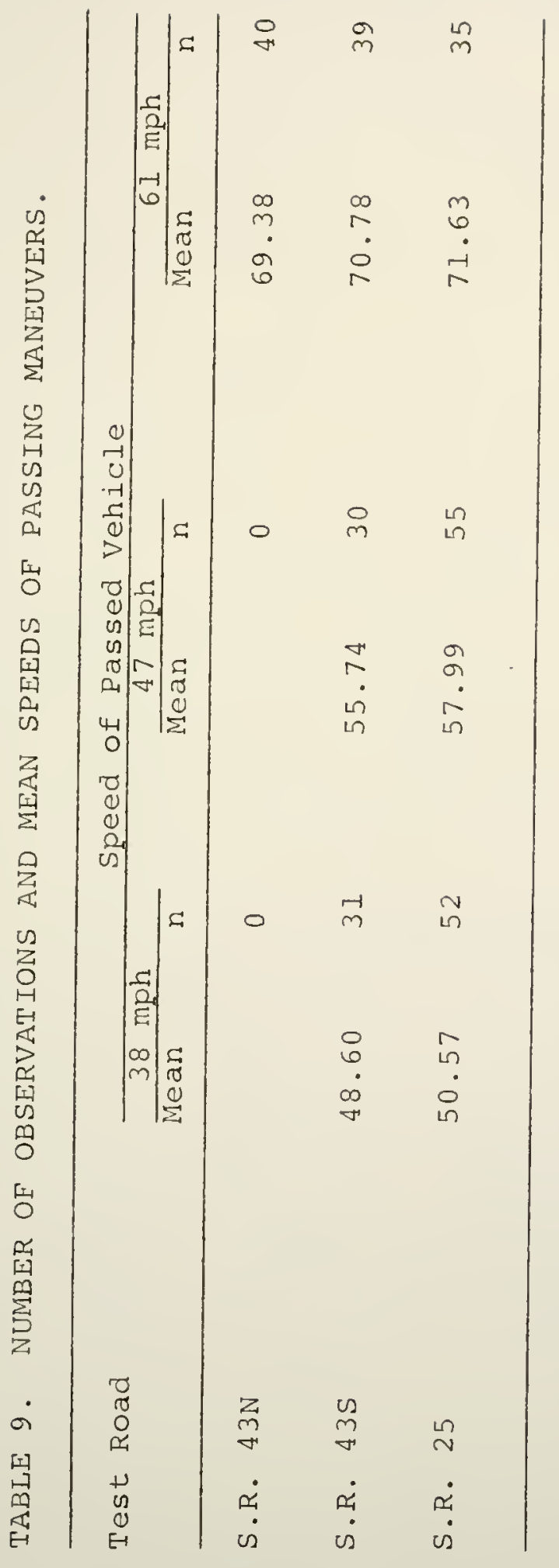


passing maneuver increased significantly as the speed of the overtaken car increased, with a maximum difference of about .06 mile or 315 feet.

The mean speed of the passing vehicle was analyzed to determine if the effects of road and/or speed of the overtaken vehicle were significant. The data analyzed is shown in Table 9 .

As previously mentioned, there were missing data at lower speeds on S. R. 43N. Therefore, a two-way analysis of variance could be performed only on two roads, S. R. 43S and S. R. 25, and on the three speeds of overtaken vehicle. A one-way analysis of variance was used to compare the mean speeds passing a car traveling at 61 miles per hour on all three test roads. The results of these analyses are shown in Table 10 .

The same general conclusions that were mentioned for length of passing maneuver also apply to the speed of passing maneuver. The analysis of variance shows that the interaction between test road and the speed of overtaken vehicle were insignificant. The main effect of test road on the speed of the passing mancuver was significant at the alpha level of .05. The difference between mean speeds was only about two miles per hour, however. The main effect of the speed of the overtaken vehicle was quite significant. The application of the scheffe' method of analysis indicates that it can be stated, at the alpha level of .05 , that the 


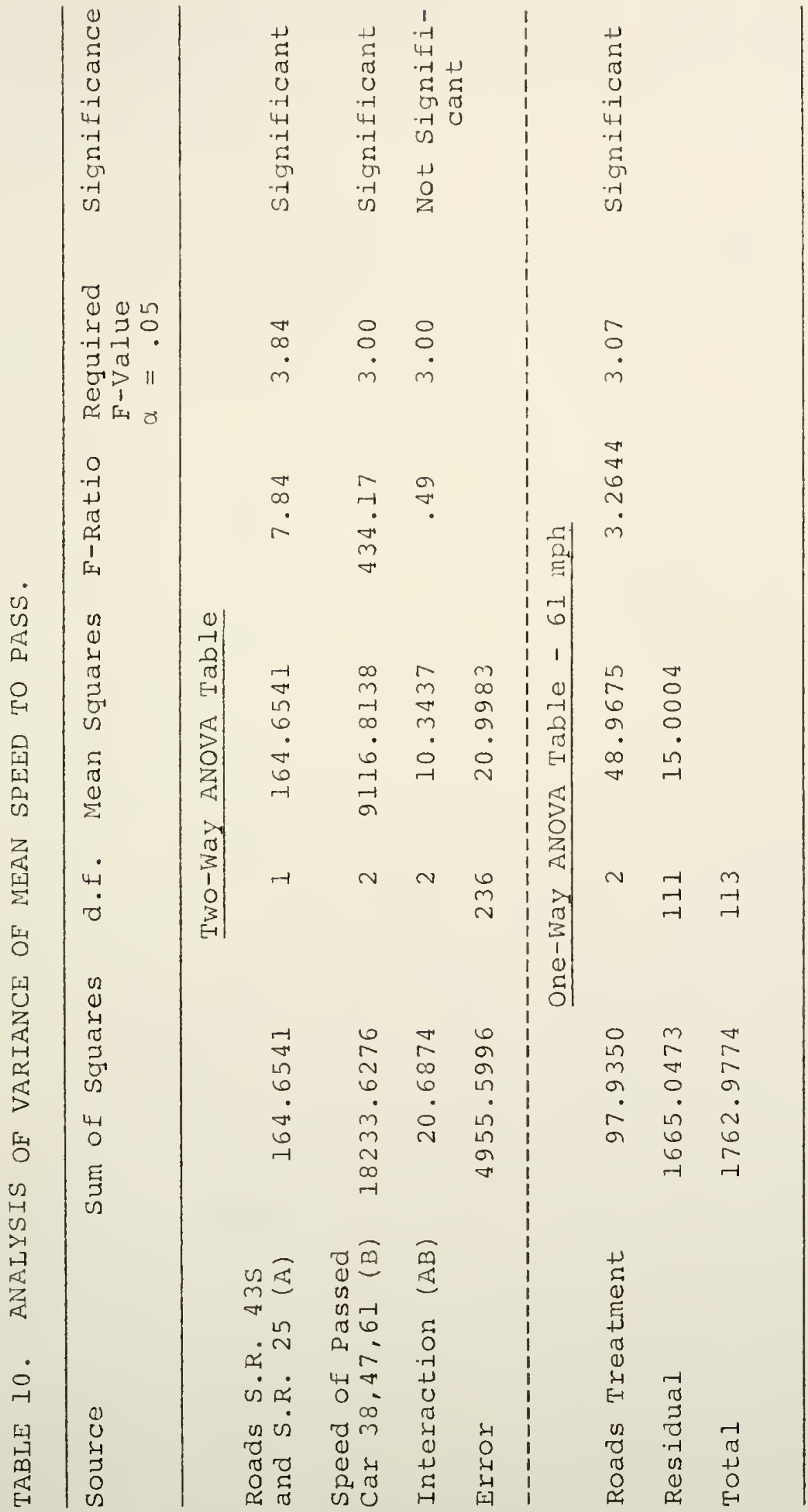


difference between the mean speeds of the passing vehicle can be attributed to all three levels of the speed of the overtaken vehicle.

The Results of the Statistical Analyses indicate that there was an influence on the length and speed of the passing maneuver by the test road. This is precisely the reason that roads of different geometric alignments were chosen originally. However, it would he neither practical nor logical to conduct this experiment on every road in the state to determine the length and speed of passing maneuvers. Throughout the study, it has been the intent to be conservative. Passing maneuvers that were forced and subsequently much shorter (at least 150 feet; see Figure 15) than those with a voluntary return were removed from the analyses. On the other hand, passes by motorists who were obviously lazy in returning to the proper lane were included.

Also, there seems to be a correlation between the sight distance available on a test road and the length and speed of the passing maneuver (see Table 11). The less sight distance available, the shorter and faster were the passing maneuvers, generally. This indicates that the mean length and speed of passing maneuvers on test road $S$. R. 25, which had generally short sight distance, were probably closer to the true minimum values than those observed on test road S. R. $43 \mathrm{~N}$ which had relatively long sections of long sight distance. By combining data observed on all three roads, 


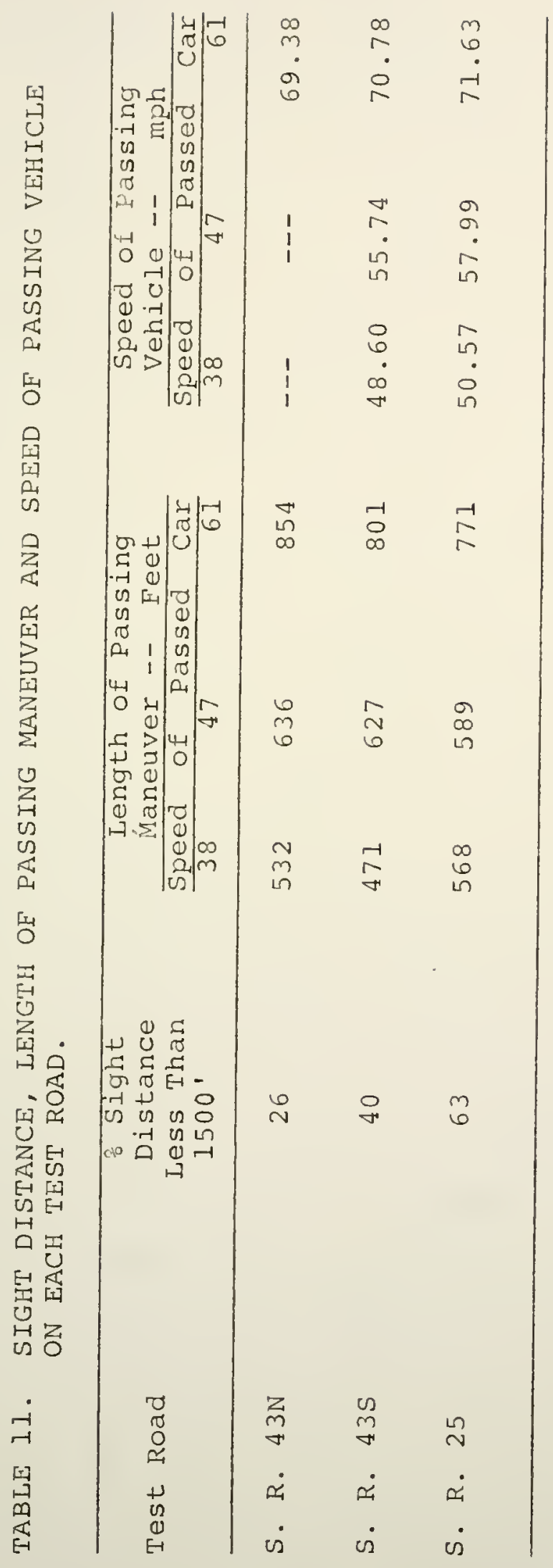


the resulting average values would still be conservative.

It was the intent of this research project to develop criteria that could have a broad application to all roads. To do this, however, it would have been necessary to select a random sample of test roads throughout the United States. It was obviously impossible to do that in this study. Therefore, the criteria, which were developed by combining data on all three test roads in this study, are theoretically applicable only to roads in the central area of Indiana. However, it is the belief of the author that the effect of roads on the length and speed of passing maneuvers is minimal and that the recommended criteria are sufficiently conservative to be applicable to all roads.

Confidence Limits on the mean length and speed of the passing maneuver were computed to provide an idea of how close the computed mean is to the true mean. One can be 95\% confident that the true means of the length and speed of passing maneuvers are between the upper and lower limits listed in Tables 12 and 13. The upper limit is the most important from a safety viewpoint. As can be seen in Table 12, the greater the speed of the overtaken car, the greater the variation in the length of the passing maneuver. The upper confidence limit at 61 miles per hour for all roads combined was still only .007 mile or 37 feet longer than the mean length. From this it seems apparent that the test results are well within the accuracy desired to establish criteria for no-passing zones. 


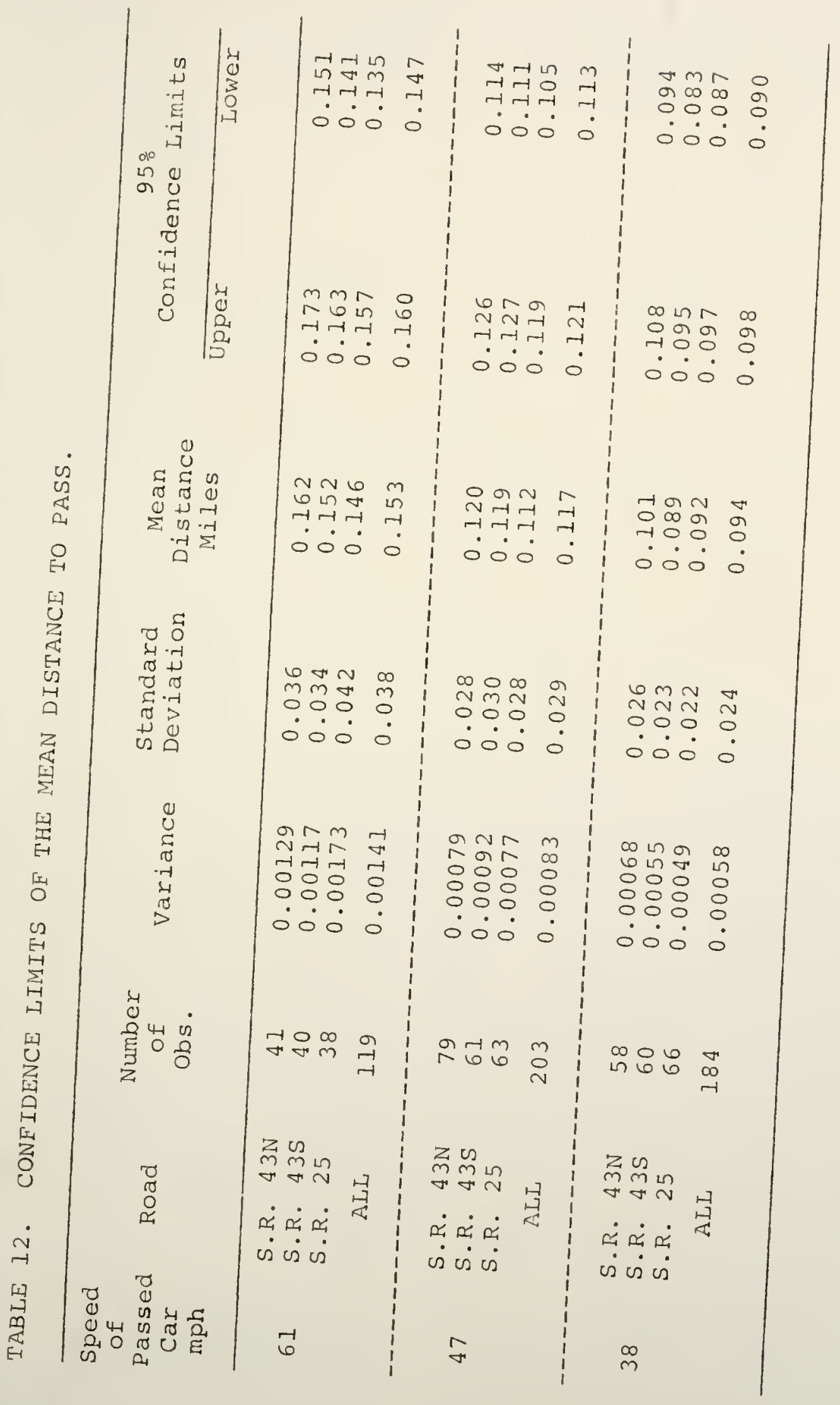




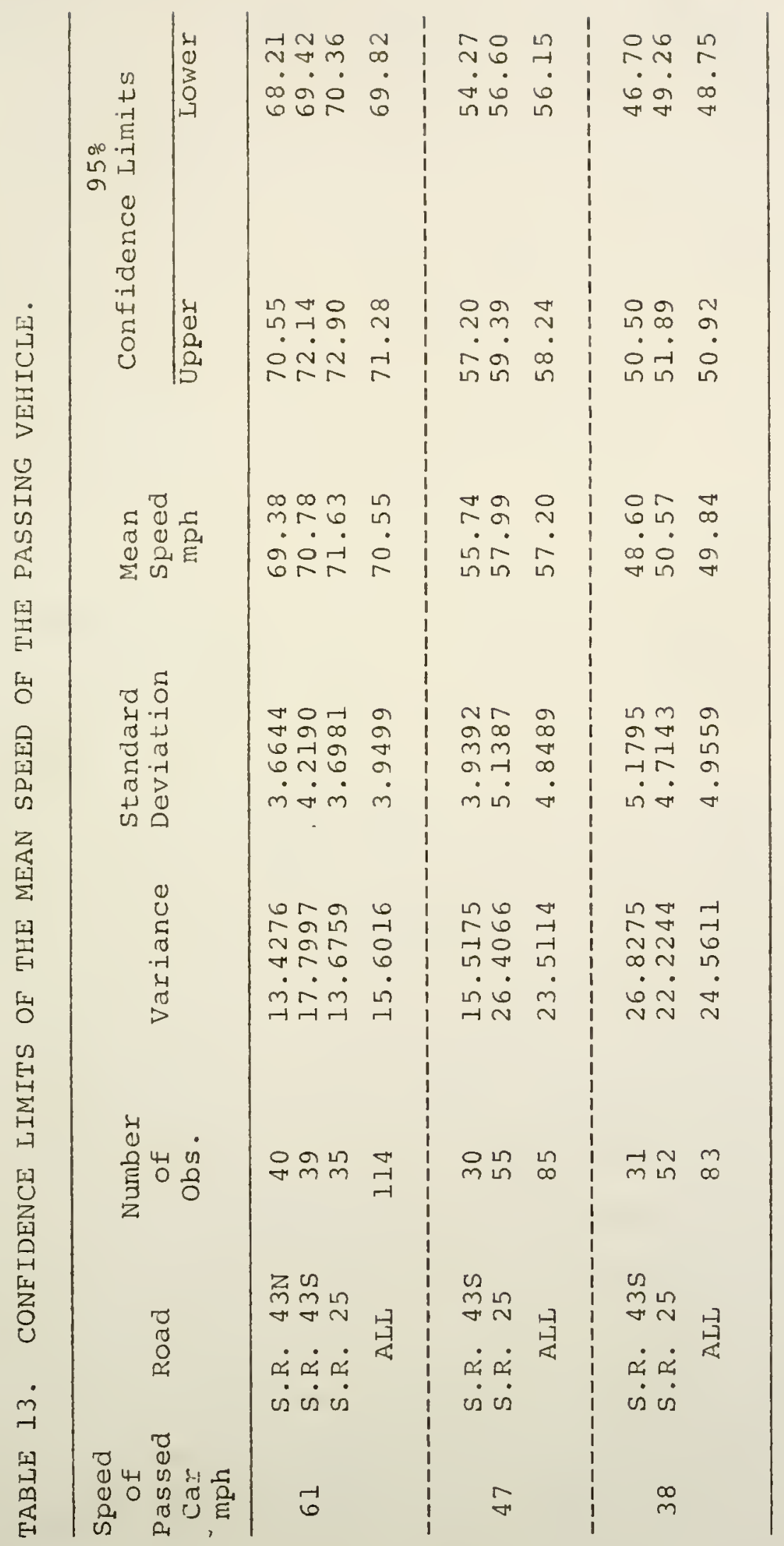




\section{Speed of Traffic on Test Roads}

The results of the speed studies of traffic on the test roads are shown in Figures 20,21 and 22 for test roads S. R. $43 N$, S. R. 435 and S. R. 25, respectively. The mean speeds of traffic on these roads did not differ by more than two miles per hour. The speed studies were taken on a level tangent section on each of the three test roads. As explained previously, these sites were chosen because this is where passing maneuvers take place. It would not be logical to choose a site for a speed study in the middle of a hill, for instance, where traffic -- especially truck traffic -- would be traveling slow and where passing maneuvers would be restricted.

The speed distribution curves in Figure 20, 21 and 22 indicate that about $70 \%$ of the traffic (15th to 85 th percentile) traveled in a speed range of about 20 miles per hour (48 to 68 miles per hour). About $50 \%$ traveled within a range of plus or minus 5 miles per hour of the mean speed of traffic. Considerable passing of vehicles traveling less than the mean speed will likely occur while fewer vehicles traveling above the mean speed will be passed. Therefore it would be conservative -- and in the interest of safety -- to base no-passing zone criteria on the sight distance required to pass an automobile traveling at the mean speed of traffic. It is believed by the author that most drivers who pass a vehicle traveling above the average speed of traffic will 


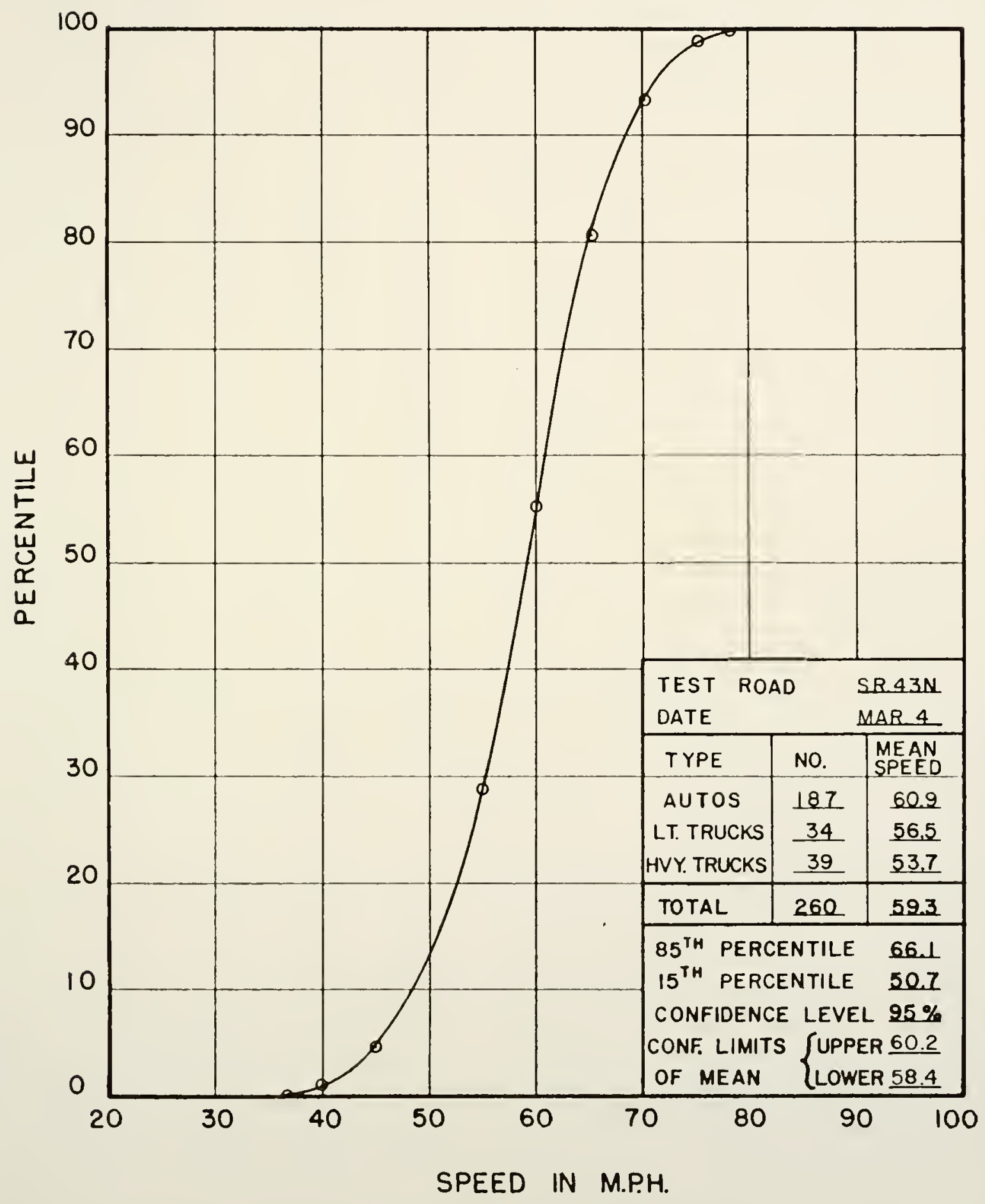

FIGURE 20. ACCUMULATIVE DISTRIBUTION OF TRAFFIC SPEEDS ON S.R. $43 \mathrm{~N}$. 


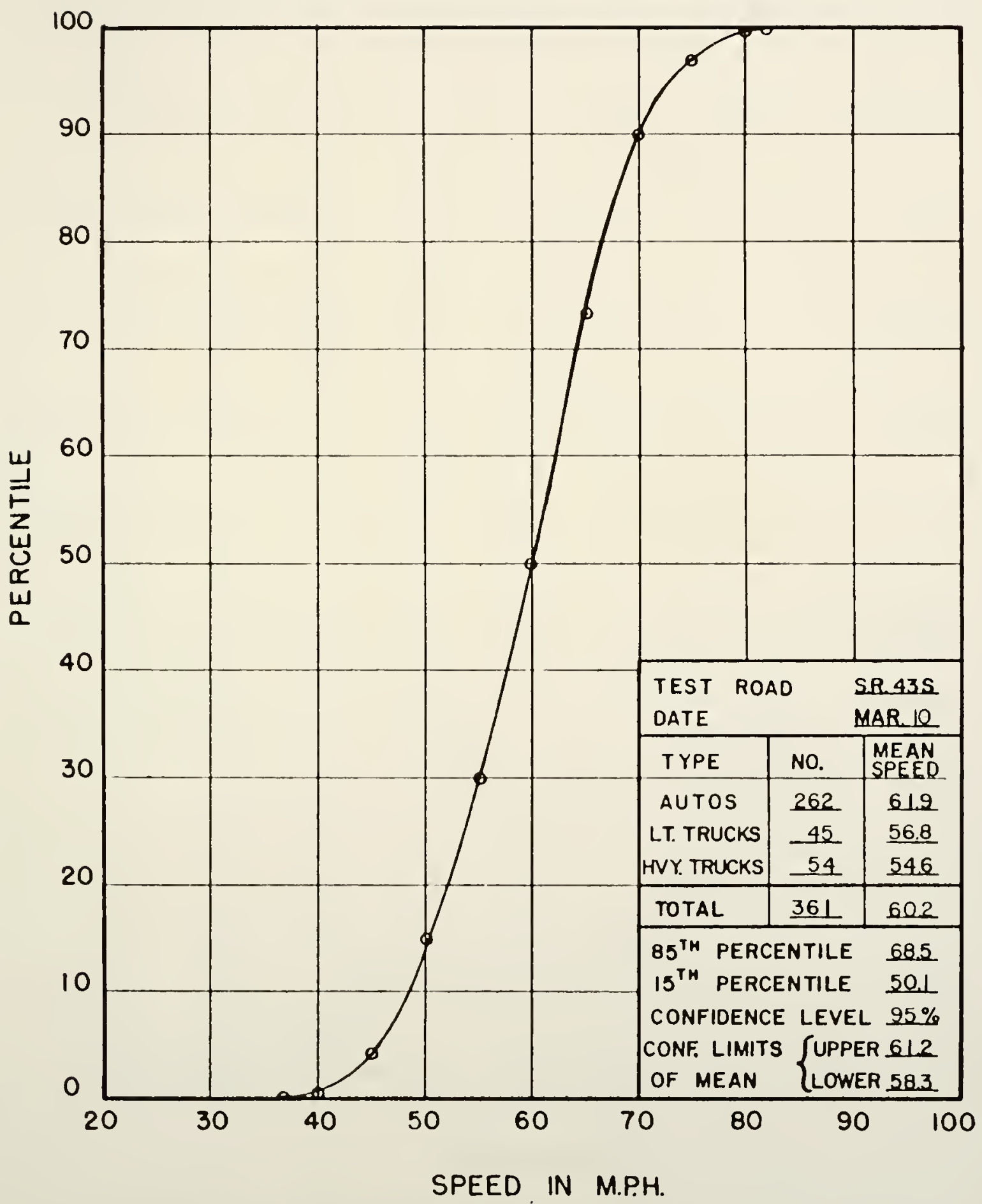

FIGURE 21. ACCUMULATIVE DISTRIBUTION OF TRAFFIC SPEEDS ON S.R.43S. 


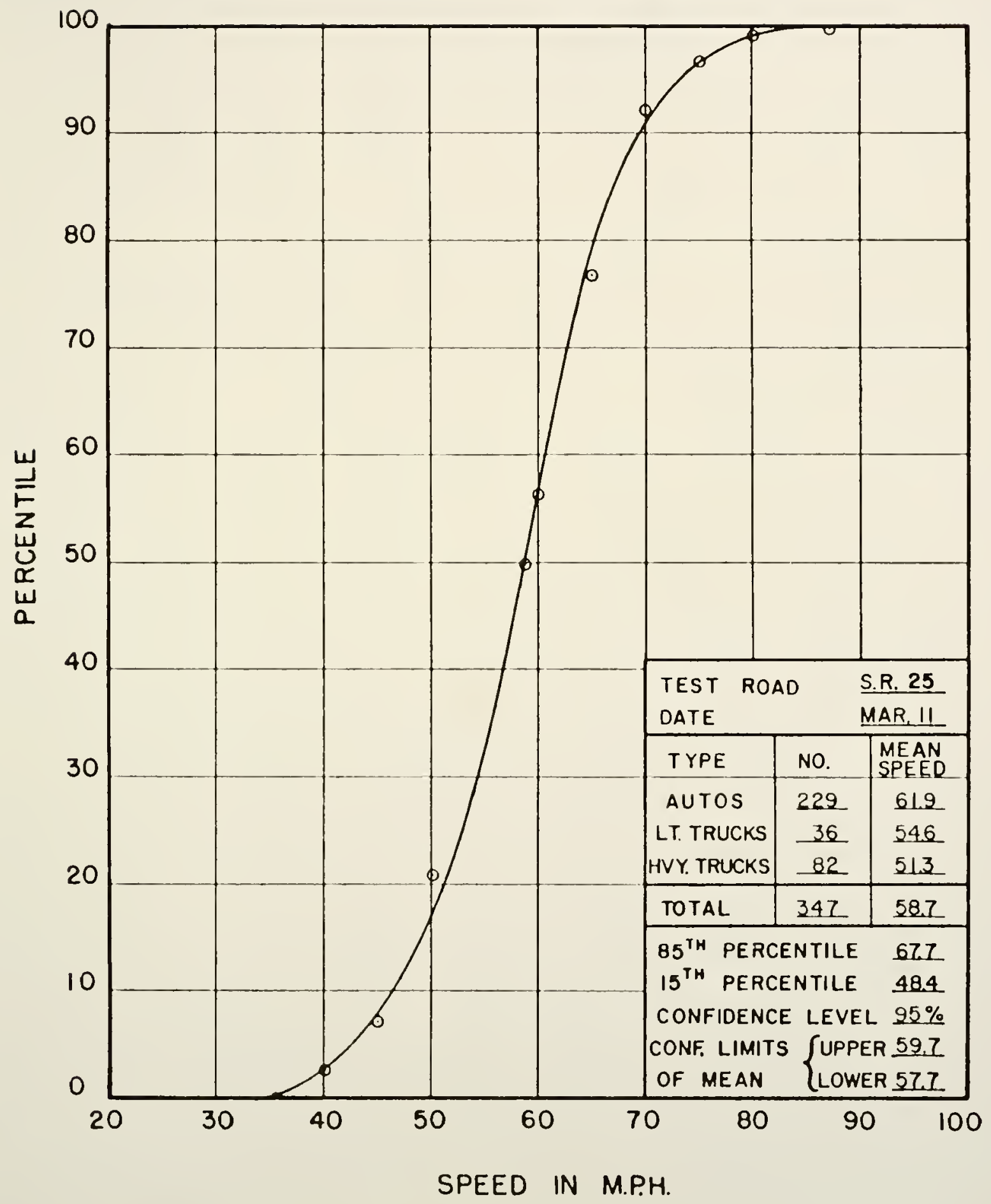

FIGURE 22. AC CUMULATIVE DISTRIBUTION OF TRAFFIC SPEEDS ON S.R. 25. 
realize the danger associated with this pass decision and will exercise appropriate safety precautions. The speed of the oncoming vehicle (which is out of sight) is an unknown quantity to the driver who is about to pass another vehicle. To base the minimum sight distance requirements on the average speed of oncoming vehicles might be dangerous because half of the approaching vehicles would be traveling faster than average. Therefore, it seems logical to choose a speed which would include most of the oncoming traffic. Obviously, it is not practical to design for the looth percentile speed. Therefore, it is simply a matter of judgment as to which speed to choose. The decision is not too critical, however, because the difference in speed between the 85 th and 90 th percentile, for instance, would be only about two miles per hour.

The 85 th percentile speed is often used in traffic engineering so this value was chosen for the speed of oncoming traffic in this study. The 85 th percentile speed varied between five and seven miles per hour above the average speed on the test roads. This is also confirmed by annual speed studies conducted by Purdue University [1]. Therefore, a speed of seven miles per hour faster than the average speed of the traffic was used as the speed of the oncoming vehicle.

In summary, it is concluded that the minimum sight distance requirements should be based on the sum of the 
distance required to pass a vehicle traveling at the average speed of traffic and the distance traveled during that passing maneuver by an oncoming vehicle traveling at the 85 th percentile speed of traffic.

\section{Sight Distance on Test Roads}

The Sight Distance - Passing Maneuver Relationship

The relationship between sight distance and the passing maneuvers on the test roads was studied to determine the percentage of passes completed with various amounts of sight distance available. The results of these studies are shown in Figure 23. The accumulative percentile distribution of sight distance available when the passing vehicle reached the "point-of-no-return" is shown for each speed of the passed vehicle - 38, 47 and 61 miles per hour. All types of passing maneuvers by all types of vehicles were included.

As would be expected, there was a greater percentage of passes at the slow speeds than at high speeds where the sight distance was low. This relationship was consistent for the passed car speeds of 38,47 and 61 m.p.h. between sight distances of 1100 feet and 1800 feet.

At passed car speeds of 38,47 and 61 m.p.h., only ten percent of the passes had a sight distance of less than 1300 feet, 1500 feet and 1600 feet, respectively. This gives an indication of what motorists consider to be minimum sight distance to pass a car. The differences, however, would have been greater if passing maneuvers on the test 


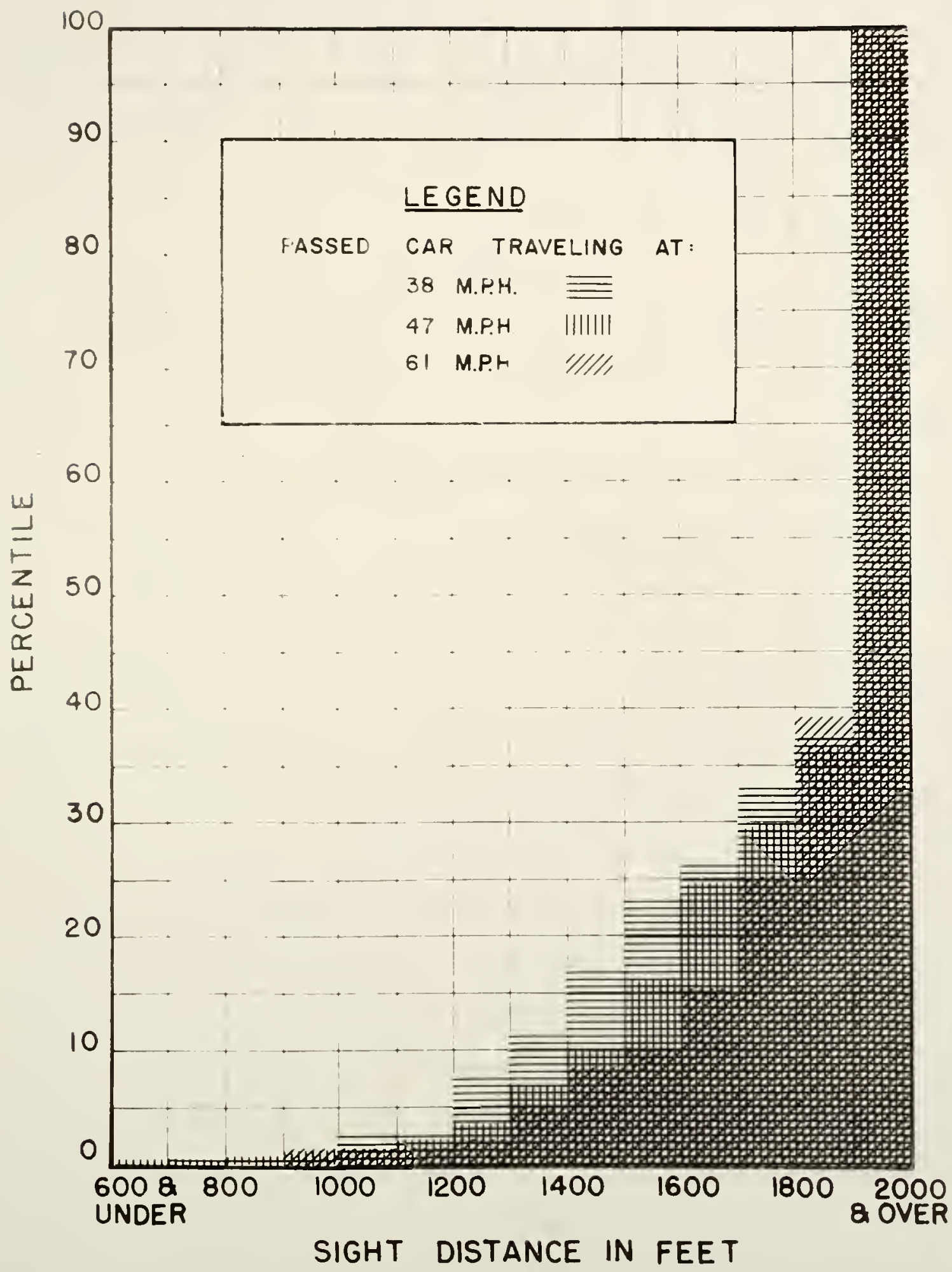

FIGURE 23. SIGHT DISTANCE AVAILABLE WHEN VEHICLES REACHED THE "POINT-OF-NO-RETURN" 
roads had not been restricted by no-passing zones. Actually most passing maneuvers completed with less than 1200 feet of sight distance were completed by crossing the yellow line.

\section{Capacity}

The effect on capacity of restricting passing maneuvers when the sight distance is low does not seem to be too great. It appears that most drivers do not make a passing maneuver juagment solely on the absence of an oncoming vehicle and the absence of a yellow line. If the drivers cannot see what they consider to be a safe distance in front of them, they will not initiate a passing maneuver even though there may be no yellow line to stop them. This became apparent during the data collection period and after observing the locations of no-passing zones, the location of passing maneuvers, and the available sight distance shown in Figures 9 through 14. This occurred most noticeably on test road S. R. $43 \mathrm{~N}$ in the northbound direction at station 4.0, (see Figure 9) and in the southbound direction at station 1.4 (see Figure 10). In this area there is a horizontal curve which is not marked by a yellow line but notorists do not think they can see far enough to make a safe passing maneuver. Not a single pass was completed at any speed in these two areas despite the absence of no-passing zones. 
It might be concluded from this result that motorists do not place total reliance on marked no-passing zones but rely on their judgment of safe passing sight distance. Undoubtedly drivers use no-passing zones as guides to their judgement and perhaps no-passing zones should be just that -- advisory and not regulatory.

\section{Violations of the No-Passing Zones}

There were frequent violations of the norpassing zones, i.e., the passing vehicle crossed the yellow line at some point. For this analysis, the crossing of a yellow line on the right side of the road at any point was a violation. This is also the interpretation given to Indiana laws by the state police. There were 104 known violations (12\% of all passes), shown in Figures 9 through 14. In adaition there were some violations that were not recorded because the point where the passing vehicle first crossed the centerline when initiating the passing maneuver could not be recorded and is unknown. It was observed, however, that some vehicles -- especially when the passed vehicle was traveling at a slow speed and where the end of a no-passing zone had been unduly extended -- initiated a passing maneuver prior to the end of the noppasing zone. Several locations were noted where the no-passing zone extended beyond the point where adequate passing sight distance first became avail able. This could be the result from annual extensions of the line in the repainting process. 


\section{Minimum Sight Distance}

The minimum sight distance required to safely pass another vehicle depends on three distances as explained earlier in Chapter III: (1) the distance to pass; (2) the distance traveled by an oncoming car during that pass; and (3) a clearance between the passing vehicle and the oncoming vehicle. The distance needed to pass and the speed of the passing vehicle has been established and is shown in Figures 15 and 16. Values were taken from these figures for each incremental speed and by knowing the distance and speed of the passing maneuvers, the duration of the passing maneuvers could be calculated. These values are shown in Table 14.

The distance traveled by the oncoming vehicle is a function of the duration of the passing maneuver. Table 15 shows the distance $\left(S_{2}\right)$ for a range of speeds that an oncoming vehicle would travel during the time needed to pass a vehicle traveling at a given speed.

The sum of the distances traveled by the passing vehicle and oncoming vehicle is shown in Table 16. The total distance $\left(S_{1}+S_{2}\right)$ for any speed of passed vehicle between 38 and $61 \mathrm{~m} \cdot \mathrm{p} . \mathrm{h}$. and any speed of oncoming vehicle in a range up to 14 miles faster than the speed of the passed car, can be read from that table. The values underlined are the distances required if the oncoming vehicle is traveling at a speed seven miles per hour faster than the speed of the passed car. 
TABLE 14. THE DURATION OF PASSING MANEUVERS.

\begin{tabular}{|c|c|c|c|}
\hline $\begin{array}{c}\text { Speed of } \\
\text { Passed } \\
\text { Vehicle } \\
\text { mph }\end{array}$ & $\begin{array}{c}\text { Distance } \\
\text { to } \\
\text { Pass } \\
\text { feet }\end{array}$ & $\begin{array}{c}\text { Speed of } \\
\text { Passing } \\
\text { Vehicle } \\
\text { mph }\end{array}$ & $\begin{array}{c}\text { Time to } \\
\text { Pass } \\
\text { Sec. }\end{array}$ \\
\hline $\begin{array}{l}38 \\
39 \\
40 \\
41 \\
42 \\
43 \\
44 \\
45 \\
46 \\
47 \\
48 \\
49 \\
50 \\
51 \\
52 \\
53 \\
54 \\
55 \\
56 \\
57 \\
58 \\
59 \\
60 \\
61\end{array}$ & $\begin{array}{l}496 \\
510 \\
523 \\
537 \\
550 \\
564 \\
577 \\
591 \\
605 \\
618 \\
632 \\
645 \\
659 \\
672 \\
686 \\
700 \\
713 \\
727 \\
740 \\
754 \\
767 \\
781 \\
795 \\
808\end{array}$ & $\begin{array}{l}49.6 \\
50.4 \\
51.2 \\
52.0 \\
52.8 \\
53.7 \\
54.5 \\
55.3 \\
56.1 \\
56.9 \\
57.9 \\
58.9 \\
60.0 \\
61.0 \\
62.0 \\
63.0 \\
64.0 \\
65.1 \\
66.1 \\
67.1 \\
68.1 \\
69.1 \\
70.2 \\
71.2\end{array}$ & $\begin{array}{l}6.82 \\
6.90 \\
6.96 \\
7.04 \\
7.10 \\
7.16 \\
7.22 \\
7.29 \\
7.35 \\
7.40 \\
7.44 \\
7.46 \\
7.49 \\
7.51 \\
7.54 \\
7.57 \\
7.59 \\
7.61 \\
7.63 \\
7.66 \\
7.68 \\
7.70 \\
7.72 \\
7.74\end{array}$ \\
\hline
\end{tabular}




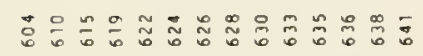

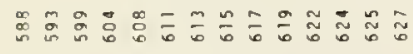

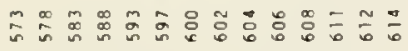

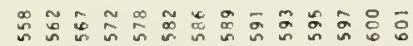

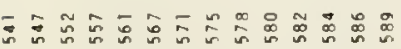

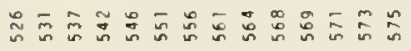

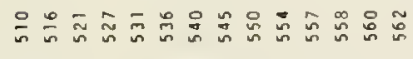

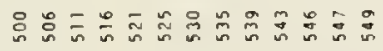

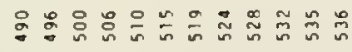

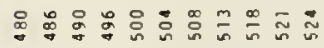

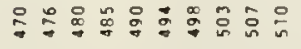

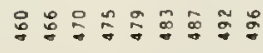

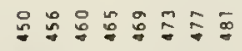

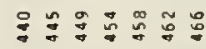

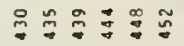

$\cong \cong \cong$

$\frac{\dddot{*}}{\approx} \cong$

年

ㅇํㅇ

品

: 


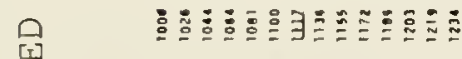

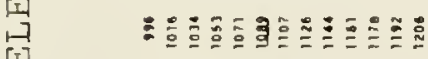

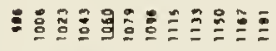

E ละะล

$\sum \vdots \vdots$

$\stackrel{-1}{\circ}$

\section{วั}

$\vdots$

凅 
The total required sight distance is the sum of the distances $S_{1}+S_{2}+20$ feet. As previously defined: $S_{1}$ is the distance traversed by a vehicle which passes another vehicle moving at the average speed of traffic on the road; $\mathrm{S}_{2}$ is the distance traversed by an oncoming vehicle, which is moving at the 85 th percentile speed of traffic on the road, during the above mentioned passing maneuver; the 20 feet is a minimum clearance interval between the passing vehicle and the approaching vehicle (see Figure 3 ).

This minimum sight distance is plotted in Figure 24. The dashed line indicates extrapolated values outside the limits of this study. Such values should be used with caution. The minimum sight distance is also shown in Table 17.

\section{Comparison with the Criteria of MUTCD}

Both the sight distance criteria according to the 1961 edition of MUTCD and the proposed draft of MUTCD are shown in Figure 24. The MUTCD minimum sight distances are stated for the 85 th percentile speed of traffic while the minimum sight distances developed in this research project are for average speed of traffic, the speed of the passed vehicle. As noted previously the 85th percentile speed of traffic on two-lane two-way state arterial highways in Indiana is approximately seven miles per hour higher than the average speed. As a consequence the minimum sight distances required by the MUTCD were plotted in Figure 24 at speeds seven miles per hour less than the stated 85 th percentile 


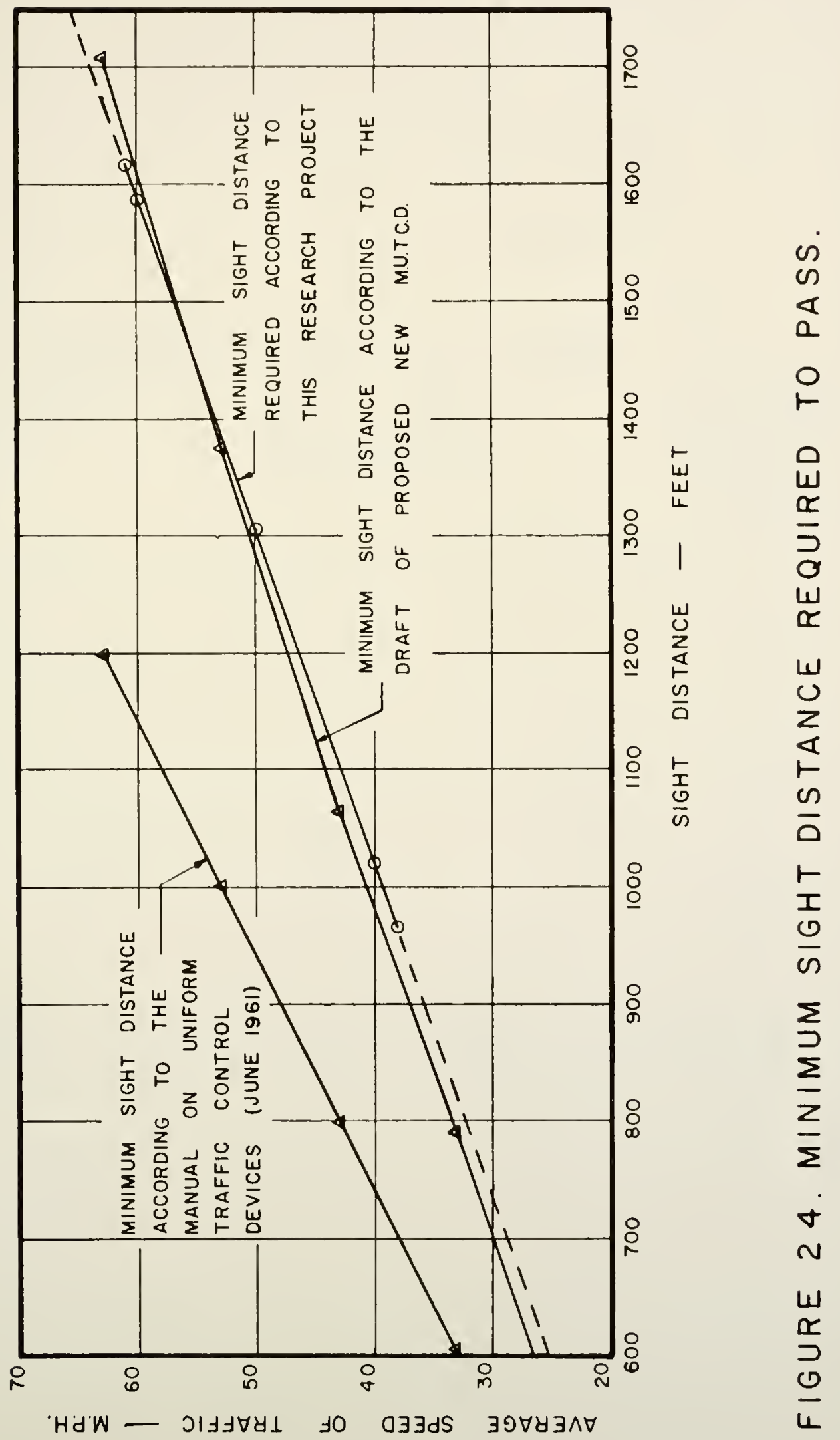


TABLE 17. RECOMMENDED MINIMUM SIGHT DISTANCE.

\begin{tabular}{ccc}
\hline $\begin{array}{c}\text { Average Speed } \\
\text { (Off Peak) } \\
\text { mph }\end{array}$ & $\begin{array}{c}\text { Distance Taken } \\
\text { From Figure } 24 \\
\text { feet }\end{array}$ & $\begin{array}{c}\text { Recommended } \\
\text { Minimum } \\
\text { Sight } \\
\text { Distance } \\
\text { feet }\end{array}$ \\
\hline 35 & 860 & 900 \\
40 & 1020 & 1050 \\
45 & 1170 & 1200 \\
50 & 1305 & 1300 \\
65 & 1440 & 1450 \\
65 & 1575 & 1600 \\
\hline
\end{tabular}

A curve shall warrant a no-passing zone and shall be so marked where the sight distance is equal to or less than that listed above for the prevailing (off peak) average speed. 
speeds for comparison with the average speeds used in this study. It is apparent that the proposed MUTCD minimum sight distances coincide with the distances established in this research froject.

The proposed MUTCD draft, however, contains the same regulation as the 1961 MUTCD recommendations concerning the crossing of yellow lines. It is recommended in the MUTCD that an applicable yellow line not be crossed at any time. In effect this extends each no-passing zone by several hundred feet.

As an example, assume a motorist begins to pass a vehicle that is traveling $60 \mathrm{~m} . \mathrm{p} . \mathrm{h}$. and just as his vehicle reaches the "point-of-no-return" he sees a no-passing zone sign ahead. At that moment he has the choice of braking the car to fall back into line or continuing the pass. Assuming that the pass is normal and average as defined in this study, he will need to be approximately 800 feet from the no-passing zone to be able to complete the pass and avoid crossing the yellow line (see Figure 15). Ordinarily a no-passing sign can only be seen about 300-400 feet away and a yellow line is even less visible. He would most likely be trapped into crossing the yellow line and would thereby become an offender of the law.

Many motorists are aware of the law and rather than continue a normal passing maneuver they swerve abruptly in front of the passed car to avoid crossing the yellow line. 
This unnatural movement was observed Erequently during this experiment. It was obvious that such a maneuver did not contribute to the safety and pleasure of either the passed or passing motorist and their passengers. It should be recognized that serious problems exist with this method of regulating the behavior of motorists where there is inadequate sight distance. A solution to the problem must be found.

\section{Long zone vs. Short zone Concept}

Traffic laws that prohibit driving on the left side of an applicable yellow line throughout its length constitute what is known as the short zone concept. An alternative to this is the long zone concept which would prohibit the beginning of a passing maneuver but would allow the completion of a passing maneuver within a no-passing zone.

The short zone concept is contained within the recommended policy of the "Uniform Vehicle Code" and the "Manual on Uniform Traffic Control Devices." Consequently, most states have laws that incorporate the short zone concept. Only four or five states in 1966 specifically allowed the completion of a passing maneuver within a no-passing zone $[10]$

However, the problem associated with the short zone concept has been realized for many years. The visibility of the beginning of a no-passing zone is severely limited. A "DO NOT PASS" sign can be seen only a few hundred feet 
under the best conditions and while following another vehicle, the sign may not be seen at all. Many states do not use a "DO NOT PASS" sign but rely solely on the solid yellow line to mark some or all no-passing zones. The 1961 MUTCD states: "Where pavement markings are present the sign need not be used." Consequently, many motorists are "trapped" during a passing maneuver by the sudden appearance of a no-passing zone.

Many states, recognizing the problem, have experimented with the use of additional marking devices to warn of impending no-passing zones. Perhaps the most popular and well known device is the pennant shaped "NO PASSING ZONE" sign mounted on the left side of the pavement. In 1967 there were three states, Iowa, North Dakota and South Dakota, which were using this sign and numerous other states have been experimenting with it [11]. Although the pennant shaped sign is not in the 1961 MUTCD, it is included in the draft of the new MUTCD.

Other devices which have been studied include a broken yellow line and semi-circular blobs painted on the pavement preceding the solid yellow line. In Great Britain, large arrows are painted on the pavement to direct traffic back to the proper lane [11].

The problem is realized but the solution has not been found. Usually studies have shown only a small reduction, if any, in the number of violations of the no-passing zone by these additional warning devices [11,18]. Perhaps, 
traffic engineers have been addressing themselves to the wrong question. Instead of asking how to reduce or prevent violations of the no-passing zone, the first question should be -- Is it always dangerous to the motoring public when vehicles cross a yellow line? For instance, is it dangerous to pass a farm tractor that is moving $10 \mathrm{~m} \cdot \mathrm{p} . \mathrm{h}$. through a no-passing zone when it is obvious that there is ample distance free of obstructions or oncoming traffic in which to pass? According to the UVC and MUTCD it would be illegal.

Is it dangerous to finish a passing maneuver within a no-passing zone? Or, is it more dangerous to slam on the brakes when a no-passing zone is seen midway into a passing maneuver or to abruptly swerve in front of a passed vehicle to avoid crossing a yellow line? These irregular maneuvers are repeated constantly.

The long zone concept allows the completion of a passing maneuver on the yellow line. If the motorist is so far into the maneuver that a severe braking action is required to stop the maneuver in order to avoid crossing the barrier line, the motorist is allowed to continue the maneuver. The beginning of a no-passing zone becoming visible during a passing maneuver provides a similar cautionary warning as the yellow caution light in traffic signals. This requires no more judgment on the part of law enforcement personnel than the enforcement of traffic signal regulations. Almost everyone agrees that the use of the yellow caution light in 
traffic signals is logical and necessary.

There is an important aspect to the problem that cannot be ignored. Uniformity of traffic laws and criteria throughout the nation is a necessary and desirable goal. It is true that several years will be required before all states would or could change their laws to adopt the long zone no-passing concept. However, the shortcomings of the short zone concept are well known and never will all states be convinced that they should adopt a law that is known to be unsatisfactory. And most important, many motorists either are unable or do not want to comply to the short zone concept, as evidenced by the large number of violations of nopassing zones in this study and others $[11,18]$.

The logical alternative is to allow the applicable yellow line to be crossed for the purpose of finishing a passing maneuver that was well underway before the beginning of a no-passing zone was reached. This can be achieved through the universal adoption of laws and criteria to implement the long zone concept.

An initial reaction of many people to the long zone concept will probably be that the length of no-passing zones should be increased over those used at present for the short zone concept. However, New Jersey, which has had a law since 1963 that specifically allow's the completion of a passing maneuver on yellow lines, uses the minimum sight distance criteria as stipulated in the 1961 MUTCD. When the law was changed, the no-passing zone criteria were not 
changed. According to the Chief, Bureau of Engineering and Planning of the Division of Motor Vehicles, there has not been a significant change in accident experience. In addition, under the present short zone criteria in Indiana a large percentage of drivers are now crossing the yellow line without apparent danger.

The minimum sight distances for no-passing zones are proposed to be increased significantly in the current araft of the new MUTCD. These are substantially the same as those developed in this research project and should be appropriate for use under either the short or long zone concept.

\section{Minimum Distance Between lio-Passing Zones}

The mininum distance between no-passing zones that should be allowed without making one continuous zone is stipulated in the 1961 MUTCD as 400 feet. The proposed draft of the new MUTCD would increase this distance, especially at higher speeds, in line with requirements of the short zone concept (see Table 4). If this minimum distance is increased, the effect will be to increase the length of nopassing zones and decrease the legal opportunities to pass slov moving vehicles. Consequently, capacity will be reduced and the frustration of motorists following slow moving vehicles will be increased.

The distance required to initiate a passing maneuver was investigated. Assuming that the initial phase of the passing maneuver is equal to one third of the total distance 
to pass (as also assumed by AASHO, see Figure 2), one half of the distance $S_{1}$ as measured in this study would correspond to the length of the initial phase. This distance represents the average distance that a motorist would need to accelerate and arrive at the "point-of-no-return" if he were watching and waiting for the end of the no-passing zone to appear. These distances are shown in Table 18. It appears from this table that the existing 400 foot minimum distance is adequate and could even be reduced for slower speeds under the long zone concept. 


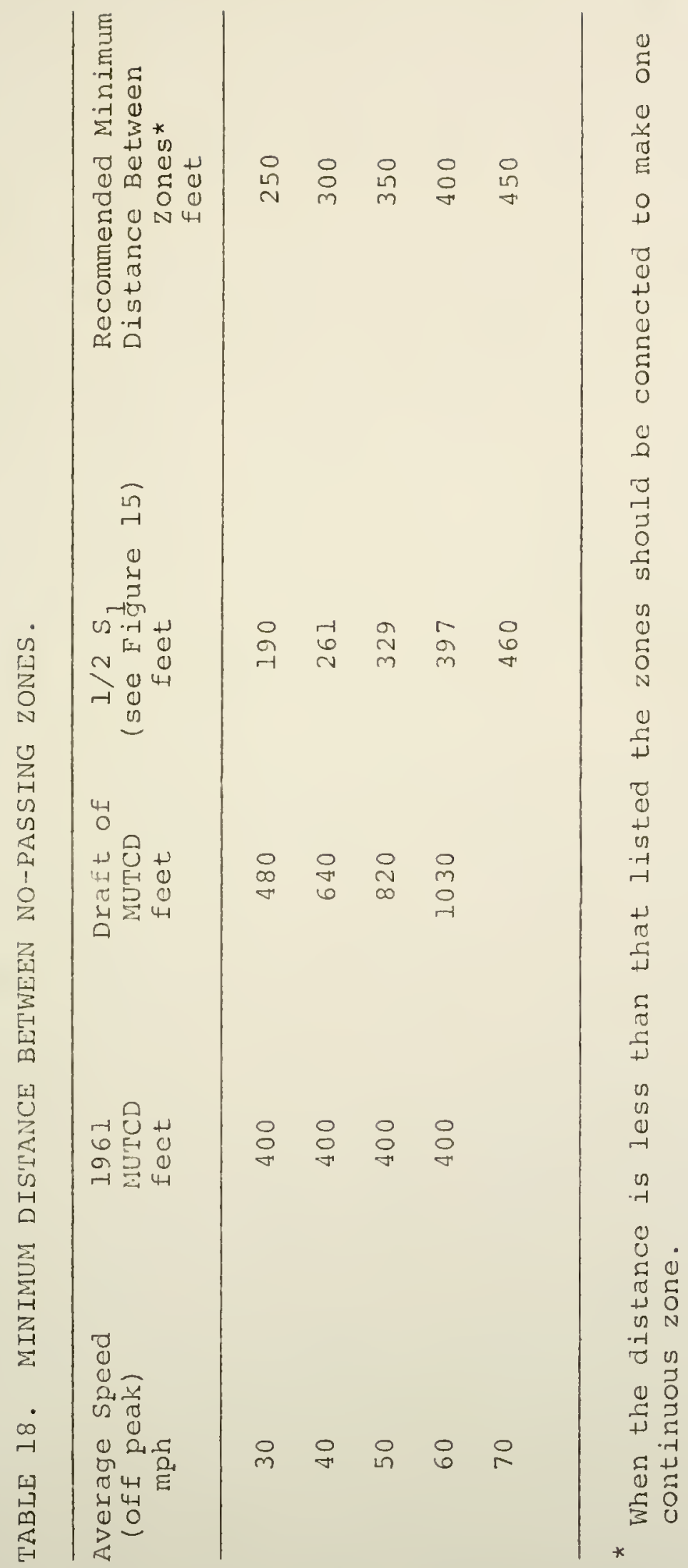


CHAPTER V. CONCLUSIONS AND RECOMMENDATIONS

The findings of this research show that the long zone concept should be used for locating and marking no-passing zones on two-lane two-way highways. This concept prohibits initiation of a passing maneuver in a marked no-passing zone but permits completion of a passing maneuver within such a zone. To implement this concept, criteria, legislation and a field method to locate limits of nopassing zones are suggested.

\section{Criteria for No-Passing zones at Curves}

A no-passing zone at a horizontal or vertical curve is warranted where the sight distance as defined below is less than the minimum necessary for safe passing at the prevailing speed of traffic. Dassing sight distance on a vertical curve is the distance at wich an object 3.75 feet above the pavement surface can just be seen from another point 3.75 feet above the pavement (see Figure 1). Similarly passing sight distance on a horizontal curve is the distance measured along the centerline (or right-hand lane line of a three-lane highway) between two points 3.75 feet above the pavement on a line tangent to the embankment, or other obstruction that cuts off the view on the inside of the curve. Where centerlines are installed, a curve warrants 
a no-passing zone and should be so marked where the sight distance is equal to or less than that listed below for the prevailing (off peak) average speed:

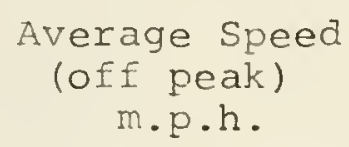

Minimum Passing

Sight Distance

feet

\begin{tabular}{ll}
30 and under & 750 \\
$31-35$ & 900 \\
$36-40$ & 1050 \\
$41-45$ & 1200 \\
$46-50$ & 1300 \\
$51-55$ & 1450 \\
$56-60$ & 1600 \\
$61-65$ & 1750 \\
$66-70$ & 1900 \\
\hline
\end{tabular}

The beginning of a no-passing zone (point "a" in Figure 1) is that point at which the sight distance first becomes less than that specified in the above data. The end of the zone (point "b") is that point at which the sight distance again becomes greater than the minimum specified. The following tabular data indicates the minimum distance between no-passing zone markings necessary for initiation of a passing maneuver: 


\begin{tabular}{cc}
$\begin{array}{c}\text { Average Speed } \\
(\text { off peak }) \\
m \cdot p \cdot h .\end{array}$ & $\begin{array}{c}\text { Minimum Distance } \\
\text { Between Zones } \\
\text { feet }\end{array}$ \\
\hline 30 and under & 250 \\
$31-40$ & 300 \\
$41-50$ & 350 \\
$51-60$ & 400 \\
$61-70$ & 450 \\
\hline
\end{tabular}

Where these minimum distances cannot be provided, the no-passing zone markings should be connected to form one continuous zone.

\section{Legislation}

The following law is suggested so that the long zone concept may be incorporated into no-passing zone legislation, supplanting the law as stated in the "Uniform Vehicle Code" Section 11-307-No-Passing Zones.

\section{Model Law - No-Passing Zones}

(a) The (State Highway Commission) is hereby authorized to determine those portions of any highway where overtaking and passing or driving to the left of the roadway would be especially hazardous and may by appropriate signs or markings on the roadway indicate the becinning and end of such zones and 
when such signs or markings are in place and clearly visible to an ordinarily observant person every driver of a vehicle shall obey the directions thereof.

(b) Where signs or markings are in place to define a no-passing zone as set forth in paragraph (a) no driver shall at any time drive on the left side of the roadway within such no-passing zone or on the left side of any pavement striping designed to mark such no-passing zone except for the purpose of safely completing a passing maneuver begun prior to the beginning point of such a zone.

Indiana Laws - No-Passing zones

Indiana Law $239^{*}$ should be revised to conform to the "Model Law - No-Passing Zones" stated above. Indiana Laws 233 and 236 should be revised to conform with the "Uniform Vehicle Code" (Sections 11-301 and 11-304, respectively). Indiana Law 372 should be repealed or, if necessary to establish penalty provisions for violations of no-passing zones, revised to provide only for such penalties. Details of these revisions are shown in Appendix $A$.

The Indiana law numbers are taken from the 1965 and 1967 "Indiana Motor Vehicle Laws." [8,9] 
Field Method to Locate Limits of No-Passing Zones

Evaluation of the several methods of locating and marking no-passing zones in the field resulted in the finding that a modified two-car method, frequently used now by State Highway Departments, to be used to conduct a complete sight distance survey. A suggested procedure for this survey and subsequent location of the limits of no-passing zones is given in Appendix B. 
BI BL IOGRAPHY 


\section{BIBLIOGRAPHY}

1. Hejal, S. S., 1968, "Traffic Speed Report No. 86," Joint Highway Research Project, Purdue University, Lafayette, Indiana.

2. National Joint Committee on Uniform Traffic Control Devices, 1961, "Manual on Uniform Traffic Control Devices for Streets and Highways," U. S. Department of Commerce, Washington, D. C., pp. 122-127.

3. National Joint Committee on Uniform Traffic Control Devices, 1968, Part III of Draft of New MUTCD, unpublished, pp. 11-15.

4. American Association of State Highway Officials, 1965, "A Policy on Geometric Design of Rural Highways," AASHO, Washington, D. C., pp. 140-152.

5. Prisk, C. W., 1941, "Pass Practices on Rural Highways," Highway Research Board Proceedings.

6. Traffic Research Section, 1967, "Review of Driver Eye Height as Related to Registered Passenger Vehicles," Michigan Department of State Highvays, unpublished.

7. National Comittee on Uniform Traffic Laws and Ordinances, 1962, "Uniform Vehicle Code," Washington, D. C., pp. 114-117.

8. "Indiana Motor Vehicle Laws," 1965, Central Publishing Company, Indianapolis, Indiana.

9. "Indiana Motor Vehicle Laws, Revised," 1967, Central Publishing Company, Indianapolis, Indiana.

10. National Committee on Uniform Traffic Laws and Ordinances, 1967, "Uniform Vehicle Code: Rules of the Road with Statuatory Annotations," Washington, D. C., pp. 192-234.

11. Kelly, Don C. and Sidnell, John E. D., 1967, "The Researchable Aspects of No-Passing Zone Signing and Marking," Department of Civil Engineering, University of Kentucky, Lexington, Kentucky. 
12. Marshal1, F. C., 1966, "Determining and Marking NoPassing Zones," Public Works, Vol. 92, No. 2, pp. $76-78$.

13. Traffic Engineering Division, 1962, "A Plan and Procedure for Locating No-Passing Zones, "Arizona Highway Department.

14. Bartels, W. J., 1958, "No-Passing Zone Procedures," Traffic Engineering, Vol. 28, No. 7, pp. 15-16.

15. Traffic Division, 1963, "A Review of the Criteria for Marking No-Passing Zones," Michigan Department of State Highways, Lansing, Michigan.

16. Traffic \& Safety Division, 1968, "A Review of the Criteria for Marking No-Passing Zones - 1968," Michigan Department of State Highways, unpublished.

17. Ostle, Bernard, 1963, "Statistics in Research," The Iowa State University Press, Ames, Iowa.

18. Traffic Research Section, 1965, "Study of No-Passing zone Signing," Michigan Department of State Highways, Lansing, Michigan. 
APPENDIX A. INDIANA TRAFFIC LAWS 
APPENDIX A. INDIANA TRAFEIC LAWS

There are a few laws of Indiana that should be changed to conform to the "Uniform Vehicle code," as explained in Chapter II, in addition to the recommended model law included in Chapter $V$. The existing laws and suggested changes follow: Indiana Law 239 - No-Passing Zones

The State Highway Commission is hereby authorized to determine by an engineering and traffic investigation those portions of any highway where overtaking and passing or driving to the left of the roadway would be especially hazardous and may, by appropriate signs, or marks on the roadway, indicate the beginning and end of such zones and when such signs or markings are in place and clearly visible to an ordinarily observant person, every driver of a vehicle shall obey the directions thereof $(47-2016$.

Paragraph (b) of the model $l$ aw as stated in Chapter $V$ should be added to this law as follows:

(b) Where signs or markings are in place to define a no-passing zone as set forth in paragraph (a) no driver shall at any time drive on the left side of the roadway within such no-passing zone or on the left side of any pavement striping designed to mark such no-passing zone except for the purpose of safely completing a passing maneuver begun prior to the beginning point of such a zone.

Indiana Law 233 - Drive on Right Side of Roadway - Overtaking and Passing.

Upon all roadways of sufficient width a vehicle shall be driven upon the right half of the roadway except as follows: 
1. When overtaking and passing another vehicle proceeding in the same direction under the rules governing such movement;

2. When the right half of a roadway is closed to traffic (while under construction or repair);

3. Upon a roadway divided into three (3) marked lanes for traffic under the rules applicable thereon; or

4. Upon a roadway designated and signposted for oneway traffic.

5. Upon all roadways vehicles proceeding at less than the normal speed of traffic at the time and place and under the conditions then existing shall be driven in the right-hand lane then available for traffic, or as close as practicable to the roadway, except when overtaking and passing another vehicle proceeding in the same direction or when preparing for a left turn at an intersection or into a private road or driveway. (47-2010.)

This law should be revised to conform to the "Uniform Vehicle Code," Section 11-301, which was revised in 1962, as follows:

Sec. 11-301-Drive on Right Side - Exceptions

(a) Upon all roadways of sufficient width a vehicle shall be driven upon the right half of the roadway, except as follows:

1. When overtaking and passing another vehicle proceeding in the same direction under the rules governing such movement;

2. When an obstruction exists making it necessary to drive to the left of the center of the highway; provided, any person so doing shall yield the right-of-way to all vehicles traveling in the proper direction upon the unobstructed portion of the highway within such distance as to constitute an immediate hazard; (Revised, 1962).

3. Upon a roadway divided into three marked lanes for traffic under the rules applicable thereon; or 
4. Upon a roadway designated and signposted for one-way traffic.

(b) Upon all roadways any vehicle proceeding at less than normal speed of traffic at the time and place and under the conditions then existing shall be driven in the right-hand lane then available for traffic, or as close as practicable to the right-hand curb or edge of the roadway, except when overtaking and passing another vehicle proceeding in the same direction or when preparing for a left turn at an intersection or into a private road or driveway.

(c) Upon any roadway having four or more lanes for moving traffic and providing for two-way movement of traffic, no vehicle shall be driven to the left of the center line of the roadway, except when authorized by official traffic control devices designating certain lanes to the left side of the center of the roadway for use by traffic not otherwise permitted to use such lanes, or except as permitted under subsection (a) (2) hereof. (New, 1962)

Indiana Law 236 - When Overtaking on the Right is Permitted.

(a) The driver of a vehicle may overtake and pass upon the right of another vehicle which is making or about to make a left turn.

(b) The driver of a vehicle may overtake and, allowing a sufficient clearance, pass another vehicle proceeding in the same direction either upon the left or upon the right on a roadway with unobstructed pavement of sufficient width for four or more lines of moving traffic when such movement can be made with safety. No person shall drive off the pavement or upon the shoulders of the roadway in overtaking or passing on the right. $(47-2013)$

This law should be revised to conform to the "Uniform Vehicle code," Section 11-304, which is as follows:

Sec. 11-304-When Overtaking on the Right is Permitted.

(a) The driver of a vehicle may overtake and pass upon the right of another vehicle only under the following conditions: 
1. When the vehicle overtaken is making or about to make a left turn;

2. Upon a street or highway with unobstructed pavement not occupied by parked vehicles of sufficient width for two or more lanes of moving vehicles in each direction;

3. Upon a one-way street, or upon any roadway on which traffic is restricted to one direction of movement, where the roadway is free from obstructions of sufficient width for two or more lines of moving vehicles.

(b) The driver of a vehicle may overtake and pass another vehicle upon the right only under conditions permitting such movement in safety. In no event shall such movement be made by driving off the pavement or main traveled portion of the roadway. 
APPENDIX B. DETAILS OF FIELD METHOD TO LOCATE LIMITS OF NO-PASSING ZONES 


\section{APPENDIX B. DETAILS OF FIELD METHOD TO LOCATE LIMITS OF NO-PASSING ZONES}

A suggested procedure to determine the limits of nopassing zones in the field is detailed in this section. The method is similar to the procedure used in this study to measure sight distance on the test roads. The procedure is actually a modification of the two-car method, used frequently by State highway departments.

The conventional two-car method of determining the limits of no-passing zones requires that two vehicles maintain a constant interval equal to the minimum sight distance while both vehicles are moving at a constant rate along the highway under study. Each time the leading or target vehicle disappears and reappears the position of the lagging or recording vehicle is noted. The positions noted are the limits of the no-passing zone.

The criteria developed in this report and the criteria proposed in the draft of the new MUTCD require that sight distances up to 1600 feet or more be measured in the field. It becomes increasingly difficult to see a target as sight distance increases to over a quarter of a mile. Inaccuracies in the two-car method may increase significantly due to the movement of the vehicles during the perception and reaction time required to determine exactly when the target disappears 
and reappears. Also, as the interval between the vehicles is increased, so does the chance that a dip in the alignment, which may hide oncoming cars, may occur within the interval and remain undetected.

The author has come to the conclusion that there is no easy, fast, accurate and practical method to determine the limits of no-passing zones that can be substituted for a complete sight distance survey. Some of the advantages of the sight distance survey method are as follows:

1. A permanent record of sight distance profile can be established for each road. If average traffic speeds change requiring a change in sight distance criteria or the existing markings are destroyed by construction of new pavement, the markings can be readily applied without additional sight distance surveys.

2. The method simulates actual conditions as close as possible.

3. The sight distance profile can be plotted in the office and, by examination, those zones which should be connected can be easily identified.

4. The sight distance survey need be done in only one direction because the distance from the beginning point of a zone in one direction to the ending point of a zone in the opposite direction is equal to the required sight distance (see Figure 1). 
5. The method is relatively accurate and efficient.

6. A record of sight distance is readily available if an analysis of capacity is required in a planning study.

The equipment and personnel required for the field survey are described below:

\section{Equipment}

1. A target vehicle (preferably a yellow pickup) equipped with a rotating amber light mounted 3.75 feet off the pavement on the left rear side, another rotating amber light mounted on the roof to warn traffic, an odometer or electronic measuring wheel, a hand measuring wheel and a $1-1 / 2$ watt walkie-talkie.

2. A recording vehicle (preferably a yellow low profile car with the driver eye height 3.75 feet off the pavement) equipped with a rotating amber light on the roof, an odometer or electronic measuring wheel and a $1-1 / 2$ watt walkie-talkie.

3. An additional vehicle equipped with a rotating amber light for use by the rear flag man. This third vehicle can be stopped on the shoulder far enough behind the recording vehicle to warn traffic to slow down. Two additional walkie-talkies on the same frequency for use by the flagmen would be desirable to assure adequate communications between all personnel. 
Personnel

A total of six persons are required as follows: Target vehicle - one man to drive, one man to operate the walkie-talkie and hand measuring wheel when needed; and one man to flag traffic. Recording vehicle - one man to drive, one man to record, and one man to flag traffic and advance the warning vehicle.

\section{Procedure}

The field survey consists basically of recording the positions of each vehicle when the target light on the target vehicle is just out of sight of the driver in the recording vehicle at selected intervals along the highway. Initially, the odometers or measuring wheels on both vehicles are set to zero at the beginning point of the road section under study. The target vehicle proceeds slowly up the road until the target light disappears from view. At that moment the driver of the recording vehicle gives a command over the walkie-talkie to stop and give a reading. The position of the target vehicle is entered opposite the position of the recording vehicle on the record. The difference between the two readings provides the sight distance available (the distance between the vehicles) at the location of the recording vehicle. Then the recording vehicle moves up to a desired position, usually .05 or .10 mile and gives a conmand for the target vehicle to advance until 
the target once again disappears. This procedure is repeated over and over along the entire length of the highway. When sight distances over 2500 feet are apparent for long distances, the two vehicles can advance slowly at a constant rate keeping the 2500 foot interval between them. Numerous readings should be recorded in the area where the minimum sight distance criteria are equal or nearly equal to the distance between vehicles.

Unless the measuring wheel on the target vehicle is designed to allow the vehicle to go in reverse and to allow the meter to go in the reverse direction, a hand measuring wheel will be required in some instances. This is illustrated in Figure 8. If the target vehicle cannot go in the reverse direction, the helper in the target vehicle becomes the target by walking toward the recording vehicle. He carries the walkie-talkie and operates the hand measuring wheel, which is set to zero before commencing to walk. The position of the target is entered in the record by subtracting the distance measured by the target man from the position of the target vehicle.

Care must be taken to keep the height of the driver's eye at 3.75 feet above the pavement and to drive the recording vehicle so that the driver's eye is nearly above the center line and drive the target vehicle next to the center line so that the target light is directly above the center line. The target man should wear a bright flourescent safety jacket and traffic survey signs should be placed at each end of the section under study. 
The accuracy of the odometers or measuring wheels should be checked and corrected frequently. The location of all crossroads and structures should be recorded. Also the cause of the sight restriction should be noted so that it may be determined if corrective action may be taken to increase sight distance. Often trees, limbs or brush within the right-of-way or a dilapidated building or fence may restrict sight distance that may be removed at small cost. The next step is to draft the sight distance profile and the location of cross roads and structures on a map of the highway, similar to Figures 9-14. By drawing a horizontal line at the required sight distance and drawing a vertical line at the intersection of this horizontal line and the sight distance profile, the limits of sight distance restriction are located. The limits of yellow lines needed at structures and cross roads are also located on the drawing. The minimum distances between zones are checked and the limits of the no-passing zones are thereby determined for one direction. The limits of the no-passing zones in the opposite direction are determined simply by adding the sight distance to the end points of the no-passing zones determined above. The ending point of a no-passing zone in one direction is located a distance, equal to the sight distance, from the beginning point of a no-passing zone in the opposite lane. 
Finally, a crew of two men consisting of a driver and a technician, return to the field and paint the beginning and ending points of the no-passing zones on the pavement, locating these points by odometer readings from points identifiable in the field and on the sight distance chart. 

